\title{
Konventionelle Individualität. Zur Münzprägung nordanatolischer Städte in der römischen Kaiserzeit
}

\section{Vera Sauer}

\section{(2) OpenEdition} Journals

Édition électronique

URL : http://journals.openedition.org/anatoliaantiqua/381

DOI : 10.4000/anatoliaantiqua.381

\section{Éditeur}

IFEA

Édition imprimée

Date de publication : 1 mai 2016

Pagination : 163-209

ISBN : 9782362450648

ISSN : 1018-1946

\section{Référence électronique}

Vera Sauer, « Konventionelle Individualität. Zur Münzprägung nordanatolischer Städte in der römischen Kaiserzeit », Anatolia Antiqua [En ligne], XXIV | 2016, mis en ligne le 11 décembre 2018, consulté le 16 février 2021. URL : http://journals.openedition.org/anatoliaantiqua/381 ; DOI : https:// doi.org/10.4000/anatoliaantiqua.381 


\section{ANATOLIA ANTIQUA ESKI ANADOLU}

\section{XXIV}

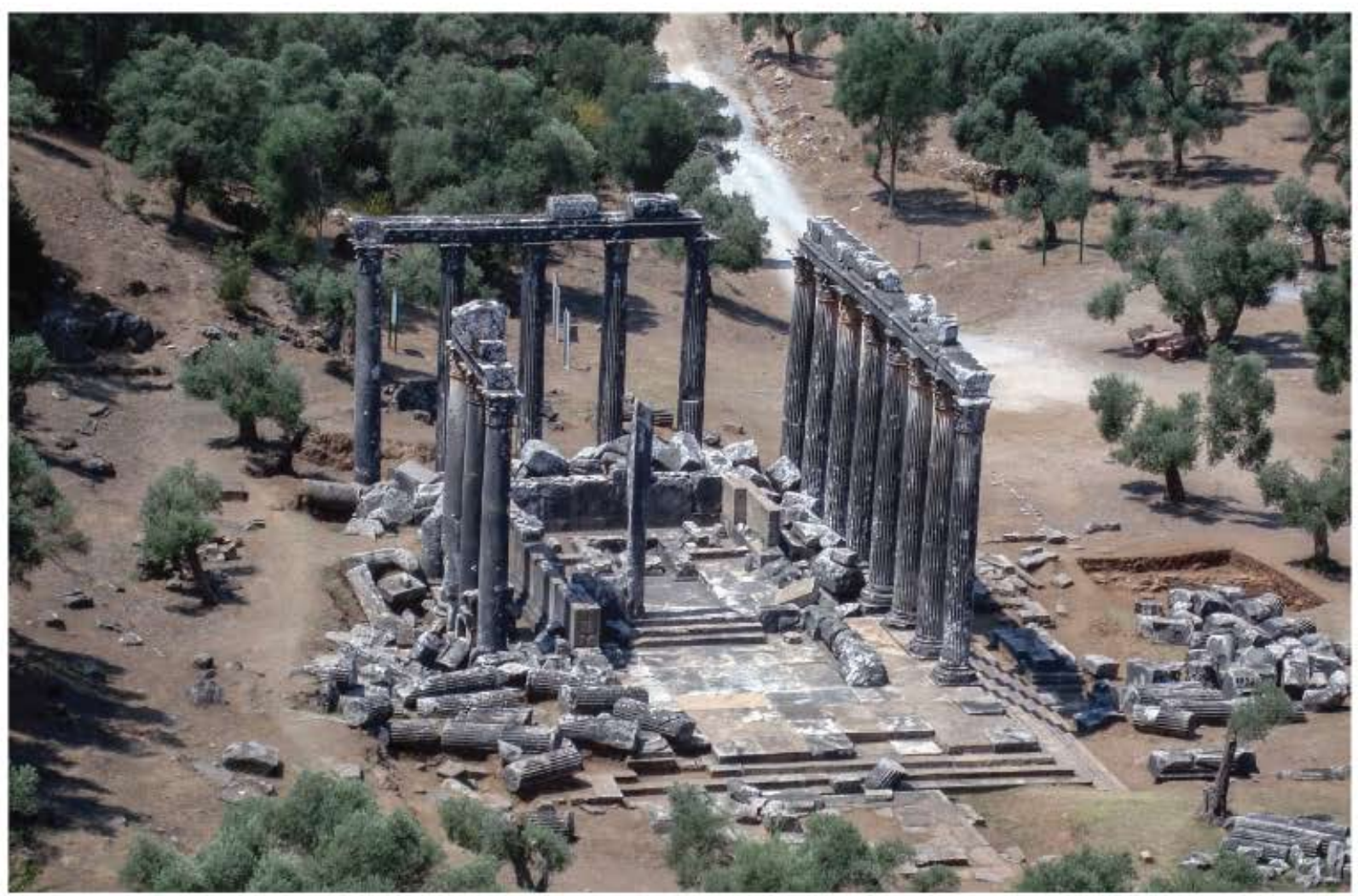

INSTITUT FRANÇAIS D'ETUDES ANATOLIENNES GEORGES-DUMEZIL

CNRS USR 3131

DE BOCCARD 


\section{TABLE DES MATIERES}

Ergul KODAS,

Le surmodelage du crâne au Néolithique au Proche-Orient : techniques de surmodelage et

expérimentations

Isabella CANEVA et Eric JEAN,

Mersin-Yumuktepe : une mise au point sur les derniers travaux

Turan EFE et Bérengère PERELLO,

Second Millenium site distribution and pottery of Inland Northwestern Anatolia

Antoine PEREZ,

Amida 6 : Antiochos IV, le "Hanigalbat" et la Sophène

Ergün LAFLI et Hadrien BRU,

Inscriptions et monuments funéraires gréco-romains d'Anatolie occidentale

Oğuz TEKİN et Aliye EROL-ÖZDİZBAY,

Coins from Allianoi excavations: Campaign of 2001

Nuran ŞAHIN,

Etude iconographique des monnaies autonomes frappées par Colophon-sur-Mer :

nouveaux acquis

Vera SAUER,

Konventionelle Individualität. Zur Münzprägung nordanatolischer Städte in der römischen

Kaiserzeit

Oğuz TEKIN,

Balance weights in the collection of the Anatolian Civilizations Museum in Ankara

\section{CHRONIQUES DES TRAVAUX ARCHEOLOGIQUES EN TURQUIE 2015}

Çiğdem MANER,

Preliminary report on the third season of the Konya-Ereğli Survey (KEYAR) 2015

Dominique BEYER, Isabelle CHALIER et Françoise KIRNER,

Rapport préliminaire sur les travaux de la mission archéologique de Zeyve Höyük-Porsuk 2015 ...

Sami PATACI et Ergün LAFLI,

Field surveys in Ardahan in 2015

Jean-Charles MORETTI avec la collaboration de Nicolas BRESCH, Isabel BONORA,

Jean-Jacques MALMARY et Olivier RISS,

Claros, le temple d'Apollon : travaux réalisés en 2015

Serdar Hakan ÖZTANER,

La basilique civile de Nysa du Méandre

Abuzer KIZIL, Koray KONUK, Patrice BRUN, Laurent CAPDETREY, Raymond DESCAT,

Pierre FROHLICH, Didier LAROCHE, Enora LE QUERE, Francis PROST, Baptiste VERGNAUD,

Eurômos : rapport préliminaire sur les travaux réalisés en 2015

O. HENRY et E. ANDERSON, Chr. BOST, Ö. ÇAKMAKLI, F. CEDERLING, A. COMMITO,

M. CORMIER-HUGUET, A. COUTELAS, A. DOLEA, D. ERGENÇ, A. FRECCERO,

A. FREJMAN, P. LEBOUTEILLER, F. LESGUER, D. LÖWENBORG, V. LUNGU,

Fr. MARCHAND-BEAULIEU, A. SITZ, P. DE STAEBLER, B. VERGNAUD, 


\section{KONVENTIONELLE INDIVIDUALITÄT. ZUR MÜNZPRÄGUNG NORDANATOLISCHER STÄDTE IN DER RÖMISCHEN KAISERZEIT}

Lange Zeit war die Münzprägung, die in der römischen Kaiserzeit auf städtischer Ebene in den Provinzen erfolgte, ein Stiefkind der Numismatik. ${ }^{1}$ Im Lauf der letzten drei Jahrzehnte hat sich dies jedoch grundlegend geändert. ${ }^{2}$ Das gilt insbesondere auch für die Münzprägung nordanatolischer Städte. So haben Michel Amandry, Laurent Bricault, Zeynep Çizmeli, Julie Dalaison, Fabrice Delrieux, Marie-Claire Ferriès, Bernard Rémy, Hans-Dietrich Schultz und Franck Wojan Corpora der Münzen von Abonouteichos, Amaseia, Germanikopolis, Kerasous, KomanaHierokaisareia, Neokaisareia, Neoklaudiopolis, Nikopolis, Pompeiopolis, Sebasteia, Sebastopolis-Herakleopolis, Trapezous und Zela vorgelegt ${ }^{3}$ das Corpus der Münzen von Amastris wird derzeit erarbeitet, ebenso das Corpus der Münzen der auf dem Territorium von Sinope angesiedelten Colonia Iulia Felix. ${ }^{4}$

All diese Corpora leisten weit mehr als nur die möglichst umfassende Zusammenstellung und Systematisierung der Münzen - sowohl in numismatischer als auch in allgemein historischer Hinsicht. So identifizieren die Autoren sämtliche Prägestempel, schätzen das Volumen der Prägungen ab und unter- suchen den Radius des Münzumlaufs. Darauf aufbauend stellen sie Überlegungen zur ökonomischen, aber auch zur politischen Bedeutung der Prägungen an und versuchen, sowohl deren historischen Kontext zu klären als auch die Münzen selbst als historische Quelle auszuwerten. Ein Aspekt, der in den Corpora immer wieder angesprochen wird, betrifft die Frage, ob und gegebenenfalls an welchen Vorbildern sich die städtischen Prägungen orientiert haben - seien es Vorbilder, die sich in anderen provinzialen Prägungen, speziell in denen anderer Städte der Region, seien es Vorbilder, die sich in der römischen Reichsprägung fanden. ${ }^{5}$

Im Zentrum der vorliegenden Untersuchung steht die Münzprägung von neun Städten: Amaseia, Komana, Pompeiopolis, Neokaisareia, Neoklaudiopolis, Nikopolis, Sebasteia, Sebastopolis und Zela. Aus historisch-geographischer Sicht kann man sie, etwas pauschalisierend, mit ihren unmittelbar aneinander angrenzenden Territorien als Region auffassen und als ,inner-' oder ,binnenpontisch' bezeichnen (vgl. Abb. 1). ${ }^{6}$ Diese Region ist vom Schwarzen Meer durch die nördlichste Kette des Nordanatoli-

*) Dr. Vera Sauer, Mühlweg 6, D-72414 Rangendingen. vera.sauer@gmx.de

1) Nollé 1997: 11. Vgl. auch Sear 1982: vii; Butcher 1988: 6.

2) Das spiegelt sich insbesondere in dem unter der Ägide von Andrew Burnett und Michel Amandry stehenden Projekt Roman Provincial Coinage, aber beispielsweise auch in dem von William E. Metcalf herausgegebenen Handbook of Greek and Roman Coinage.

3) Abonouteichos: Dalaison, Delrieux, Ferriès 2015; Amaseia: Dalaison 2008; Germanikopolis: Bricault, Delrieux 2014; Kerasous: Wojan 2003; Komana-Hierokaisareia: Amandry, Rémy 1999; Neokaisareia: Çizmeli 2006; Neoklaudiopolis: Dalaison, Delrieux 2014 (im Folgenden ergänzt um http://www.aeruginis.de/aeruginis/Sammlung/Detail.php?page=889 [1 Ex.; vgl. unten Abb. 7]); Nikopolis: Dalaison 2007; Pompeiopolis: Dalaison 2010; Sebasteia: Schultz 1989 (ergänzt um Weiser 1998: 283 [1 Ex.]; RPC-online temp. nr. 5454 [2 weitere Ex.] und 5455 [1 Ex.]); Sebastopolis-Herakleopolis: Amandry, Rémy 1998; Trapezous: Wojan 2006; Zela: Dalaison, Rémy, Amandry 2009.

4) Amastris: Frédérique Brenier; Colonia Iulia Felix: Pierre Manisse. Denkt man an die Städte der unten beschriebenen Regionen, steht dann lediglich das Corpus der Münzen von Amisos noch aus.

5) Schultz 1989: 265; Çizmeli 2006: 111f., 117f., 121-130, 137-141; Dalaison 2007: 230-233; 2008, 52-54, 147-152, 154, 160171; 2010, 65-71; Dalaison, Delrieux 2014: 186-191; Bricault, Delrieux 2014: 85-115.

6) Zu einem gewissen Grad pauschalisierend ist dies hinsichtlich antiker Begrifflichkeit; so galten Pompeiopolis und Nikopolis grundsätzlich nicht als pontisch, vielmehr als paphlagonisch bzw. kleinarmenisch, ,Pontus Mediterraneus' bezeichnete in der Zeit zwischen Traian oder Hadrian und Alexander Severus eine Eparchie, die mit Amaseia, Komana, Sebastopolis, Neokaisareia, Zela und eventuell Sebasteia lediglich einen Teil der hier gemeinten Region umfaßte. Zu einem gewissen Grad pauschalisierend ist dies aber auch hinsichtlich der politisch-administrativen Verhältnisse, da sich das politische Schicksal der Städte dieser Region im ersten Jahrhundert nach ihrer Einbeziehung in die römische Machtsphäre recht unterschiedlich gestaltete und sie schließlich nach ihrer dauerhaften Einbindung in die direkte römische Herrschaft zu verschiedenen und teils auch immer wieder umgestalteten Eparchien, Provinzen und koina gehörten, die Region über die Zeiten also keine politische oder administrative Einheit darstellte. Zur komplexen und zum Teil höchst umstrittenen politisch-administrativen Geschichte der Region vgl. Dalaison 2014: 125-129, die entsprechenden Abschnitte in den oben in Anm. 3 genannten Corpora und etwa Rémy 1986, Marek 1993; 2015 und Vitale 2012; 2014, außerdem Bekker-Nielsen 2014 und Sørensen 2016. 


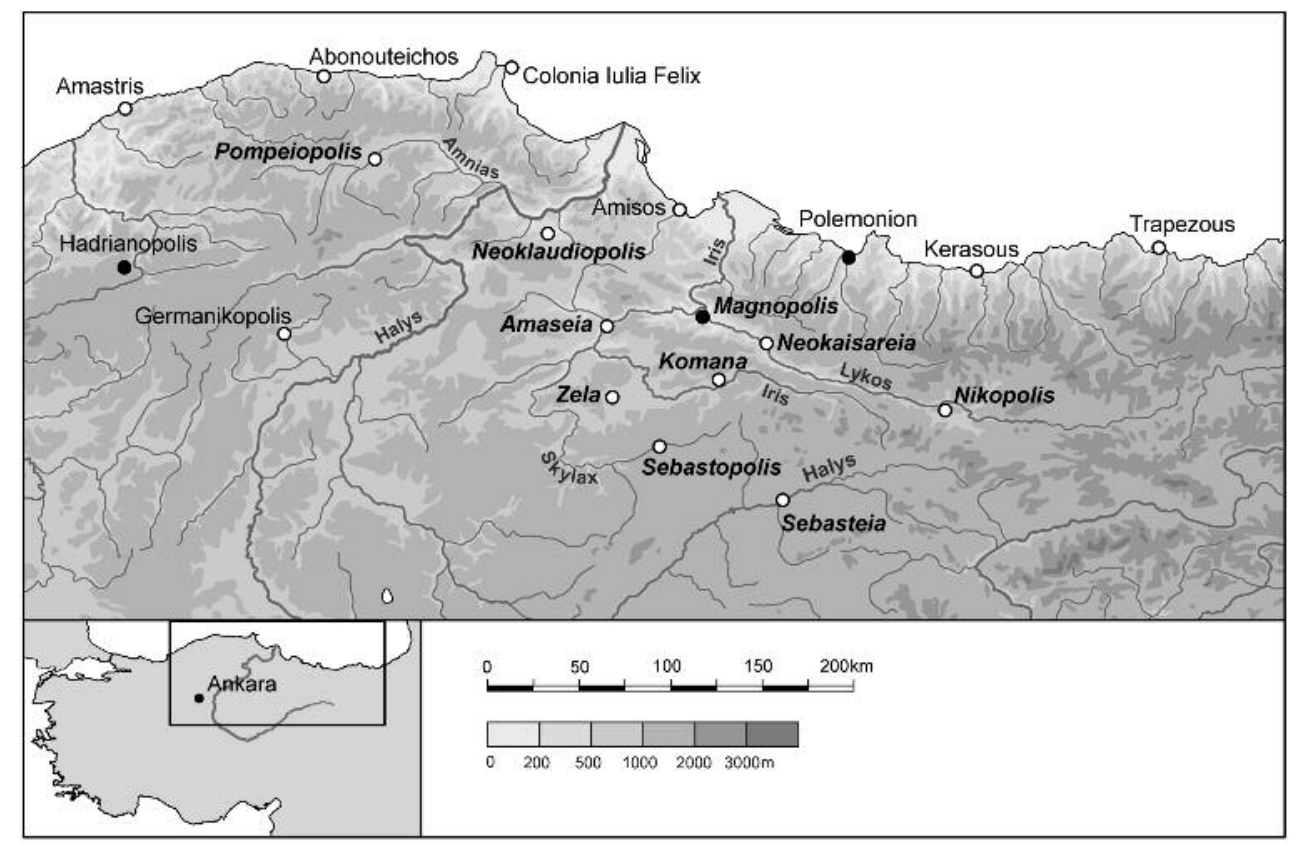

Abb. 1 : Städte, deren Münzprägung in diesem Aufsatz untersucht wird (Kartographie: Richard Szydlak). - Kursiv: ,innerpontische` Städte. Ausgefüllter Punkt: Städte, die nicht geprägt haben.

schen Randgebirges getrennt und wird ganz wesentlich vom Flußsystem des Iris, des Lykos und des Skylax geprägt, außerdem vom Ober- und vom Unterlauf des Halys und seines linken Nebenflusses, des Amnias. ${ }^{7}$ Über ,Innerpontos' hinausgehend, befaßt sich die Untersuchung, soweit das der Grad an Aufarbeitung, den das numismatische Material bislang erfahren hat und soweit es - insbesondere $\mathrm{zu}$ Vergleichszwecken - thematisch sinnvoll erscheint, auch mit den Prägungen der pontischen Küstenstädte Amisos, Kerasous und Trapezous und der in Paphlagonien gelegenen Städte Abonouteichos, Amastris, Germanikopolis und Colonia Iulia Felix. Diese weiter gefaßte Region hat, von Germanikopolis abgesehen, bei allen Unterschieden der Geschichte ihrer Städte im Detail, immerhin gleichsam einen gemeinsamen historischen Nenner: Sie umfaßt das Gebiet, das in den Jahren 65 bis 63 v.Chr. von Pompeius reorganisiert wurde und das zuvor insofern zum Kern des Mithradatischen Reiches gehört hatte, als es von Mithradates VI. bereits in der Zeit vor 89 v.Chr. beherrscht worden war. ${ }^{8}$ Punktuell werden außerdem die Prägungen der koina Paphlagonias, Pontou und Armenias einbezogen. ${ }^{9}$

Beim ersten Hinsehen erweckt die Münzprägung der Städte dieser Region - der engeren wie der weiteren - den Eindruck, weitgehend uniform und in hohem Maß an der reichsrömischen Prägung orientiert und in diesem Sinn ausgesprochen konventionell gewesen zu sein. Bei genauerem Hinsehen wird jedoch deutlich, daß die Prägung einer jeden Stadt auch individuelle Züge trug. Im Folgenden soll anhand unterschiedlicher Beobachtungen gezeigt werden, daß diese individuellen Züge ausgeprägter und

7) Zur Geographie der Landschaft Pontos vgl. jüngst Olshausen 2014. Daß die Wahl als Untersuchungsgegenstand gerade auf die Münzprägung der Städte dieser Region fiel, ist nicht zuletzt dem Umstand geschuldet, daß die Untersuchung im Rahmen des an der Süddänischen Universität angesiedelten Projekts „Where East meets West“ entstanden ist, das ganz wesentlich am Beispiel von Neoklaudiopolis die Prozesse der Urbanisierung und Provinzialisierung in Pontos und auch in Paphlagonien untersucht. Es ist ein überaus glücklicher Umstand, daß mit den oben erwähnten Corpora eben gerade für diese Städte ein Arbeitsinstrument zur Verfügung steht, das einer derartigen Untersuchung erst eine solide Basis bietet. Meinen Kolleginnen und Kollegen von „Where East meets West" und besonders Christina Hildebrandt danke ich für die hilfreiche Diskussion meiner Überlegungen. Herrn Ruprecht Ziegler danke ich für den intensiven Gedankenaustausch zur Lesung und Interpretation von Dalaison, Delrieux 2014 Nr. 1, der sich in Anhang 4 widerspiegelt.

8) Germanikopolis ist hinzugenommen, da diese Stadt mit Pompeiopolis im Wettstreit um den Vorrang in der Eparchie Paphlagonia lag und dieser Wettstreit auch in der Münzprägung Spuren hinterlassen hat (vgl. Dalaison 2010: 51-53 und auch Bricault, Delrieux 2014: $10,48,93 \mathrm{f}$.).

9) Vgl. unten Anm. 50, 136. Zu der einzigen aus der Prägung des koinon Paphlagonias bekannten Münze (Rec. 165* Nr. 1; RPC II 1629) vgl. Dalaison 2010: 47; Bricault, Delrieux 2014: 48. Die Münzen des koinon Pontou: Çizmeli 2006 Nr. 496-501, die des koinon Armenias: Dalaison 2007 Nr. 25-31. 
in numismatischer wie historischer Hinsicht erheblicher sind, als man zunächst meinen könnte. ${ }^{10}$ M.E. kann dies nicht nur dazu beitragen, das Bild, das wir uns von der Münzprägung dieser Städte machen, weiter zu verfeinern, sondern insbesondere auch dazu, ein treffendes Bild von deren polis-Mentalität und -Identität zu zeichnen. ${ }^{11}$

\section{DER USUS, MÜNZEN ZU PRÄGEN, ZEITPUNKT UND ANLASS DER PRÄGUNGEN}

Münzen zu prägen war , an sich' konventionell: als Stadt ${ }^{12}$ tat man das üblicherweise. ${ }^{13}$ In ,Innerpontos' stellte Magnopolis die einzige Ausnahme dar. Sie ist wohl damit zu erklären, daß diese Stadt, nach allem, was wir wissen, nur bis in das späte 1 . Jh. n.Chr. existierte, ${ }^{14}$ und also die Zeit gar nicht erlebte, in der die anderen Städte der Region dann tatsächlich gleichsam flächendeckend prägen sollten. ${ }^{15}$ Medail- lons wurden dagegen offenbar nur in seltensten Ausnahmen geprägt: aus ,Innerpontos ' ist sogar nur ein einziger Fall bekannt, bei dem dies zu diskutieren ist; dabei handelt es sich um eine Prägung von Pompeiopolis. ${ }^{16}$

Obwohl Münzen zu emittieren , an sich' konventionell gewesen ist, prägten die Städte üblicherweise nur sporadisch (vgl. Tabelle 1a). ${ }^{17}$ Dabei unterschied sich die Gesamtzahl wie auch die Frequenz der Emissionen von Stadt zu Stadt. Gleichsam Spitzenreiter sind Amaseia und Neokaisareia mit jeweils 17 Emissionen; Schlußlicht ist Sebasteia mit zwei Emissionen. Nikopolis, Zela, Sebastopolis und wohl auch Pompeiopolis kamen nicht über drei Emissionen hinaus; Neoklaudiopolis brachte es zumindest auf acht Emissionen, Komana auf neun. ${ }^{18}$ Die Städte, die nur selten prägten, taten dies meist mit großen zeitlichen Abständen von mehreren Jahrzehnten,

10) Die Notizen in Sauer 2015a: Abschnitt 2 und 3 stellen teils Vorarbeiten zu der vorliegenden Untersuchung dar, teils basieren sie auf solchen.

11) $\mathrm{Zu}$ den Wechselwirkungen zwischen Münzprägung auf der einen und Selbstvergewisserung, Selbstdarstellung und Identität auf der anderen Seite vgl. Harl 1987; Howgego, Heuchert, Burnett (Hg.) 2005; Dalaison 2014; Sauer 2014.

12) >Stadt` ist hier im Sinn von politeia/civitas zu verstehen, unabhängig vom konkreten juristischen und administrativen Status des jeweiligen Gemeinwesens.

13) Das gilt für den ganzen Osten des Römischen Reichs bis weit in die 2. Hälfte des 3. Jh. (allerletzte Prägungen in der Zeit des Tacitus 275/6; vgl. dazu unten S. 169); im Westen kam die städtische Prägung dagegen bereits im 2. Viertel des 1 . Jh. zum erliegen (allerletzte Prägung in der Zeit des Claudius; vgl. dazu etwa RPC I: 18f.). Zu der kontrovers diskutierten Frage, ob die Städte für ihre Prägungen eine spezielle kaiserliche bzw. statthalterliche Autorisierung benötigten, vgl. etwa RPC I: 2f.; RPC II: 1-3; Weiß 2005: 58-61. Es ist aber mit großer Wahrscheinlichkeit davon auszugehen, daß die römischen Autoritäten zumeist nicht restriktiv agierten und die Frage, ob geprägt werden sollte und speziell auch, welche Münzbilder und -legenden gewählt werden sollten, in erster Linie innerhalb der Städte selbst entschieden wurde; vgl. mit ähnlichem Tenor etwa auch Dalaison 2008: 179f.

14) Pace Sørensen 2016. Vgl. Marek 1993: 52f. Das Ende dieser Stadt mochte nicht zuletzt in der topographischen Lage ihres urbanen Zentrums seine Ursache gehabt haben; diese war nicht unproblematisch, selbst wenn das Zentrum nicht so nahe am Zusammenfluß von Iris und Lykos gelegen haben sollte, wie bislang angenommen (vgl. Olshausen, Biller 1984: 35-40), sondern ca. 2,5km weiter südwestlich bei Çevresu, wofür Sørensen kürzlich Anzeichen feststellen konnte.

15) In der Region im weiteren Sinn prägten auch Kaisareia-Hadrianopolis und Polemonion nicht. Angesichts der nur rudimentären Kenntnis, die wir von den inneren Verhältnissen dieser Städte wie auch allgemein von deren Geschichte haben - zu Kaisareia-Hadrianopolis vgl. Marek 1993: 116-122; Lafl1, Christof 2012: 1-25, 129-131, zu Polemonion E. Olshausen, Polemonion, in: DNP 10, 2001, 10 (mit Lit.) -, fällt es schwer, auch nur Hypothesen darüber zu entwickeln, weshalb gerade diese Städte - zumindest unserer Kenntnis nach - nicht geprägt haben.

16) Dalaison 2010 Nr. 15 und S. 61; vgl. auch unten Anm. 85, 165.

17) Selbstredend gilt diese wie auch viele der folgenden Aussagen nur mit der Einschränkung, soweit es die Quellen, d.h. die erhaltenen (und auch publizierten) Münzen erkennen lassen'. Angesichts der Tatsache, daß manche Emissionen nur durch ganz wenige Münzen belegt sind, ist es leicht vorstellbar, daß wir von anderen Emissionen schlicht nichts wissen, da sich von ihnen eben keine einzige Münze erhalten hat. Diese Skepsis ist im Wesentlichen freilich nur in Bezug auf die Existenz oder Nichtexistenz von Emissionen des 1. Jh. und auch im Fall der Städte angebracht, von deren Münzen insgesamt nur wenige Exemplare bekannt sind - insbesondere also im Fall von Sebasteia. In allen anderen Fällen ist das Bild mit recht großer Wahrscheinlichkeit jedoch - jedenfalls der Größenordnung nach - zutreffend.

18) Im Fall von Pompeiopolis ist die Unsicherheit dadurch bedingt, daß diese Stadt ihre Münzen nicht datierte, im Fall von Neoklaudiopolis teils dadurch, daß auch hier ein kleiner Teil der Münzen keine Jahresangabe trägt, teils dadurch, daß diese nicht immer lesbar ist. (Die Angabe ,14 Emissionen` bei Dalaison, Delrieux 2014: 181 ist m.E. ein Versehen.) Auch Amaseia und Zela haben in geringer Zahl Münzen ohne Jahresangabe geprägt; es ist jedoch unwahrscheinlich, daß diese in andere als die bekannten Prägejahre zu datieren sind oder im Fall der frühesten Münzen von Amaseia aus verschiedenen Jahren stammen. In der weiteren Region bewegen sich die Zahlen von Germanikopolis, Abonouteichos und Kerasous mit zumindest 2 bzw. 8 bzw. 11 Emissionen im selben Rahmen. Gleichsam gesprengt wird dieser Rahmen jedoch von Trapezous, Amastris, Amisos und der Colonia Iulia Felix, für die zumindest 19 bzw. 22 bzw. 47 bzw. 68 Emissionen nachweisbar sind. Die Angaben für die Städte der weiteren Region sind - von Germanikopolis, Kerasous und Trapezous abgesehen - nur als Abschätzung der Mindestzahl zu verstehen. Das liegt zum einen daran, daß hier lediglich die Münzen berücksichtigt werden konnten, die in Rec., Leschhorn 1993, RPC I und II und in RPC-online verzeichnet sind, zum andern daran, daß auch diese Städte ihre Münzen zumindest teilweise oder, wie Abonouteichos und - von den frühesten Prägungen abgesehen - auch Amastris, grundsätzlich nicht datierten. 
Tabelle 1a : Emissionen der ,innerpontischen' Städte und der Städte der weiteren Region.

$+\quad$ Münzen ohne Jahresangabe

* Münzen, deren Jahresangabe nicht lesbar ist

kursiv Silberprägungen von Amisos

(1) Die Datierung in die Zeit des Tiberius ist nicht ganz sicher; Alternativen: Augustus oder Caligula (vgl. Dalaison 2008: 24).

(2) Vgl. dazu Anhang 4 .

(3) Die Jahresangabe ist nicht lesbar. Zu Anhaltspunkten, die eine Datierung in das Jahr 199/200 statt 200/201 nicht ausgeschlossen erscheinen lassen, vgl. Dalaison, Delrieux 2014: 181.

(4) Jahr nicht lesbar (vgl. RPC I: 2126).

(5) Zuschreibung zur Colonia Iulia Felix nicht sicher (vgl. RPC II: 723-725).

(6) $\mathrm{Zu}$ den unter dem Namen Hestia geprägten Münzen vgl. oben Anm. 21.

\begin{tabular}{|c|c|c|c|c|c|c|c|c|c|}
\hline \multicolumn{10}{|c|}{ Emissionen der, innerpontischen' Städte } \\
\hline & Komana & Amaseia & Neokaisareia & Neoklaudiopolis & Nikopolis & Sebastopolis & Zela & Sebasteia & Pompeiopolis \\
\hline Tiberius & $\begin{array}{l}35 / 6 \\
36 / 7\end{array}$ & $+(1)$ & & & & & & & \\
\hline Caligula & $\begin{array}{c}37 / 8 \\
39 / 40\end{array}$ & & & & & & & & \\
\hline Claudius & $46 / 7$ & & & & & & & & \\
\hline Nero & $56 / 7$ & & & & & & & & \\
\hline Vespasian & & $78 / 9$ & & & & & & & \\
\hline Domitian & & $92 / 3$ & $92 / 3$ & & & & & & \\
\hline Nerva & $96 / 7$ & & & & & & & & \\
\hline Traian & * & $112 / 3$ & $\begin{array}{l}100 / 1 \\
101 / 2\end{array}$ & $\begin{array}{c}109 / 10 \\
111 / 2 \\
112 / 3 \\
*(2)\end{array}$ & $\begin{array}{l}104 / 5 \\
112 / 3\end{array}$ & $106 / 7$ & $113 / 4$ & $114 / 5$ & \\
\hline Hadrian & & $135 / 6$ & & $*$ & & & & & \\
\hline Antoninus Pius & & $\begin{array}{l}153 / 4 \\
154 / 5\end{array}$ & & $\begin{array}{l}155 / 6 \\
156 / 7\end{array}$ & & & & & + \\
\hline $\begin{array}{l}\text { M. Aurel, L. } \\
\text { Verus }\end{array}$ & & $\begin{array}{c}161 / 2 \\
162 / 3 \\
*\end{array}$ & $161 / 2$ & & $161 / 2$ & & & $161 / 2$ & + \\
\hline Commodus & & $\begin{array}{l}186 / 7 \\
187 / 8 \\
188 / 9\end{array}$ & $184 / 5$ & $\begin{array}{c}185 / 6 \\
*\end{array}$ & & & & & \\
\hline $\begin{array}{l}\text { Septimius } \\
\text { Severus }\end{array}$ & $205 / 6$ & $\begin{array}{c}205 / 6 \\
206 / 7 \\
*\end{array}$ & $\begin{array}{l}204 / 5 \\
205 / 6\end{array}$ & $\begin{array}{c}200 / 1 \\
*(3) \\
+\end{array}$ & & $205 / 6$ & $\begin{array}{c}205 / 6 \\
206 / 7 \\
*\end{array}$ & & + \\
\hline $\begin{array}{l}\text { Severus Alex- } \\
\text { ander }\end{array}$ & & $\begin{array}{l}225 / 6 \\
226 / 7 \\
231 / 2\end{array}$ & $\begin{array}{l}226 / 7 \\
234 / 5\end{array}$ & & & & & & \\
\hline Gordian III. & & & $241 / 2$ & & & & & & \\
\hline $\begin{array}{l}\text { Philippus Ar- } \\
\text { abs }\end{array}$ & & & $248 / 9$ & & & & & & \\
\hline $\begin{array}{l}\text { Trebonianus } \\
\text { Gallus, } \\
\text { Volusianus }\end{array}$ & & & $251 / 2$ & & & & & & \\
\hline $\begin{array}{l}\text { Valerian, Gal- } \\
\text { lienus }\end{array}$ & & & $255 / 6$ & & & & & & \\
\hline Gallienus & & & $\begin{array}{l}262 / 3 \\
263 / 4 \\
264 / 5 \\
265 / 6 \\
\end{array}$ & & & $263 / 4$ & & & \\
\hline
\end{tabular}


ZUR MÜNZPRÄGUNG NORDANATOLISCHER STÄDTE IN DER RÖMISCHEN KAISERZEIT 167

\begin{tabular}{|c|c|c|c|c|c|c|c|}
\hline \multicolumn{8}{|c|}{ Emissionen der Städte der weiteren Region } \\
\hline & Amastris & & $\begin{array}{c}\text { Colonia } \\
\text { Iulia Felix }\end{array}$ & Abonouteichos & Trapezous & Kerasous & Germanikopolis \\
\hline & $\begin{array}{c}71 / 0 \\
70 / 69 \\
62 / 1 \\
61-59 \\
59 / 8 \\
52 / 1 \\
46 / 5 \\
40 / 39 \\
39 / 8 \\
32 / 1 \\
29 / 8\end{array}$ & $\begin{array}{c}61-59 \\
56\end{array}$ & $\begin{array}{c}45 \\
38 \\
35 \\
+\end{array}$ & & & & \\
\hline Augustus & & $\begin{array}{c}5 / 4 \\
2 / 1 \mathrm{aC} \\
9 / 10 \mathrm{pC} \\
+\end{array}$ & $\begin{array}{c}27 \\
26 \\
24 \\
23 \\
11 \\
10 \\
9 \\
7 \\
4 \mathrm{aC} \\
5 \mathrm{pC} \\
6 \\
14\end{array}$ & & & & \\
\hline Tiberius & & $28 / 9$ & $\begin{array}{c}18^{(4)} \\
19\end{array}$ & & & & \\
\hline Caligula & & & $\begin{array}{l}37 \\
38\end{array}$ & & & & \\
\hline Claudius & & $53 / 4$ & $\begin{array}{l}41 \\
42 \\
52 \\
54 \\
\end{array}$ & & & & \\
\hline Nero & & & $\begin{array}{c}58 \\
59 \\
68 \\
+\end{array}$ & & & & \\
\hline Vespasian & & $69 / 70$ & $\begin{array}{l}73 \\
75 \\
77 \\
\end{array}$ & & & & \\
\hline Domitian & + & & $*(5)$ & & & & \\
\hline Nerva & & & $\begin{array}{l}96 \\
97\end{array}$ & & & & \\
\hline Traian & + & $\begin{array}{c}97 / 8 \\
98 / 9 \\
106 / 7 \\
108 / 9 \\
113 / 4\end{array}$ & $\begin{array}{l}104 \\
108 \\
117\end{array}$ & + & $113 / 4$ & & \\
\hline Hadrian & & $\begin{array}{l}131 / 2 \\
132 / 3 \\
133 / 4 \\
133 / 4 \\
134 / 5 \\
135 / 6 \\
136 / 7 \\
137 / 8\end{array}$ & $\begin{array}{l}123 \\
125 \\
133 \\
137\end{array}$ & & & $137 / 8$ & \\
\hline
\end{tabular}




\begin{tabular}{|c|c|c|c|c|c|c|c|}
\hline & Amastris & & $\begin{array}{l}\text { Colonia } \\
\text { Iulia Felix }\end{array}$ & Abonouteichos & Trapezous & Kerasous & Germanikopolis $^{(6)}$ \\
\hline Antoninus Pius & + & $\begin{array}{l}151 / 2 \\
158 / 9 \\
160 / 1\end{array}$ & $\begin{array}{l}138 \\
140 \\
143 \\
159\end{array}$ & + & $*$ & $\begin{array}{c}(137) / 138 \\
141 / 2 \\
144 / 5 \text { od. } 147 / 8 \\
145 / 6 \\
151 / 2\end{array}$ & \\
\hline M. Aurel, L. Verus & + & $\begin{array}{c}163 / 4 \\
+\end{array}$ & $\begin{array}{c}162 \\
+\end{array}$ & + & $\begin{array}{c}161 / 2 \\
163 / 4 \\
*\end{array}$ & $161 / 2$ & \\
\hline Commodus & + & $\begin{array}{l}182 / 3 \\
191 / 2\end{array}$ & & & $\begin{array}{l}183 / 4 \\
188 / 9\end{array}$ & $\begin{array}{c}184 / 5 \\
186 / 7 \\
*\end{array}$ & \\
\hline Septimius Severus & + & $\begin{array}{l}209 / 10 \\
*\end{array}$ & $\begin{array}{c}194 \\
198 \\
207 \text { od. } 09 \\
208 \text { od. } 10 \\
210 \text { od. } 12 \\
+\quad \\
\end{array}$ & + & $\begin{array}{l}194 / 5 \\
198 / 9 \\
204 / 5\end{array}$ & & $\begin{array}{c}208 / 9 \\
209 / 10 \\
+\end{array}$ \\
\hline Caracalla & & $\begin{array}{c}213 / 4 \\
216 / 7 \\
*\end{array}$ & $\begin{array}{l}212 \text { od. } 14 \\
213 \text { od. } 15 \\
214 \text { od. } 16 \\
215 \text { od. } 17\end{array}$ & & $216 / 7$ & & \\
\hline Macrinus & & $217 / 8$ & 217 od. 18 & & & & \\
\hline Elagabal & & $219 / 20$ & 219 od. 20 & & $\begin{array}{c}218 / 9 \\
219 / 20\end{array}$ & $\begin{array}{c}218 / 9 \\
219 / 20\end{array}$ & \\
\hline Severus Alexander & + & $\begin{array}{c}221 / 2 \\
229 / 30 \\
231 / 2 \\
232 / 3\end{array}$ & $\begin{array}{l}223 \\
224\end{array}$ & + & $\begin{array}{l}224 / 5 \\
225 / 6 \\
226 / 7\end{array}$ & $225 / 6$ & \\
\hline Maximinus Thrax & + & $\begin{array}{c}234 / 5 \\
235 / 6 \\
236 / 7 \\
* \\
+\end{array}$ & 235 & & & & \\
\hline Balbinus & & $237 / 8$ & & & & & \\
\hline Gordian III. & + & $\begin{array}{c}240 / 1 \\
*\end{array}$ & $\begin{array}{l}238 \\
239 \\
241 \\
242 \\
\end{array}$ & + & $\begin{array}{l}238 / 9 \\
242 / 3 \\
243 / 4\end{array}$ & & \\
\hline Philippus Arabs & & $\begin{array}{c}245 / 6 \\
+\end{array}$ & 244 & & $244 / 5$ & & \\
\hline Traianus Decius & & $\begin{array}{c}249 / 50 \\
250 / 1 \\
+\end{array}$ & 249 & & & & \\
\hline $\begin{array}{l}\text { Trebonianus Gal- } \\
\text { lus, Volusianus }\end{array}$ & + & & & + & & & \\
\hline Aemilianus & & $252 / 3$ & & & & & \\
\hline Valerian, Gallienus & & $\begin{array}{c}254 / 5 \\
257 / 8 \\
+\end{array}$ & $\begin{array}{l}254 \\
255 \\
259\end{array}$ & & & & \\
\hline Gallienus & + & + & $\begin{array}{l}260 \\
265\end{array}$ & & & & \\
\hline
\end{tabular}


oder im Fall von Sebastopolis einmal auch im Abstand von einem Jahrhundert. Amaseia und Neoklaudiopolis prägten relativ regelmäßig, wobei abgesehen von den Fällen, in denen in direkt aufeinanderfolgenden Jahren Emissionen erfolgten - meist um die 20, nie jedoch mehr als 30 Jahre zwischen den Prägungen lagen. Komana prägte im Lauf der Zeit - grob gesprochen - immer seltener, Neokaisareia dagegen immer häufiger. ${ }^{19}$

Ebenso wie Gesamtzahl und Frequenz der Emissionen differierte sowohl der Zeitpunkt, zu dem die Städte zu prägen begannen, als auch der Zeitpunkt, zu dem sie letztmalig prägten. Viele - Neoklaudiopolis, Nikopolis, Sebasteia, Sebastopolis und Zela prägten seit traianischer Zeit. Teils sogar deutlich früher setzten jedoch die Emissionen von Komana (in tiberischer Zeit), Amaseia (vermutlich auch in tiberischer Zeit ${ }^{20}$ ) und Neokaisareia ein (in domitianischer Zeit). Die früheste Prägung von Pompeiopolis datiert dagegen erst in die Zeit des Antoninus Pius. ${ }^{21}$ Von Nikopolis und Sebasteia abgesehen, die bereits unter M. Aurel letztmalig prägten, datiert die letzte Emission relativ vieler Städte (Komana, Neoklaudiopolis, Zela, Pompeiopolis) in die Zeit des Septi- mius Severus. Amaseia prägte freilich auch noch unter Severus Alexander, Neokaisareia und Sebastopolis gar bis in die Zeit des Gallienus. ${ }^{22}$

Diese Unterschiede zu erklären, gelingt allenfalls ansatzweise. Daß nach der Zeit des Gallienus nicht mehr geprägt wurde, liegt zwar im Trend der Zeit, kam die städtische Münzprägung im Römischen Reich doch nur wenig später insgesamt zum Erliegen. ${ }^{23}$ Weshalb manche Städte jedoch schon deutlich früher darauf verzichteten zu prägen, ist unklar. Es mag sein, daß sie früher oder intensiver mit Aspekten der Reichskrise des 3. Jh. konfrontiert wurden; ${ }^{24}$ es mögen aber auch gleichsam hausgemachte, und damit von Stadt zu Stadt unterschiedliche Probleme ursächlich gewesen sein. ${ }^{25} \mathrm{Zu}$ überlegen ist freilich auch, ob das frühe Ende der Prägetätigkeit mancher Stadt überhaupt als Zeichen einer wie auch immer gearteten Krise zu werten ist. Nicht ausgeschlossen ist nämlich, daß in diesen Städten schlicht ein die Prägung auslösendes Moment - ein Anlaß oder aber der Wille, erneut zu prägen, gefehlt hat.

Das die jeweilige Prägung der ,innerpontischen Städte auslösende Moment läßt sich, soweit ich sehe, in keinem einzigen Fall mit Sicherheit festma-

19) In der weiteren Region sind - von Germanikopolis abgesehen - alle Städte zu den relativ regelmäßig prägenden zu zählen. Hier betrug der zeitliche Abstand zwischen den Prägungen meist weniger als 20 Jahre; nicht selten erfolgten die Emissionen sogar in noch deutlich dichterer Folge. Freilich gibt es auch auffallende Lücken. So unterbrach Amisos offenbar zwischen 55 und 6/5 v.Chr. die Prägetätigkeit (was wohl nicht nur mit der kurzzeitigen Ausgliederung aus der Provinz durch Antonius zu tun gehabt haben dürfte), Amastris zwischen 27/6 v.Chr. und domitianischer Zeit. (Daß die Prägungen von Amastris, anders als aufgrund von Rec. noch zu denken, tatsächlich schon in domitianischer Zeit wieder einsetzen, zeigt RPC II: 712f.).

20) Die Zeit des Augustus, aber auch die des Caligula ist freilich nicht ganz auszuschließen; vgl. dazu Dalaison 2008: 24.

21) In der weiteren Region ist die Bandbreite noch größer: Während Kerasous offenbar erst seit dem letzten Jahr der Herrschaft Hadrians prägte, taten Abonouteichos und Trapezous dies seit der Zeit des Traian. Die Colonia Iulia Felix emittierte seit 45 v.Chr., d.h. seit ihrer Gründung (RIC I: 2107; zu den Ären vgl. Leschhorn 1993: 150-162), Amisos seit der Statthalterschaft des C. Papirius Carbo (61-59 v.Chr.). Amastris prägte vermutlich bereits seit 71/0 v.Chr. - dies ist anzunehmen, vorausgesetzt, die Jahresangaben auf den Münzen beziehen sich auf eine in diesem Jahr beginnende Ära und nicht auf eine später, etwa 64/3 v.Chr., beginnende (zu diesem Problem vgl. Leschhorn 1993: 167f.). Germanikopolis prägte höchst wahrscheinlich ausschließlich in der Zeit des Septimius Severus: Vermeintlich unter dem Namen Hestia geprägte Münzen aus neronischer Zeit sind sicherlich nicht, und tatsächlich unter diesem Namen geprägte Münzen aus der Zeit des M. Aurel sind aller Wahrscheinlichkeit nach nicht Germanikopolis zuzuordnen: Bricault, Delrieux 2014: 12 Anm. 29, 48f.

22) In der weiteren Region prägte Kerasous bis in die Zeit des Severus Alexander, Trapezous bis in die des Philippus Arabs, Abonouteichos prägte noch unter Trebonianus Gallus, Amastris, Amisos und die Colonia Iulia Felix bis in die Zeit des Gallienus.

23) Vgl. etwa Nollé 2006: 272, 276; Dalaison 2008: 184f.; Johnston 2012: 462f.; Estiot 2012: 543. Es war eine Vielzahl von Faktoren, die, von Fall zu Fall durchaus in unterschiedlicher Gewichtung, die Städte veranlaßt haben dürften, nicht mehr zu prägen. Dazu zählt die massive Entwertung der Reichsprägung: Da die städtischen Prägungen grundsätzlich in einem festen Wechselverhältnis zur Reichsprägung standen, konnte es geschehen, daß die Produktionskosten die mit der Prägung intendierte Wertschöpfung, die aus dem Schlagschatz und aus Wechselgebühren erzielt werden konnte, überstiegen (vgl. Nollé 2006: 273-276). Dazu zählt aber auch das jeweilige lokale Preisniveau bzw. die lokale Inflationsrate, die dazu beitragen konnte, daß man Nominale, die unterhalb des Gegenwerts eines Denar oder eines Antoninian lagen, schlicht nicht mehr benötigte. Vgl. zu dieser komplexen Thematik Howgego 1985: 60-73; Johnston 2007: bes. 241-243.

24) Von kriegerischen Auseinandersetzungen wurde die Region im engeren wie im weiteren Sinn jedoch erst in der Zeit des Valerianus, des Gallienus und des Tacitus bzw. dann des Florianus und des Probus direkt getroffen: So wurde Trapezous wohl im Jahr 258 von Boranern erobert und geplündert. Sebasteia wurde 260 von den Sasaniden in Mitleidenschaft gezogen. Herakleia Pontike wurde wohl im Jahr 267 von Goten erobert; Plünderungen im ,Hinterland“ (Bithynien, Galatien, evtl. auch Kappadokien) schlossen sich an. 276 führten neuerliche gotische Plünderungszüge durch Pontos - u.a. bis nach Galatien und Kappadokien. Zu Trapezous: vgl. Olshausen 1991: 30-37; Wojan 2006: 190f., zu Sebasteia: Kettenhofen 1982b: 118, 120, 122; Schultz 1989: 265, zu Herakleia Pontike: Schwarcz 1992: 51, zu dem Zug von 276: Schwarcz 1992: 56. Zu den Einfällen von Verbänden aus dem Norden allgemein Schwarcz 1992; Kettenhofen 1992, zu denen der Sasaniden Kettenhofen 1982a und b; Olshausen 2007 (mit weiterer Lit.).

25) Vgl. Dalaison 2008: 184. 


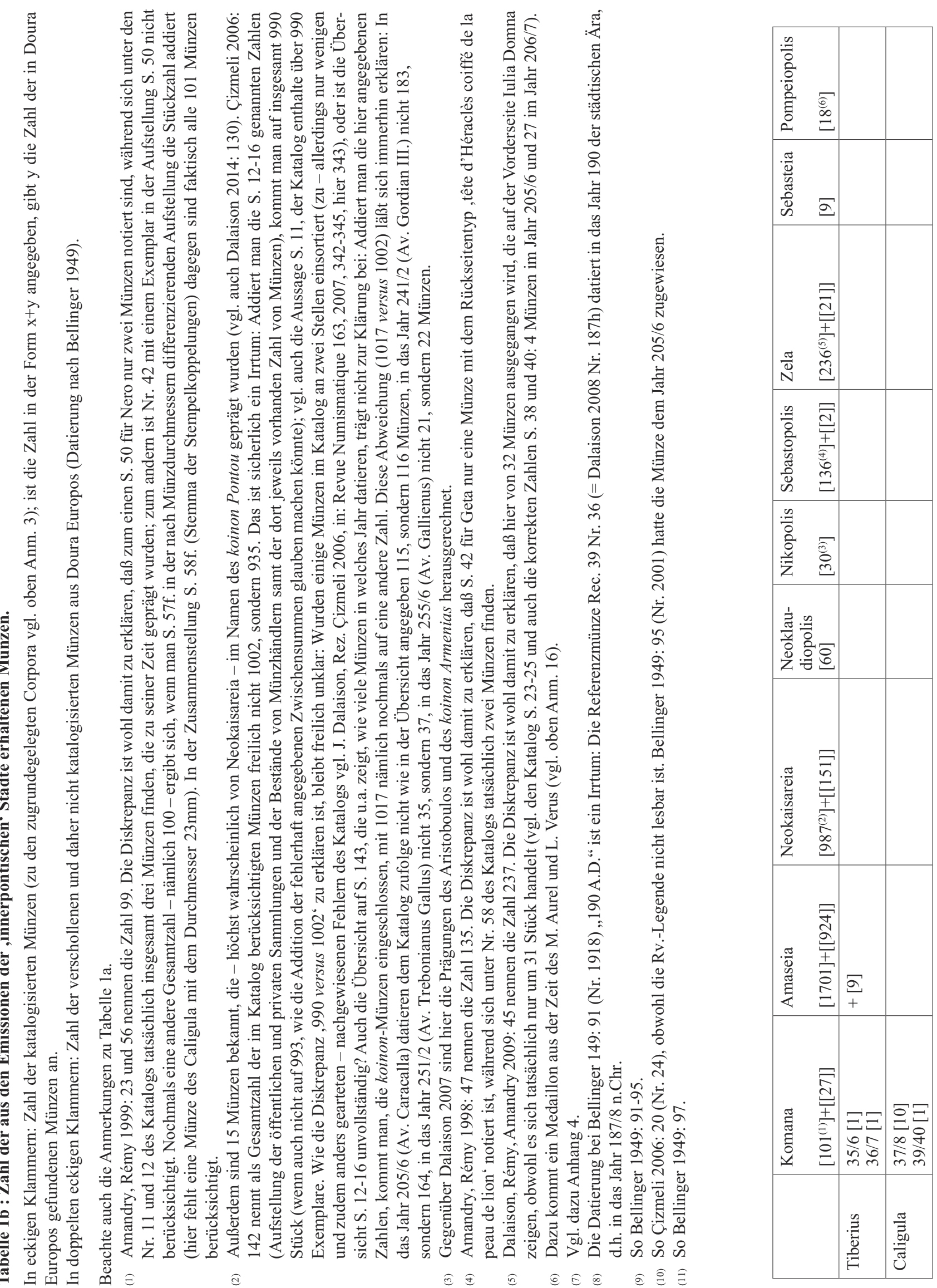




\begin{tabular}{|c|c|c|c|c|c|c|c|c|c|c|c|c|c|c|c|c|}
\hline & & & & & & & $\underset{+}{\stackrel{D}{+}}$ & $\underset{\square}{\Xi}$ & & $\underset{+}{\Xi}$ & & & & & & \\
\hline & & & & & $\begin{array}{l}\underset{\Xi}{n} \\
\stackrel{a}{J} \\
=\end{array}$ & & & 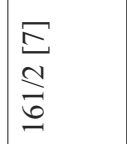 & & & & & & & & \\
\hline & & & & & $\underset{\substack{E \\
\stackrel{D}{\Xi}}}{=}$ & & & & & 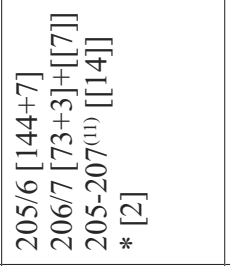 & & & & & & \\
\hline & & & & & $\begin{array}{l}\infty \\
\frac{\infty}{0} \\
\frac{\sigma}{\sigma}\end{array}$ & & & & & 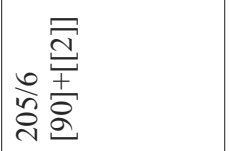 & & & & & & $\begin{array}{l}\infty \\
\infty \\
\stackrel{\infty}{+} \\
\stackrel{\infty}{\infty} \\
\stackrel{N}{N}\end{array}$ \\
\hline & & & & & 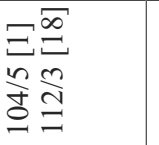 & & & $\begin{array}{l}\Xi \\
\Xi \\
\stackrel{\Xi}{\Xi} \\
\underline{-}\end{array}$ & & & & & & & & \\
\hline & & & & & 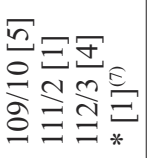 & $\Xi$ & 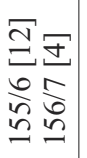 & & 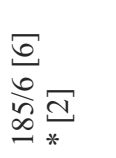 & 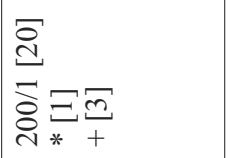 & & & & & & \\
\hline & & & $\begin{array}{l}\bar{d} \\
\frac{m}{d} \\
\Omega\end{array}$ & & $\begin{array}{l}\bar{\Xi} \\
\vec{\Xi} \\
\vec{\Xi} \\
\stackrel{\Xi}{\Xi}\end{array}$ & & & $\begin{array}{l}\infty \\
\underline{\infty} \\
\stackrel{D}{\sigma} \\
\underline{6}\end{array}$ & 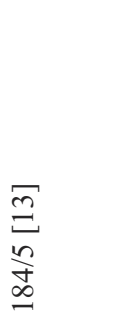 & 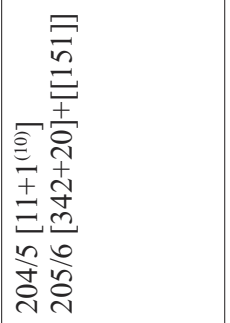 & 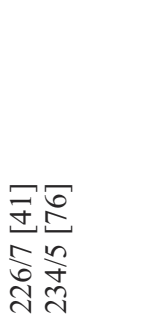 & 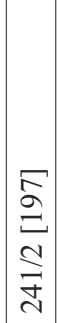 & $\begin{array}{l}\frac{\infty}{\infty} \\
\frac{\alpha}{\infty} \\
\stackrel{\alpha}{\sim}\end{array}$ & 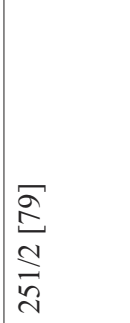 & 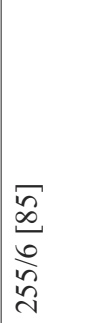 & 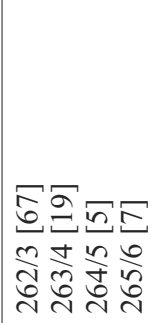 \\
\hline & & $\mid \begin{array}{l}\frac{n}{n} \\
\stackrel{\infty}{\infty} \\
\infty\end{array}$ & $\begin{array}{l}\underset{\sigma}{\Xi} \\
\stackrel{m}{\Sigma} \\
\sigma\end{array}$ & & $\begin{array}{l}\infty \\
\stackrel{\infty}{c} \\
\stackrel{m}{c} \\
=\end{array}$ & 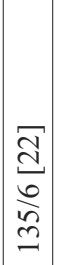 & 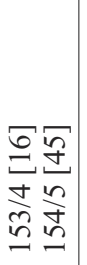 & 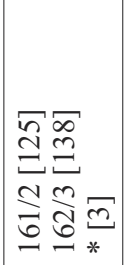 & 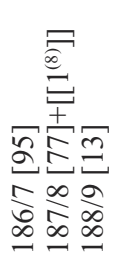 & 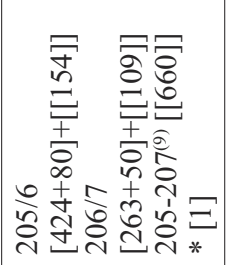 & 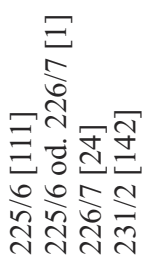 & & & & & \\
\hline$\frac{\bar{d}}{\frac{\pi}{6}}$ & $\begin{array}{l}\bar{m} \\
\frac{n}{5} \\
\delta \\
n\end{array}$ & & & $\begin{array}{l}\Xi \\
\frac{\Xi}{\delta} \\
\sigma\end{array}$ & $\Xi$ & & & & & 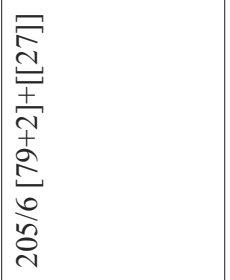 & & & & & & \\
\hline 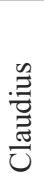 & $\begin{array}{l}0 \\
\dot{0} \\
z \\
z\end{array}$ & 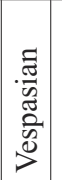 & 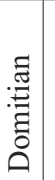 & 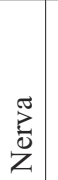 & 䔍 & 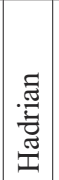 & 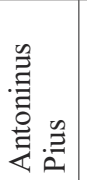 & ن & $\begin{array}{l}\text { है } \\
\text { ठ } \\
\vdots \\
\text { छ̇ }\end{array}$ & 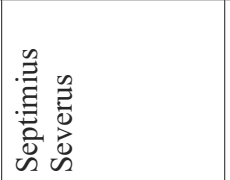 & 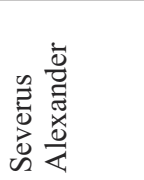 & 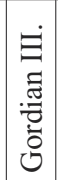 & 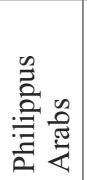 & 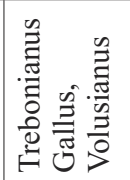 & 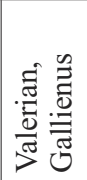 & 咅 \\
\hline
\end{tabular}


chen. ${ }^{26}$ Das gilt letztlich, anders als man zunächst meinen könnte, auch für die Prägungen von Pompeiopolis in der Zeit des M. Aurel und für die Prägungen von Amaseia in den Jahren 205/6 und 206/7.

Im Fall von Pompeiopolis war im Unterschied zu allen anderen ,innerpontischen' Städten, die bis in das 3. Jh. Münzen emittierten, das Volumen der Prägung nicht in der Zeit des Septimius Severus, sondern in der Zeit des M. Aurel am größten. ${ }^{27}$ Vieles spricht dafür, daß dies damit zusammenhängt, daß ein Schwiegersohn des Kaisers, Cn. Claudius Severus, ${ }^{28}$ aus Pompeiopolis stammte. ${ }^{29}$ Worin aber genau der Zusammenhang besteht und was konkret die Prägung veranlaßt hat, läßt sich nicht sagen ${ }^{30} \mathrm{da} ß \mathrm{Cn}$. Claudius Severus in seiner Vaterstadt jedoch als

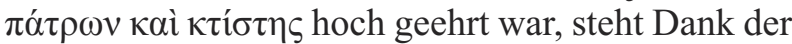
epigraphischen Befunde außer Frage. ${ }^{31} \mathrm{Da}$ auch die Medaillonprägung ${ }^{32}$ der Stadt, die ebenfalls in die Zeit des M. Aurel datiert, mit der Person des Cn. Claudius Severus zu tun hat, ist durchaus möglich, aber nicht zwingend. Angesichts der Vorder- und vor allem der Rückseitengestaltung ${ }^{33}$ ist ihre Produktion mit gutem Grund als mit den unter der Leitung des L. Verus stehenden Feldzügen gegen die Parther in den Jahren 162-166 in Zusammenhang stehend zu sehen; aber auch hier läßt sich der konkrete Anlaß der Prägung nicht identifizieren. ${ }^{34}$

Im Fall von Amaseia kann man zwar mit großer Wahrscheinlichkeit eine der Ursachen dafür, daß die Emissionen dieser Stadt in den Jahren 205/6 und 206/7 einen exzeptionell großen Umfang hatten, identifizieren - Amaseia dürfte einer Anordnung römischer Autoritäten Folge leistend Münzen gleichsam für den Export produziert haben, um einer Münzknappheit in Doura Europos abzuhelfen ${ }^{35}-$, daß diese Anordnung aber auch das diese Emissionen an sich auslösende Moment gewesen ist, kann, wenn auch nicht ausgeschlossen, so doch nicht sensu stricto nachgewiesen werden. Offenkundig hat Amaseia in diesen Jahren jedenfalls nicht einzig und vielleicht nicht einmal primär für Doura Europos geprägt: Der Anteil der Münzen, die hier zum Vorschein kamen, an den insgesamt aus diesen beiden Emissionen bekannten Münzen macht lediglich ca. $60 \%$ aus - trotz der aufgrund der Geschichte und der Forschungsgeschichte des Ortes geradezu unvergleichlich günstigen Fundlage. ${ }^{36}$ Die restlichen $40 \%$ gehören zu dem Teil der Emissionen, der offenbar

26) Theoretisch können ganz unterschiedliche Dinge Auslöser für eine Emission gewesen sein. Um nur wenige Beispiele zu nennen: der Mangel an Münzen mit kleinen Nominalen, der Wunsch, der Stadtkasse eine Einnahme zu verschaffen, die Absicht, etwa anläßlich eines Festes eine Geldspende zu verteilen, die Absicht einen Wohltäter zu ehren oder einen neuen Titel der Stadt zu propagieren. - Der Frage nach dem auslösenden Moment auch der Emissionen der Städte der weiteren Region nachzugehen, kann im Rahmen dieser Untersuchung nicht geleistet werden.

27) 9 der 12 bekannten Vorderseitenstempel sind in die Zeit des M. Aurel zu datieren (ebenso der Vorderseitenstempel des Medaillons), nur einer in die des Septimius Severus (vgl. Dalaison 2010: 55-59; S. 63 ist - den Stempel des Medaillons einberechnend - aber irrtümlich von „11 coins de droit sur 14“ die Rede).

28) $\mathrm{PIR}^{2} \mathrm{C} 1024$.

29) Vgl. Dalaison 2010: 63f.

30) Weder gibt die Thematik der Münzrückseiten (vgl. dazu unten S. 195) noch geben andere Quellen einen Hinweis, noch läßt sich das Jahr der Prägung genau ermitteln (vgl. Dalaison 2010: 53f., 70f. mit der wahrscheinlichen Eingrenzung auf 163-169). Spekulieren könnte man über einen Besuch des Cn. Claudius Severus in seiner Vaterstadt, über einen speziellen euergetischen Akt desselben, oder auch - durch seine Vermittlung - des Kaisers, usw.

31) Vgl. Marek 1993: 136-139 Nr. 2-10; Marek 2011: 189

32) Vgl. zu ihr auch oben S. 165 und unten Anm. 85, 165 und S. 196.

33) Die Vorderseite zeigt einander zugewandte Büsten des M. Aurel und des L. Verus (beide mit Bart und Lorbeerkranz, gepanzert und drapiert). Die Rückseite zeigt beide Kaiser in Militärkleidung nebeneinander zu Pferd mit eingelegter Lanze, einen Feind niederwerfend. Die Rückseitenlegende kommentiert die dargestellte Szene gleichsam: NEIKH CEBACTSN. NEIKH ist sicherlich als Variante

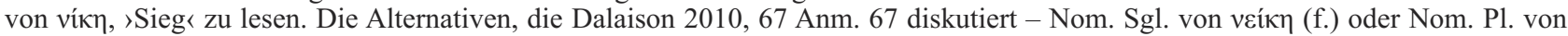

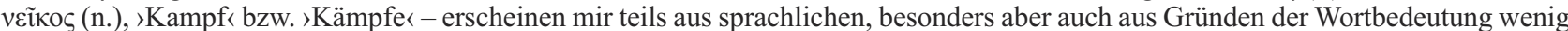
wahrscheinlich, dürfte man doch weniger den Kampf als vielmehr das Ergebnis desselben, den Sieg, gleichsam beschwören oder aber

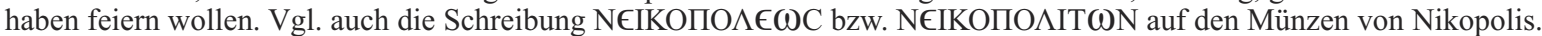

34) Dalaison 2010: 69-71. Denkbar ist etwa, daß man gleichsam einen Teilerfolg der Feldzüge feierte (vgl. die Titel Armeniacus, Medicus, Parthicus Maximus, die die Kaiser nach und nach und zeitlich versetzt annahmen) oder aber das Gesamtergebnis derselben anläßlich des Triumphs der Kaiser über die Parther nach der Rückkehr des L. Verus nach Rom. Vorstellbar ist auch, daß man mit den Medaillons aus Pompeiopolis stammende Personen ehrte, die an den Kämpfen beteiligt gewesen waren.

35) Dalaison 2008: 185-188, bes. 187; vgl. auch unten S. 180.

36) Vor der Zerstörung dieses wichtigen römischen Stützpunkts durch die Sasaniden im Jahr 256 waren teils ausgesprochen große Horte angelegt worden. Seit den 1920er Jahren wurden hier wiederholt umfangreiche systematische Grabungen durchgeführt. Zu den Münzfunden vgl. insbesondere Bellinger 1939; 1943; 1949; weiter Lit. bei Dalaison 2008: 186-188. - Die Zahl ,60\%" ergibt sich aus folgender Berechnung (vgl. Tabelle 1b): In Doura Europos wurden insgesamt 1053 von Amaseia geprägte Münzen gefunden, die, abgesehen von einer einzigen, in die Jahre 205/6 und 206/7 datieren; von den 818 bei Dalaison 2008 zu diesen beiden Jahren aufgeführten Münzen wurden 130 in Doura Europos gefunden, 688 sind von anderer Provenienz. 1052 Münzen entsprechen 60,5\% der 1052+688=1740 aus diesen Emissionen insgesamt bekannten Münzen. - Daß Julie Dalaison nur einen Bruchteil der aus Doura Europos stammenden Münzen katalogisieren konnte, liegt im Wesentlichen daran, daß ein Großteil dieser Münzen heute verschollen ist (vgl. Dalaison 2008: 186 Anm. 51). 
für den lokalen Gebrauch gedacht war. ${ }^{37}$ Auch waren nicht etwa spezielle ,Tranchen' der Prägung eigens für Doura Europos bestimmt. Vielmehr waren Münzen, die mit den in Doura Europos gefundenen stempelgleich sind, auch in Amaseia und der Region um Amaseia im Umlauf, ${ }^{38}$ und es ist nicht zu erkennen, daß bestimmte Bildthemen für den ,Export' nach Doura Europos favorisiert worden wären. Im Fall der anderen ,innerpontischen' Städte, die mit ihrer Münzprägung in den Funden von Doura Europos vertreten sind, ${ }^{39}$ ist der Anteil der Münzen, die dort zum Vorschein kamen, an den insgesamt aus Emissionen dieser beiden Jahre bekannten Münzen noch deutlich geringer. Im Fall von Neokaisareia beträgt er ca. 33\%, im Fall von Komana ca. 27\%, im Fall von Zela ca. $12 \%$ und im Fall von Sebastopolis ca. $2 \%$. Zudem prägten von diesen Städten nur Zela ebenfalls sowohl im Jahr 205/6 als auch 206/7, Komana und Sebastopolis dagegen nur 205/6, Neokaisareia ebenfalls nur 205/6 - diese Stadt hatte aber auch schon 204/5 emittiert. Angesichts dieser Zahlen ist insbesondere im Fall von Sebastopolis zu bezweifeln, daß die Prägung auf römische Anordnung hin erfolgte. Aber auch im Fall der anderen Städte, Amaseia eingeschlossen, fragt es sich, ob es nicht wahrscheinlicher ist, daß man in den betreffenden Jahren aus anderen, d.h. lokalen Gründen geprägt hat, dann aber auf eine wie auch immer genau gestaltete römische Anfrage hin das Prägevolumen zu Gunsten von Doura Europos erhöht hat, als daß eine römische Anordnung diese Städte überhaupt erst zur Prägung veranlaßt hat.

$\mathrm{Da}$ sich das die jeweilige Prägung der, innerpontischen' Städte auslösende Moment in keinem Fall genau und sicher bestimmen läßt, ist umso über- raschender, als sich - wie eben schon im Fall der Jahre 205/6 und 206/7 gesehen - in mehreren Jahren gleich zwei ${ }^{40}$ oder gar mehrere Städte ${ }^{41}$ zu einer Emission entschlossen, was zunächst einen zumindest über der Ebene der einzelnen Stadt liegenden, vielleicht gar einen überregionalen Hintergrund vermuten läßt, der dann doch leichter auszumachen sein sollte. Zu denken ist insbesondere an den Besuch des Kaisers oder an Truppenverschiebungen und Feldzüge.

Der einzige Besuch eines Kaisers in einer Stadt der hier untersuchten (weiteren) Region, der sich mit Sicherheit nachweisen läßt - der des Hadrian in Trapezous im Jahr 131/2 oder eher schon im Jahr $123^{42}$ hat sich in der Münzprägung dieser Stadt jedoch nicht niedergeschlagen: Trapezous hat in der Zeit des Hadrian allem Anschein nach überhaupt nicht geprägt.

Relevante militärische Ereignisse lassen sich für die betreffenden Jahre entweder nicht oder zumindest nicht in zwingender Weise feststellen, ${ }^{43}$ oder aber - und dies betrifft die Jahre 112/3 und 161/2 und die Feldzüge des Traian und des M. Aurel bzw. des L. Verus gegen die Parther - man kann lediglich Vermutungen darüber anstellen, was genau den $\mathrm{Be}$ schluß zu prägen ausgelöst hat. Infrage kommt beispielsweise die profectio des Kaisers, die Bekanntgabe oder das Bekanntwerden der Marschroute, eine konkrete an die Städte gerichtete Aufforderung, sich auf die bevorstehenden Ereignisse vorzubereiten, oder auch die Notwendigkeit, auf einen Mangel an Kleingeld zu reagieren, der im Vorfeld der Kriege entstanden sein mochte. Zudem ist die Vorstellung, es habe ein ursächlicher Zusammenhang zwischen diesen Feldzügen und den betreffenden Emissionen bestanden, m.E. nicht über alle

37) Zum Münzumlauf allgemein vgl. unten S. 179f.

38) Dalaison 2008 Nr. 301d wurde in Doura Europos gefunden, Nr. 301a aber in Zile (ant. Zela); dasselbe gilt für Nr. 422b respektive a. Dalaison 2008 Nr. 233f wurde in Doura Europos gefunden, Nr. 233a findet sich aber im Bestand des Museums Amasya, ist angesichts der Erwerbungsusancen des Museums (vgl. Ireland 2000: 6) also mit größter Sicherheit lokaler oder regionaler Provenienz; dasselbe gilt für Nr. $300 \mathrm{~g}$ respektive a, $305 \mathrm{~b}$ respektive a, 314b respektive a, $347 \mathrm{~g}$ respektive a, $370 \mathrm{~g}$ respektive a, $444 \mathrm{c}$ respektive a, 457c respektive a und für Nr. 488f respektive a. Darüber hinaus finden sich gleichsam weltweit in diversen Sammlungen Münzen, die mit in Doura Europos gefundenen stempelgleich sind und die - angesichts des Verbreitungsbereichs der Münzen von Amaseia (vgl. wiederum unten S. 179f. und auch oben S. 172f.) - in ihrer Mehrzahl lokaler oder regionaler Provenienz sein dürften. (Daß sie zu den aus den Grabungen von Doura Europos stammenden, mittlerweile aber verschollenen Exemplaren gehören, kann angesichts des frühen Erwerbungsdatums für viele dieser Münzen ausgeschlossen werden.)

39) Von den Städten der weiteren Region sind nur die Colonia Iulia Felix und Trapezous vertreten - freilich nur mit jeweils einer im Jahr 210 bzw. 244/5 geprägten Münze (vgl. Bellinger 1949: 97).

40) In den Jahren 92/3 und 226/7 Amaseia und Neokaisareia (im Jahr 226/7 außerdem in der weiteren Region Trapezous), im Jahr 263/4 Neokaisareia und Sebastopolis.

41) Im Jahr 112/3 Amaseia, Neoklaudiopolis und Nikopolis, 161/2 Amaseia, Neokaisareia, Nikopolis, Sebasteia und vielleicht auch Pompeiopolis (die Münzen dieser Stadt notieren freilich nicht das Jahr, in dem die Emission erfolgte; außerdem in der weiteren Region Kerasous, Trapezous und die Colonia Iulia Felix).

42) Vgl. Halfmann 1986: 41, 69, 127, 190, 198

43) Vgl. aber Ziegler 1993: 73-80, 81; 1996, 131f. zu den Jahren 92/3, 205-207 und 226/7, der zu überlegen gibt, daß in den ersten beiden Fällen Züge gegen die Parther geplant gewesen sein könnten, die dann aber nicht durchgeführt wurden, und daß im dritten Fall Anlaß bestanden habe, die Truppenverbände an der Grenze zu den Sasaniden zu verstärken. 
Zweifel erhaben. Diese Zweifel ${ }^{44}$ gründen im ersten Fall etwa auf der Beobachtung, daß die Jahre, in denen in der Zeit um das Jahr 112/3 in der Region insgesamt gesehen Emissionen erfolgten, erheblich streuen: So prägte Neoklaudiopolis anders als Amaseia und Nikopolis nicht nur im Jahr 112/3, sondern bereits 111/2 (und auch schon 109/10), Zela aber erst 113/4 (ebenso in der weiteren Region Amisos und Trapezous) und Sebasteia gar erst 114/5. Noch schwerer wiegt, daß Neokaisareia, obwohl die Stadt an der Durchmarschroute der Truppen gelegen haben dürfte, in der fraglichen Zeit offenbar überhaupt nicht geprägt hat. Im zweiten Fall gehört Neokaisareia zwar zum Kreis der prägenden Städte und die Streuung der Jahre, in denen Emissionen erfolgten, ist geringer (vgl. Tabelle 1), das Volumen, das diese Prägungen erreichten, ist nach allem, was wir wissen, jedoch so klein gewesen, daß ein wie auch immer gearteter ökonomischer Zusammenhang zwischen diesen Emissionen und dem Feldzug nur schwer vorstellbar ist. ${ }^{45}$ Entsprechendes gilt im Übrigen auch für die Prägungen um das Jahr 112/3. ${ }^{46}$
Auch ist es im Fall von Pompeiopolis, wie oben diskutiert, ${ }^{47}$ sehr wahrscheinlich, daß die Prägung dieser Stadt in der Zeit M. Aurels vor einem anderen als einem militärischen Hintergrund gesehen werden sollte. Auffallend ist außerdem, daß in den Emissionen der, innerpontischen' Städte in den Jahren 112/3 und 161/2 und auch in den Jahren 113/4 und 162/3 im weitesten Sinn kriegerische Motive bei der Gestaltung der Münzbilder so gut wie keine Rolle gespielt haben. ${ }^{48}$

Insgesamt gesehen ist zu vermuten, daß zumindest in einem Teil der Fälle, in denen synchrone Emissionen festzustellen sind, der Synchronismus zufällig und der Anlaß der Prägung doch in jeder Stadt ein anderer gewesen ist. Ein Versuch, in den einzelnen Städten liegende Anlässe zu identifizieren, scheitert freilich nicht zuletzt daran, daß wir von deren Interna und individueller Geschichte nur geringe Kenntnis haben. ${ }^{49}$ Zudem beschäftigten sich die Prägungen der Städte, anders als man es aufgrund der Usancen der Reichsprägung erwarten könnte, grundsätzlich nicht mit konkreten aktuellen Ereignissen. ${ }^{50}$

44) Ihnen genauer nachzugehen, sie zu untermauern - oder sie vielleicht doch auszuräumen -, würde den Rahmen der vorliegenden Untersuchung bei Weitem sprengen, ist dazu letztlich doch eine Studie ähnlich jener, die Ruprecht Ziegler für die ostkilikischen Städte vorgelegt hat (Ziegler 1993), erforderlich. Da in einer derartigen Studie unbedingt auch die paphlagonischen und pontischen Küstenstädte berücksichtigt werden sollten, ist es sicherlich sinnvoll, das Erscheinen der noch ausstehenden Münzcorpora dieser Städte abzuwarten.

45) Dies geht aus den Berechnungen von Michel Amandry (Amandry 2011: 307f.) deutlich hervor, auch wenn der Autor nicht darlegt, in welchem ökonomischen Zusammenhang die Münzprägung der Städte und die Feldzüge konkret gestanden haben könnten, sondern lediglich das hochgerechnete Volumen der betreffenden Prägungen mit den vermutlichen Unterhaltskosten der beteiligten Truppen vergleicht. Da es für die Städte selbstredend jedoch nicht darum ging, diese Truppen zu besolden, sondern lediglich darum, den erhöhten Bedarf an Kleingeld angesichts der durchziehenden Menschenmenge und der dadurch - möglicherweise auch nicht nur an der Durchmarschroute im engeren Sinn - gesteigerten ökonomischen Aktivitäten zu decken (vgl. dazu etwa Ziegler 1996), wäre zu erörtern, ob und gegebenenfalls wie das Volumen dieses Kleingeldbedarfs abgeschätzt werden kann, das neben der Kaufkraft der Soldaten von vielen anderen Faktoren und nicht zuletzt von der Verweildauer der Truppen abhing.

46) Vgl. Amandry 2011: 305-307.

47) Vgl. oben S. 172.

48) Die Ausnahmen sind: Kaiser in Rüstung, der von Tyche/Fortuna bekränzt wird (Neoklaudiopolis, 112/3: Dalaison, Delrieux 2014 Nr. 6 und 7), und Nike (Sebasteia, 161/2: Schultz 1989 Nr. 5; Amaseia, 162/3: Dalaison 2008 Nr. 101). Die Prägungen von Nikopolis sind zugegebenermaßen weitestgehend auf Nike und Zeus Nikephoros ausgerichtet; vgl. dazu aber unten Anm. 164. Zu der Prägung des koinon Armenias vgl. unten Anm. 50.

49) Insbesondere ist nicht bekannt, welche städtischen Institutionen mit der Münzprägung befaßt waren - etwa die boule oder auch eine Volksversammlung, spezielle Funktionsträger oder auch Privatpersonen. Vgl. die entsprechenden Abschnitte in den oben in Anm. 3 genannten Corpora; zu Pompeiopolis auch Summerer (Hg.) 2011, zu Sebastopolis Le Guen, Rémy 2010, zu Neoklaudiopolis Sørensen 2016 (mit weiterer Literatur). In Pompeiopolis finden seit 2006 systematische archäologische Untersuchungen statt, in Sebastopolis wurden 2013 die Arbeiten nach über 20-jähriger fast vollständiger Unterbrechung wieder aufgenommen. In Neoklaudiopolis wurden seit 2010 Surveys durchgeführt, außerdem ist ein Corpus der Inschriften dieser Stadt in Vorbereitung. So ist zu hoffen, daß immerhin in die Entwicklung dieser drei Städte in absehbarer Zeit ein vertiefter Einblick aus archäologischer und auch epigraphischer Sicht möglich sein wird. Was die Entwicklung der Stadt in ihrer Anfangsphase anbelangt, muß im Fall von Pompeiopolis diese Hoffnung freilich bereits wieder gedämpft werden: In den untersuchten Arealen des urbanen Zentrums läßt sich die Besiedlung allenfalls bis in flavische Zeit zurückverfolgen (vgl. Summerer 2011: 11); vgl. aber zur chora von Pompeiopolis Johnson 2015.

50) Anders als bislang gedacht (Dalaison, Delrieux 2014: 188; Sauer 2014: 121f.) gilt dies höchst wahrscheinlich auch für die von Julie Dalaison und Fabrice Delrieux im Corpus der Münzen von Neoklaudiopolis unter der Nummer 1 geführte Münze. Vgl. dazu unten Anhang 4. - Erwähnt sei, daß im Gegensatz zu den ,innerpontischen' Städten das koinon von Armenia Minor jedoch in seiner Prägung ein höchst aktuelles Ereignis aufgriff und so gut wie unmittelbar nach der Eroberung von Armenia Maior Münzen prägte, die auf dem Revers die vor einem Tropaion sitzende Personifikation der neuen Provinz zeigen (Dalaison 2007 Nr. 25-31 mit S. 232): Diese Münzen wurden im 43. Jahr der Ära des koinon, d.h. 113/114 n.Chr. geprägt, die Eroberung von Armenia Maior war im Herbst 114 abgeschlossen (vgl. Leschhorn 1993: 144-149; Mitford 1980: 1198). Da das koinon allem Anschein nach einzig in diesem Jahr, und in diesem Jahr mit einiger Wahrscheinlichkeit Münzbilder einzig mit dieser Thematik prägte (8 Münzen sind erhalten, die sich 7 Rückseiten- und 4 Vorderseitenstempeln zuordnen lassen), ist es nicht unwahrscheinlich, daß diese Expansion des Imperium Romanum tatsächlich auch das die Prägung auslösende Moment gewesen ist: Armenia Minor mochte sich veranlaßt gesehen haben, den eigenen Status im und die Loyalität mit dem Imperium Romanum zu betonen (vgl. Dalaison 2007: 232: „,... que ce district veut montrer son attachment à l'Empire et sa différence avec le royaume voisin, qui n'aurait de commun avec lui que le nom“). 
Der Mangel an Kenntnis, was die Interna und die individuelle Geschichte der Städte anbelangt, ist auch die Ursache dafür, daß es so schwer fällt zu erklären, weshalb die Münzprägung genau zu dem jeweils gegebenen Zeitpunkt einsetzt. Daß Neoklaudiopolis, Nikopolis, Sebasteia, Sebastopolis und Zela in traianischer Zeit zu prägen begannen, ${ }^{51}$ ist zwar sicherlich auch vor dem Hintergrund der allgemeinen politischen und kulturellen Atmosphäre dieser Zeit zu sehen. ${ }^{52}$ Nicht zuletzt um zu erklären, weshalb die ersten Emissionen von Amaseia, Komana und Neokaisareia schon früher und die von Pompeiopolis erst später erfolgten (vgl. Tabelle 1a), ${ }^{53}$ ist zu überlegen, ob insbesondere nicht auch der Grad der Polisentwicklung ${ }^{54}$ und der Grad der Bedeutung, den die jeweilige Stadt in der Region hatte, eine Rolle spielte.

Angesichts der Quellenlage, die es eben nicht erlaubt, die Polisentwicklung der ,innerpontischen Städte detailliert zu verfolgen, kann man auf den Ausweg verfallen, immerhin zu untersuchen, ob bestimmte Aspekte der Vorgeschichte der Städte, die bekannt sind, erkennbar mit dem frühen oder späten Zeitpunkt in Zusammenhang stehen, zu dem die
Münzprägung einsetzte. Dabei ist zunächst festzustellen, daß zwischen Dauer der Provinzzugehörigkeit und Beginn der Münzprägung kein gleichsam regelhafter Zusammenhang besteht (vgl. Tabelle 2): Während in Komana die Münzprägung fast unmittelbar nach der Eingliederung ${ }^{55}$ in das Imperium Romanum einsetzte, ${ }^{56}$ geschah dies in Neokaisareia, Nikopolis, Amaseia, ${ }^{57}$ Zela und Sebasteia mit einer Verzögerung von Jahrzehnten, ${ }^{58}$ in Neoklaudiopolis und Sebastopolis mit der Verzögerung von etwas mehr als einem Jahrhundert, in Pompeiopolis gar erst nach noch längerer Zeit. ${ }^{59}$ Auffallend ist, daß drei der vier Städte, in denen die Münzprägung am schnellsten aufgenommen wurde, Städte sind, von denen man vermuten kann, daß ihre Startbedingungen bei der Poliswerdung insofern günstig gewesen sind, als sie auch zuvor schon zentralörtliche Funktionen erfüllt hatten: ${ }^{60}$ Komana war das Zentrum eines bis zur Eingliederung in die Provinz von einem Oberpriester geleiteten Tempelstaats. Sebaste nachmals Neokaisareia - war zumindest unter Pythodoris königliche Residenz; ${ }^{61}$ es ist nicht unwahrscheinlich, daß hier die Münzen der pontischen Dynasten geprägt wurden. ${ }^{62}$ Nikopolis war kleinar-

51) Ebenso in der weiteren Region Abounouteichos und Trapezous.

52) Generell zu den Verbindungslinien zwischen städtischer Münzprägung und Zweiter Sophistik: Weiß 2004.

53) In der weiteren Region gehören Amastris, Amisos und Colonia Iulia Felix zu den früher, Kerasous und Germanikopolis zu den später mit der Prägung beginnenden Städten.

54) $\mathrm{Zu}$ denken ist dabei insbesondere an die Ausbildung einer polis-Mentalität. - Vgl. die Diskussion über die Ursachen der Ausgliederung der ,innerpontischen“ poleis Diospolis (nachmals Sebaste, dann Neokaisareia), Magnopolis, Megalopolis (nachmals Sebasteia), Neapolis (nachmals Neoklaudiopolis), Nikopolis, Pompeiopolis, Zela und auch Amaseia, sollte Amaseia eigenständige polis und nicht Zela zugehörig gewesen sein, aus der Provinz Bithynia et Pontus sei es durch Antonius, sei es, wie in einigen Fällen zu überlegen, bereits etwas früher oder auch etwas später durch Augustus: Möglicherweise war es der Bevölkerung nicht gelungen, sich als polis zu organisieren (vgl. zu dieser Hypothese etwa Olshausen 1980: 910; Dalaison 2010: 49f.; zu den Ausgliederungen aus der Provinz Marek 1993: 47-51 und die entsprechenden Abschnitte in den oben in Anm. 3 zitierten Corpora).

55) Wenn hier, wie im Folgenden, bezogen auf die ,innerpontischen' Städte von ,Eingliederung in die Provinz' die Rede ist, so ist - wenn nicht anders vermerkt - nicht die Eingliederung in die von Pompeius gestaltete Provinz Bithynia et Pontus, sondern die seit augusteischer Zeit in Etappen bis in die Zeit Vespasians erfolgende Eingliederung in die Provinz Galatia bzw. Cappadocia und damit die gleichsam endgültige Eingliederung in die direkte römische Herrschaft gemeint. Komana selbst stellt insofern eine Ausnahme dar, als diese politeia von Pompeius nicht in die Provinz Bithynia et Pontos eingegliedert worden war. - Soweit wir wissen, hat keine der ,innerpontischen` Städte während ihrer Zugehörigkeit zu Bithynia et Pontus geprägt.

56) In der weiteren Region setzt die Münzprägung ähnlich schnell in Amastris, Amisos und auch in der Colonia Iulia Felix ein: Die colonia prägte bereits im Jahr ihrer Gründung, Amastris höchst wahrscheinlich (vgl. oben Anm. 21) bereits im Jahr ihrer ,Befreiung‘ von der mithradatischen (71/0 v.Chr.) und damit schon vor der Eingliederung in die römische Herrschaft (64/3 v.Chr.). Die früheste bekannte Prägung von Amisos (ebenfalls 71/0 v.Chr. ,befreit') datiert in die Jahre 61-59 v.Chr., erfolgte also immerhin bereits wenige Jahre nach der Eingliederung in die Provinz (64/3 v.Chr.). Als Amisos nach der zwischenzeitlichen Ausgliederung aus der Provinz durch Antonius in die Provinz reintegriert worden war (31 v.Chr.), dauerte es offenbar jedoch über 25 Jahre, bevor man die Münzprägung wieder aufnahm.

57) Vgl. aber oben Anm. 20

58) Ebenso in der weiteren Region in Trapezous und Kerasous; zu Amisos vgl. oben Anm. 21.

59) Ebenso in der weiteren Region in Germanikopolis und in Abonouteichos. (Im Fall von Abonouteichos ist freilich festzuhalten, daß der polis-Status erst für traianische Zeit über alle Zweifel erhaben ist; vgl. Marek 1993: 82f.)

60) Wenngleich in deutlich anders gearteten politischen Systemen und vielleicht auch von anderen Personenkreisen maßgeblich getragen. Es ist wohl davon auszugehen, daß unter dynastischer Herrschaft auch die Polis-Verfassung der Städte aufgehoben war, selbst wenn Neapolis (nachmals Neoklaudiopolis), Nikopolis und Pompeiopolis - anders als Diospolis (nachmals Neokaisareia) und Megalopolis, die in Sebaste bzw. Sebasteia umbenant wurden - offenbar ihren Namen nicht änderten und ihnen so zumindest in der Benennung der polis-Charakter erhalten blieb.

61) Çizmeli 2006: 84.

62) Vgl. Rec. 116; RPC I: $567 f$. 
Tabelle 2 : Eingliederung der Städte in die Provinz, Beginn der städtischen Ären und früheste nachgewiesene Prägungen.

(1) Anderer Auffassung ist Sørensen 2016.

(2) Marek 1993: 62 plädiert insbesondere für den Fall, daß Cappadocia und Galatia 64/5 n.Chr. bereits getrennt gewesen sein sollten, freilich für Cappadocia.

(3) Im Fall von Sebasteia plädiert Marek 1993 nicht für Cappadocia; dies ist jedoch nur darauf zurückzuführen, daß ihm teils die Existenz, teils die korrekte Lesung von Münzen von Megalopolis-Sebasteia, und auch die Korrektur einer irrtümlichen Zuschreibung noch nicht bekannt war (vgl. Schultz 1989) und er folglich für die Eingliederung der Stadt in die Provinz den Zeitraum 2/1 v.Chr. bis $1 / 2$ n.Chr. annahm.

(4) 71/2 n.Chr. möglicherweise bereits wieder mit Galatia zusammengelegt. (Zur Provinzialentwicklung Cappadocia/Galatia vgl. K. Strobel, Cappadocia, in: DNP 2, 1997: 974f. mit Lit.)

(5) Der Status von Abonouteichos als polis ist jedoch erst für traianische Zeit gesichert.

(6) Amastris und Amisos wurden freilich bereits durch Lucullus 71/0 v.Chr. von der Herrschaft des Mithradates ,befreit‘.

(7) Vgl. dazu Anhang 4 .

(8) Die Datierung in die Zeit des Tiberius ist nicht ganz sicher; Alternativen: Augustus oder Caligula (vgl. Dalaison 2008: 24).

(9) Vorausgesetzt, die Prägungen unter dem Namen Hestia sind tatsächlich nicht Germanikopolis zuzuordnen (vgl. oben Anm. 21); andernfalls: M. Aurel.

\begin{tabular}{|c|c|c|c|}
\hline & \multicolumn{2}{|c|}{$\begin{array}{l}\text { Eingliederung in die Provinz/ } \\
\text { Beginn der städtischen Ära }\end{array}$} & früheste nachgewiesene Prägung \\
\hline \multicolumn{4}{|c|}{,innerpontische Städte‘ } \\
\hline Neoklaudiopolis & Galatia $^{(1)}$ & 6/5 v.Chr. & $109 / 10^{(7)}$ \\
\hline Pompeiopolis & Galatia & 6/5 v.Chr. & Antoninus Pius \\
\hline Amaseia & Galatia & 3/2 v.Chr. & Tiberius? $^{(8)}$ \\
\hline Sebastopolis & Galatia & 3/2 v.Chr. & $106 / 7$ \\
\hline Komana & Galatia & $34 / 5$ n.Chr & $35 / 6$ \\
\hline Neokaisareia & Galatia $^{(2)}$ & 64/5 n.Chr. & $92 / 3$ \\
\hline Zela & Galatia $^{(2)}$ & 64/5 n.Chr. & $113 / 4$ \\
\hline Sebasteia & Galatia $^{(3)}$ & 64/5 n.Chr. & $114 / 5$ \\
\hline Nikopolis & Cappadocia $^{(4)}$ & 71/2 n.Chr. & $104 / 5$ \\
\hline \multicolumn{4}{|c|}{ Städte der weiteren Region } \\
\hline Abonouteichos & Pontus et Bithynia (64/3 v.Chr.) ${ }^{(5)}$ & wohl 71/0 v.Chr. & Traian \\
\hline Amastris & Pontus et Bithynia (64/3 v.Chr.) ${ }^{(6)}$ & 71/0 v.Chr. & 71/0 v.Chr. \\
\hline Amisos & $\begin{array}{l}\text { Pontus et Bithynia ( } 64 / 3 \text { bis Antonius; } \\
\text { erneut } 31 \text { v.Chr.) })^{(6)}\end{array}$ & 32/1 v.Chr. & $\begin{array}{l}\text { 61-59 v.Chr. // } \\
\text { 5/4 v.Chr. }\end{array}$ \\
\hline Colonia Iulia Felix & gegründet in Pontus et Bithynia & 45 v.Chr. & 45 v.Chr. \\
\hline Germanikopolis & Galatia & 6/5 v.Chr. & $208 / 9^{(9)}$ \\
\hline Trapezous & Galatia $^{(2)}$ & 64/5 n.Chr. & $113 / 4$ \\
\hline Kerasous & Galatia $^{(2)}$ & 64/5 n.Chr. & $137 / 8$ \\
\hline
\end{tabular}

menische Residenz; deren Herrscher Aristoboulos ließ seine Münzen aller Wahrscheinlichkeit nach hier prägen. ${ }^{63}$ Das Beispiel Amaseia zeigt freilich, daß eine derartige Vorgeschichte nicht etwa gleichsam notwendige Bedingung für den recht schnellen Einstieg in die Münzprägung gewesen ist. Und der Blick in die weitere Region zeigt, daß sie auch nicht gleichsam hinreichende Bedingung gewesen ist: Gangra - nachmals Germanikopolis - war Residenz der paphlagonischen Dynasten, die wohl auch hier Münzen prägen ließen; ${ }^{64}$ die polis Germanikopolis prägte jedoch höchst wahrscheinlich erst mehr als zwei Jahrhunderte nach ihrer Eingliederung in die römische Provinz. Betrachtet man die Dinge aus umgekehrter Perspektive und richtet den Blick auf die Städte, die erst über ein Jahrhundert nach ihrer Eingliederung in die Provinz zu prägen begannen, so fällt auf, daß diese allesamt neu gegründet worden

63) Dalaison 2007: 203, 205; RPC I: 570.

64) RPC I: 537; Bricault, Delrieux 2014: 47. 
waren, respektive lediglich dörfliche Siedlungen als Vorläufer hatten: Karana - mit größter Wahrscheinlichkeit der Vorgänger von Sebastopolis - war durch Synoikismos entstanden, den die römischen Autoritäten bei der Eingliederung der Region in die Provinz Galatia 3/2 v.Chr. veranlaßt hatten. ${ }^{65}$ Neapolis - nachmals Neoklaudiopolis - und wohl auch Pompeiopolis waren an der Stelle bestehender Dörfer gegründet worden, allerdings bereits auf Veranlassung des Pompeius. ${ }^{66}$ Das Beispiel Megalopolis - nachmals Sebasteia -, ebenfalls auf Veranlassung des Pompeius gegründet, ${ }^{67}$ zeigt freilich, daß auch eine Stadt mit derartiger Vorgeschichte die Prägung schneller aufnehmen konnte: Sebasteia prägte bereits 50 Jahre nach ihrer endgültigen Eingliederung in die Provinz.

Ähnlich fällt der Befund aus, fragt man, ob ein Zusammenhang zwischen dem Grad an politisch-administrativer ${ }^{68}$ Bedeutung einer Stadt und der Ge- schwindigkeit, mit der sie die Prägetätigkeit aufgenommen hat, besteht. Wie bei der Frage nach dem denkbaren Zusammenhang zwischen der Vorgeschichte der Städte und dieser Geschwindigkeit ist zwar eine Tendenz erkennbar, Ausnahmen warnen jedoch davor, eine strikte Regelhaftigkeit zu vermuten: Von den Städten, die innerhalb der Provinz eine hervorgehobene Position hatten, oder jedenfalls zu Zeiten haben sollten - es handelt sich um die metropoleis und neokoroi Amaseia, Neokaisareia, Nikopolis und um Pompeiopolis, die immerhin metropolis war-, nahmen die drei erstgenannten die Prägetätigkeit relativ schnell auf, Pompeiopolis jedoch erst mit erheblicher Verzögerung. ${ }^{69}$ Gleichsam ungeschlagen ist freilich Komana, das ohne eine vergleichbare politisch-administrative Bedeutung zu haben, - wie gesehen - unmittelbar nach Eingliederung in die Provinz prägte. ${ }^{70}$

65) Vgl. Marek 1993: 53-56; Amandry, Rémy 1998: 7f.; Strabons Geographika. Mit Übersetzung und Kommentar herausgegeben

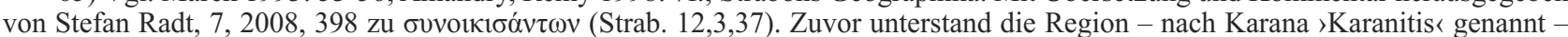

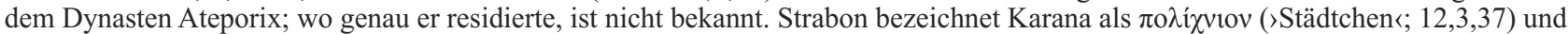
noch Plinius nennt Sebastopolis parva (nat. 6,8).

66) Zu Neapolis vgl. Dalaison, Delrieux 2014: 160-162; zu Pompeiopolis vgl. Dalaison 2010: 48; Summerer 2011: 4.

67) $\mathrm{Da}$ Megalopolis immerhin eine dörfliche Vorgängersiedlung hatte, ist zu vermuten. Von Caesar bzw. Antonius veranlaßt, hatte Megalopolis große Teile ihres Territoriums an Komana, Zela und an Ateporix - an ihn die nachmalige Karanitis - verloren. Vgl. Schultz 1989: $259 f$.

68) Die Dinge etwas vereinfachend sei die kultische Bedeutung im Rahmen der Verehrung des Kaisers hier subsumiert.

69) Im Fall von Amaseia bezieht sich der Titel metropolis höchst wahrscheinlich auf die Funktion der Stadt innerhalb der Eparchie Pontus Galaticus. Amaseia dürfte bereits mit Eingliederung in die Provinz 3/2 v.Chr. Hauptort dieser neuen Eparchie geworden sein und den Titel, der dann wohl nur noch ein ehrender gewesen ist, behalten haben, als Pontus Galaticus unter Traian oder Hadrian mit Pontus Polemoniacus zu Pontus Mediterraneus vereinigt wurde (sicher belegt ist der Titel, soweit ich sehe, jedoch erst für hadrianische Zeit). Neokoros wurde Amaseia wohl unter M. Aurel. Vgl. Burrell 2004: 210f.; Dalaison 2008: 21-23, 157f.; 2014: 125, 130, 132, 136. - Im Fall von Neokaisareia bezieht sich der Titel metropolis sehr wahrscheinlich sowohl auf die Funktion der Stadt innerhalb der 64/5 n.Chr. geschaffenen Eparchie Pontus Polemoniacus, dann des Pontus Mediterraneus, als auch auf die Funktion der Stadt als Hauptort des koinon Pontou (sicher belegt ist der Titel jedoch wiederum erst für hadrianische Zeit). Neokoros war Neokaisareia zumindest seit M. Aurel, dis Neokoros seit Severus Alexander. Vgl. Burrell 2004: 205-209 (bei der S. 206f. diskutierten Münze, welche die erste Neokorie bereits für traianische Zeit zu belegen scheint, handelt es sich nach freundlicher Mitteilung von Julie Dalaison freilich um eine Fälschung; vgl. SNG France 7, F 25); Çizmeli 2006: 100f., 131f.; Dalaison 2008: 22, 158; 2014: 130, 132. - Im Fall von Nikopolis bezieht sich der Titel metropolis sicherlich sowohl auf die Funktion der Stadt innerhalb der Eparchie als auch innerhalb des koinon von Kleinarmenien. Metropolis (und vielleicht auch neokoros) wurde Nikopolis möglicherweise bereits bei ihrer Eingliederung in die Provinz Cappadocia; gesichert sind beide Titel freilich frühestens für die Zeit Hadrians. Eine zweite Neokorie ist frühestens für die Zeit Gordians III. belegt. Vgl. Burrell 2004: 234f.; Dalaison 2007: 211f. - Im Fall von Pompeiopolis bezieht sich der Titel metropolis - belegt seit hadrianischer Zeit - mit großer Wahrscheinlichkeit auf die Funktion der Stadt innerhalb der Eparchie Paphlagonia (Dalaison 2010: 52f. möchte freilich nicht völlig ausschließen, daß der Titel allein ehrender Natur ist), möglicherweise auch auf die Funktion als Hauptort des koinon Paphlagonias. Eine 2008 entdeckte Inschrift (vgl. Marek 2011: 190f.; 2015), deren detaillierte Interpretation freilich noch aussteht, wird wohl zur Klärung insbesondere der Frage nach der Stellung von Pompeiopolis im koinon beitragen können. Die Unsicherheit, wie der Titel zu verstehen ist, rührt nicht zuletzt daher, daß zumindest anfangs höchst wahrscheinlich nicht Pompeiopolis, sondern Gangra Hauptort der Eparchie gewesen ist, und daher, daß man von keiner der Städte Paphlagoniens weiß, ob sie neokoros gewesen ist (vgl. Dalaison 2010: 47, 51-53; vgl. auch Bricault, Delrieux 2014: 10, 46, 48). - Zur Diskussion um die Identifizierung der einzelnen Eparchien und koina, um die Zugehörigkeit von Städten zu ihnen und um deren Stellung in ihnen vgl. insgesamt auch Dalaison 2014: 125-128 und, mit teils differierender Sichtweise, Vitale 2012: 145-229; 2014 und Marek 2015, außerdem Sørensen 2016.

70) Angesichts der Vorgeschichte von Komana fragt es sich, ob man im Fall dieser politeia die Münzprägung und v.a. deren zügiges Einsetzen nach der Eingliederung in die Provinz tatsächlich als Ausweis einer polis-Mentalität werten darf (vgl. oben Anm. 54), oder ob man in Komana nicht vielmehr bemüht war zu kompensieren, was man als Status- und Identitäts-Verlust empfinden mochte - freilich mit den Mitteln, die der neue Status als polis bot. Dies mochte auch ein Grund dafür sein, daß man sich, was die Auswahl der Münzbilder anbelangt, völlig auf Ma und damit nicht nur auf die Hauptgottheit der polis, sondern auch auf das Zentrum des alten, seit Pompeius nominell autonomen Tempelstaates konzentrierte und anfangs auch ,pseudoautonome' Münzen prägte (vgl. dazu unten S. 200 und Anm. 192 bzw. Anm. 101). 


\section{MÜNZSYSTEM, PRÄGEVOLUMEN UND VERBREITUNG DER MÜNZEN}

Die ,innerpontischen' Städte prägten ausschließlich Bronze. Daß dies eine nicht völlig selbstverständliche Feststellung ist, zeigt in der weiteren Region der Fall von Amisos: Diese Stadt prägte in der Zeit des Hadrian nämlich auch Silber. ${ }^{71}$ Mit größter Wahrscheinlichkeit fügten sich die Prägungen aller ,innerpontischen' Städte in das im Osten des römischen Reiches weit verbreitete Nominalsystem aus Assaria, Diassaria und Tetrassaria ein..$^{72}$ Durchmesser und Gewicht der Münzen eines Nominals unterschieden sich dabei, wie es auch in anderen
Regionen oft der Fall war, von Stadt zu Stadt. ${ }^{73}$ Einige Städte prägten zudem auch kleinere Nominale. ${ }^{74}$ Dem allgemeinen Trend der Münzverschlechterung entsprechend, wurden Gewicht und Durchmesser eines jeden Nominals im Lauf der Zeit reduziert. ${ }^{75}$ In Amaseia und Sebastopolis ist möglicherweise jedoch eine gegenläufige Entwicklung zu beobachten: jedenfalls wurden hier in der Zeit des Severus Alexander bzw. in der Zeit des Gallienus verglichen mit der Zeit des Septimius Severus wieder schwerere, in Amaseia auch größere Münzen geprägt. ${ }^{76}$

Die Städte prägten allesamt in nur geringem Umfang. Das Prägevolumen unterschied sich von Stadt zu Stadt jedoch erheblich. So entsprach das Vo-

71) Vgl. Nordbø 1988: bes. 176, der die Silberprägung von Amisos mit der Umprägung älterer Cistophoren in Asia, der Einführung der Cistophoren-Prägung in Bithynia und dem Aufkommen von Silberprägungen in einigen kilikischen Städten in Zusammenhang stehend sieht und mit dem besonderen Interesse Hadrians für griechische Geschichte und Kultur erklärt.

72) Vgl. Dalaison 2008: 33 (Amaseia); Amandry, Rémy 1999: 56 (Komana); Dalaison 2010: 61 (Pompeiopolis); Dalaison, Delrieux 2014: 184 (Neoklaudiopolis); Dalaison 2007: 224 (Nikopolis); Amandry, Rémy 1998: 47 (Sebastopolis); Dalaison, Rémy, Amandry 2009: 43 (Zela). Für Neokaisareia vgl. Çizmeli 2006: 148-153 mit 145-147 und Dalaison 2008: 35-38. Sicherlich gilt dies auch für Sebasteia; aufgrund der geringen Zahl erhaltener Münzen ist hier aber keine konkrete Identifizierung von Nominalen möglich. - Dieses Nominalsystem war mit dem der reichsrömischen Prägung bestens kompatibel: ein Assarion entsprach einem As, ein Diassarion einem Dupondius, ein Tetrassarion einem Sestertius, 16 Assaria also einem Denarius. Freilich ist für die ,innerpontischen 'Städte in keinem einzigen Fall die tatsächliche Benennung eines Nominals überliefert, die Bestimmung der Nominale allgemein, wie auch die Bestimmung des Nominals einer einzelnen Münze ist aus moderner Sicht nicht einfach; vgl. dazu die Abschnitte zur Metrologie in den oben in Anm. 3 genannten Corpora; Klose 1986; Ziegler 1992; RPC I: 30-37, 338-340; RPC II: 20.

73) Zwei Beispiele seien hier gegeben: Im Jahr 112/3 betrug der Durchmesser der Münzen des kleinsten Nominals, also mit größter Wahrscheinlichkeit des Assarion, in Amaseia zwischen 19 und 23mm bei einem durchschnittlichen Gewicht der Münzen von 6,29g, in Nikopolis aber lediglich zwischen 17,5 und 19,5mm bei durchschnittlich 4,20g. Im Jahr 205/6 betrug der Durchmesser des größten Nominals, also mit größter Wahrscheinlichkeit des Tetrassarion, in Amaseia zwischen 27 und $35 \mathrm{~mm}$ bei einem durchschnittlichen Gewicht der Münzen von 15,54g, in Komana zwischen 27 und 30mm bei durchschnittlich 14,74g, in Zela zwischen 25 und 31,5mm bei durchschnittlich 14,62g und in Sebastopolis zwischen 26 bis 28mm bei durchschnittlich 12,68g. Weitere Vergleiche bei Dalaison 2008: 3538. - Da es sich bei Bronzemünzen um Kreditgeld handelte, ergaben sich daraus keine Probleme hinsichtlich des Wertes, möglicherweise aber durchaus hinsichtlich der Erkennbarkeit der Nominale und damit der Akzeptanz in anderen als der jeweils emittierenden Stadt. Ein individueller Zug der Prägungen der ,innerpontischen' Städte ist auch in der Auswahl der Nominale zu erkennen: Nicht jede Stadt emittierte tatsächlich sowohl Assaria als auch Diassaria als auch Tetrassaria, und selbst wenn eine Stadt dies über die Zeiten betrachtet tat, so doch nicht notwendigerweise bei jeder ihrer Emissionen.

74) Amaseia (Dalaison 2008: 33), Neoklaudiopolis (Dalaison, Delrieux 2014: 184), Zela (Dalaison, Rémy, Amandry 2009: 43) und wohl auch Neokaisareia (Çizmeli 2006: 152). Diese kleinen Nominale sind im Fall von Amaseia und Zela nur durch jeweils ein einziges und im Fall von Neokaisareia lediglich durch zwei Exemplare belegt - bei Neoklaudiopolis sind es immerhin fünf -, so daß nicht auszuschließen ist, daß auch weitere Städt Hemiassaria o.ä. geprägt haben, diese sich aber wegen der sich auf kleine und leichte Münzen ungleich härter auswirkenden Bedingungen nicht erhalten haben.

75) Beispielsweise hatten Münzen des größten Nominals in Amaseia im Jahr 162/3 n.Chr. einen Durchmesser zwischen 31 und $37 \mathrm{~mm}$ bei einem durchschnittlichen Gewicht von 22,09g (berechnet aus 105 Exemplaren), im Jahr 187/8 n.Chr. einen Durchmesser zwischen 31 und 36mm bei durchschnittlich 21,58g (72 Exemplare), im Jahr 205/6 einen Durchmesser zwischen 27 und 35mm bei durchschnittlich lediglich 15,54g (475 Exemplare). - Diese Aussage beschreibt tatsächlich nur die vorherrschende Tendenz. Im Detail ist nämlich festzustellen, daß die Entwicklung nicht immer kontinuierlich gewesen ist, und auch, daß sie sich von Nominal zu Nominal in ein und derselben Stadt unterscheiden konnte: Während beispielsweise im Fall von Amaseia die im Jahr 187/8 n.Chr. geprägten Münzen des größten Nominals, wie gesehen, verglichen mit den 162/3 geprägten etwas kleiner und leichter waren, waren die im Jahr 186/7 n.Chr. geprägten des zweitgrößten Nominals verglichen mit den 162/3 geprägten etwas größer und schwerer $(26-30 \mathrm{~mm} ; 12,87 \mathrm{~g} ; 43$ Exemplare bzw. 25-30mm; 12,06g; 21 Exemplare). Zu bedenken ist außerdem, daß in vielen Fällen die Zahl der Münzen, was deren statistische Auswertbarkeit anbelangt, bedenklich klein ist. Wollte man beispielsweise das durchschnittliche Gewicht der Münzen des größten in Zela in den Jahren 113/4 und 205/6 n.Chr. geprägten Nominals vergleichen, so stünden die Werte von 133 Münzen des Jahres 205/6 denjenigen von lediglich drei Exemplaren des Jahres 113/4 gegenüber, die zudem erheblich streuen (13,10 bzw. 16,79 bzw. 22,56g). Zu Amaseia vgl. Dalaison 2008: 32, 34f., zu Zela Dalaison, Rémy, Amandry 2009: 43. Für Neokaisareia existiert trotz der großen Zahl bekannter Münzen keine statistische Auswertung der Gewichte; Çizmeli 2006: 150f. bietet lediglich ganz grobe Angaben. Vgl. außerdem Amandry, Rémy 1999: 56 (Komana); Dalaison 2010: 61 (Pompeiopolis); Dalaison, Delrieux 2014: 184 (Neoklaudiopolis); Dalaison 2007: 224 (Nikopolis); Amandry, Rémy 1998: 47 (Sebastopolis).

76) In Sebastopolis ist der Gewichtszuwachs um ca. 5\% vergleichsweise gering, in Amaseia mit bis zu ca. $72 \%$ - vergleicht man die Prägungen der Jahre 206/7 und 231/2 - enorm. In beiden Fällen ist zu überlegen, ob es sich tatsächlich um eine Erholung des bislang größten Nominals, also höchst wahrscheinlich des Tetrassarion, handelt oder aber um die Einführung eines neuen Nominals mit noch höherem Wert - beispielsweise einem halben Denarius entsprechend. Vgl. Amandry, Rémy 1998: 47; Dalaison 2008: $32,35$. 
lumen aller Emissionen von Amaseia zusammengenommen ungefähr 745.000 Denaren, das sämtlicher Emissionen von Pompeiopolis jedoch lediglich ca. 40.000 Denaren. ${ }^{77}$ In der Regel hatten die Emissionen den größten Umfang in der Zeit des Septimius Severus, ${ }^{78}$ in Pompeiopolis - wie bereits erwähnt jedoch in der Zeit des M. Aurel. ${ }^{79}$

Offenbar prägten die Städte grundsätzlich nur für den lokalen Eigenbedarf, faktisch bis zu einem gewissen Grad freilich wohl auch für den regionalen
Bedarf. ${ }^{80}$ Dafür spricht neben dem geringen Volumen der Prägungen insbesondere die Tatsache, daß der Fundort der Münzen der, innerpontischen“ Städte in den allerdings seltenen Fällen, in denen er bekannt ist, in aller Regel in der ,innerpontischen“ Region selbst liegt ${ }^{81}$ und in Fällen, in denen wenn auch nicht der Fundort, so doch der Ort bekannt ist, an dem die Münze erworben wurde, dieser sich zumindest in der weiteren Region befindet. ${ }^{82}$ Angesichts der Erwerbungsusancen regionaler Museen

77) Dalaison 2008: 39-41 (Amaseia); Dalaison 2010: 61-63 (Pompeiopolis); Grundlage ihrer Hochrechnung ist die von Giles F. Carter vorgeschlagene und u.a. von François de Callatä̈ verfeinerte Methode (Carter 1983; Callataÿ, Depeyrot, Villaronga 1993: 8f.). Die Hochrechnung für Pompeiopolis ist, grob formuliert, im Wesentlichen wegen der viel geringeren Zahl erhaltener Münzen, etwas genauer formuliert, wegen des für die meisten Serien ungünstigen Verhältnisses ,Zahl der erhaltenen Münzen : Zahl der Vorderseitenstempel $^{`}$ - deutlich unzuverlässiger als diejenige für Amaseia. Zur Problematik, die derartigen Hochrechnungen innewohnt, vgl. Esty 1984; 1986; 2011; Ireland 2005: 254f.; Callataÿ 2006 (mehrere Beiträge); Dalaison 2008: 41; 2010, 62; Çizmeli 2006: 144 Anm. 252; Bricault, Delrieux 2014: 67-69 und auch Carter 1983; generell zu Fragen der Quantifizierung Callataÿ (Hg.) 2011. Derselben Berechnungsmethode zufolge lag das Prägevolumen von Neokaisareia bei 629.375 Denaren (vgl. die Berechnung in Anhang 1), das von Sebastopolis bei 167.500 Denaren (Amandry, Rémy 1998: 47f.), das von Zela bei 158.750 (Dalaison, Rémy, Amandry 2009: 45f.), das von Komana bei 133.750 (Amandry, Rémy 1999: 56-58), das von Neoklaudiopolis bei 60.625 (Dalaison, Delrieux 2014: 184-186) und das von Nikopolis bei ca. 50.000 (vgl. Dalaison 2007: 225-227, bes. 227, wo das Volumen mit 81.250 Denaren angegeben ist; die Diskrepanz beruht darauf, daß Dalaison das Volumen der Prägungen der Münzsstätte insgesamt festzustellen sucht, nicht nur das der polis und daher die Prägungen des Aristoboulos und die des koinon von Kleinarmenien einbezieht). Für Sebasteia ist aufgrund der geringen Zahl an erhalten Münzen keine Hochrechnung möglich. - Um die Dimension dieser Zahlen greifbar zu machen, hat es sich eingebürgert, diese mit dem jährlichen Sold eines Legionärs von 600 Denaren (seit dem Jahr 197 n.Chr.; vgl. dazu Jahn 1984: 66-68 mit Speidel 1992: 88 Anm. 8, 98-100, anders jedoch Alston 1994) in Beziehung zu setzen: So hätte das Gesamtvolumen der Prägungen von Amaseia dem Jahressold von 1241 Legionären, das von Pompeiopolis dem Jahressold von 66 Legionären entsprochen. - In der weiteren Region bewegten sich die Volumina der Prägungen im Fall von Trapezous (358.750 Denare; vgl. Anhang 3), Germanikopolis (355.000 Denare; Bricault, Delrieux 2014: 67-69 [die in der Tabelle auf S. 69 genannte abweichende Zahl von 335.000 Denaren ist sicherlich ein Versehen]), Kerasous (97.500; vgl. Anhang 2) und Abonouteichos (75.300 Denare; Dalaison, Delrieux, Ferriès 2015: 149) im selben Rahmen; angesichts der in Rec. und RPC verzeichneten Münzen ist - bei aller gebotenen Vorsicht - zu vermuten, daß die Volumina der Prägungen von Amastris und insbesondere jene von Amisos und Colonia Iulia Felix aber deutlich umfangreicher gewesen sind.

78) Dalaison 2008: 41 f., 183 (Amaseia; auch mit Lit. dazu, daß dies in ganz Kleinasien in aller Regel so gewesen ist, und mit Lit., welche die Möglichkeit der Verfälschung dieses Befundes durch die für die Prägungen des 3. Jh. im Vergleich zu denen des 1 . und 2. Jh. günstigeren Erhaltungsbedingungen diskutiert); Dalaison, Rémy, Amandry 2009, 46 (Zela). Zu Komana vgl. Amandry, Rémy 1999: 56-58, zu Neokaisareia Anhang 1 und Çizmeli 2006: 142-144, zu Sebastopolis Amandry, Rémy 1998: 47f. Zu Neoklaudiopolis vgl. Dalaison, Delrieux 2014: 184f.: hier war das Volumen der Prägung in der Zeit des Antoninus Pius jedoch annähernd so umfangreich wie in der Zeit des Septimius Severus. Nikopolis und Sebasteia prägten in der Zeit des Septimius Severus bereits nicht mehr.

79) Dalaison 2010: 63f. Zu einer möglichen Ursache vgl. oben S. 172 - Was die weitere Region anbelangt, sind bislang nur Aussagen zu Kerasous, Trapezous und Germanikopolis möglich: In Kerasous war die Prägung in der Zeit des Elagabal am umfangreichsten, in Trapezous in der Zeit des Severus Alexander - freilich dicht gefolgt von den Prägungen in der Zeit des Septimius Severus (vgl. Anhang 2 und 3), in Germanikopolis selbstredend in der Zeit des Septimius Severus.

80) Amandry, Rémy 1998: 50f.; Amandry, Rémy 1999: 62f.; Çizmeli 2006: 154-170; Dalaison 2007: 233; 2008: 181-188; Dalaison, Rémy, Amandry 2009: 49; Dalaison 2010: 71f.

81) Dies gilt für eine von Komana und elf von Neokaisareia geprägte Münzen, die bei Rettungsgrabungen in der Nekropole von Niksar gefunden wurden (vgl. Rémy, Özcan 1991 Nr. 5 bzw. Nr. 6, 8-14, 16-18; dazu Çizmeli 2006: 154f.), für eine bei den Grabungen in der spätantiken oder frühbyzantinischen Kirche in Sulusaray gefundene von Neokaisareia geprägte Münze (vgl. Rémy 1990: 85; dazu Çizmeli 2006: 155), für eine von Amaseia und zwei von Neokaisareia geprägte in Özükavak (d.h. auf dem Territorium von Sebastopolis) gefundene Münzen (vgl. Rémy 1990: 86), für eine bei den Grabungen in Taşköprü gefundene von Pompeiopolis geprägte Münze (vgl. Dalaison, Delrieux 2011: 141f.; dazu Dalaison 2010: 71), für insgesamt 102 von Komana, Sebastopolis, Zela, Neokaisareia und Amaseia geprägte, in Tokat, Almus, Sulusaray, Zile, Turhal, Erbaa und Niksar gefundene Münzen im Museumsbestand von Tokat (Amandry, Rémy, Özcan 1994; dazu Amandry, Rémy 1998: 50f. = Amandry, Rémy 1999: 62, aktualisiert durch Dalaison 2008: 181f., samt genauer Aufschlüsselung der Zahl von Münzen nach Prägestätten und Fundorten; Çizmeli 2006: 155f.), für eine mit großer Wahrscheinlichkeit von Amaseia geprägte Münze, die 2014 im Zuge des Nerik-Projektes bei den Grabungen 7 km nördlich von Vezirköprü in Oymaağaç gefunden wurde (Objektnummer 7584:004:003; vgl. dazu Hnila 2015; Sauer 2015b) und schließlich für einige noch nicht en détail publizierte Münzen von Amaseia, die 2000 bzw. 2006 bei Rettungsgrabungen in einer Nekropole in Amasya (Kurşunlu Mahallesi) bzw. im Heiligtum des Zeus Stratios bei Yassıçal zum Vorschein kamen (vgl. Doğanbaş 2015; Özdemir 2015).

82) So wurden elf von Zela und jeweils eine von Amaseia, Komana und Sebastopolis geprägte Münze, die zu einem Hortfund gehören - es ist unklar, ob der Hort insgesamt nicht umfangreicher gewesen ist - in Zile erworben (vgl. Arslan 1995; dazu Dalaison, Rémy, Amandry 2009: 49; Dalaison 2008: 181; Amandry, Rémy 1998: 51; Amandry, Rémy 1999: 63). So wurde eine von Nikopolis geprägte Münze in Erbaa (Dalaison 2007: 233), eine von Neoklaudiopolis geprägte in Vezirköprü (Dalaison, Delrieux 2014 Nr. 23a; persönliche Auskunft des Besitzers Bünyamin Kıvrak) und zwei von Amaseia geprägte in Samsun (Dalaison 2008: 181), erworben. 
kann man darüber hinaus davon ausgehen, daß grundsätzlich auch die Münzen, für die kein Fundoder Erwerbungsort notiert ist, im Zuständigkeitsbereich des jeweiligen Museums und also ebenfalls in der Region gefunden wurden. ${ }^{83}$ In dieselbe Richtung weist die Tatsache, daß - gleichsam umgekehrt -, in der ,innerpontischen ' Region nur wenige Münzen gefunden wurden, die von Städten außerhalb der Region geprägt wurden. ${ }^{84}$ Und schließlich ist die Zahl der Münzen ,innerpontischer' Städte, deren Fundort tatsächlich in weiter entfernten Regionen liegt, ausgesprochen gering, ${ }^{85}$ sieht man von den Münzen ab, die in Doura Europos zum Vorschein gekommenen sind. Deren enorme Zahl - es handelt sich um 1053 von Amaseia, 172 von Neokaisareia, 31 von Zela, 29 von Komana und 2 von Sebastopolis geprägte Münzen $-{ }^{86}$ dokumentiert, wie Julie Dalaison plausibel machen konnte, mit einiger Wahrscheinlichkeit jedoch einen Sonderfall der Münzverbreitung und ist mit größter Wahrscheinlichkeit nicht mit der übli- chen, etwa auf Handel, Reisende, oder auch auf Truppenverlegungen zurückzuführenden Münzzirkulation in Zusammenhang zu bringen: Zumindest der größte Teil dieser Münzen, insbesondere der von Amaseia geprägten, dürfte - wie bereits erwähnt auf Anordnung römischer Autoritäten nach Doura Europos gebracht worden sein, um dort einer Münzknappheit abzuhelfen. ${ }^{87}$ Diese dürfte vor dem Hintergrund der Reorganisation der Grenzregion zu den Parthern nach dem Vorstoß des Septimius Severus nach Mesopotamien in den Jahren 197 und $198 \mathrm{zu}$ sehen sein.

\section{SCHRIFT UND SPRACHE DER LEGENDEN, BILDERSPRACHE}

Schrift und Sprache der Legenden war grundsätzlich Griechisch ${ }^{88}$ - die einzig ,echte' Ausnahme stellen Münzen von Neokaisareia mit der Rückseitenlegende GEN AVGG NOS dar. ${ }^{89}$ Komana, Neo-

83) $\mathrm{Zu}$ denken ist neben dem erwähnten Museum von Tokat an diejenigen von Amasya und Kastamonu (vgl. Ireland 2000, bes. 6; dazu Dalaison 2008: 8, 182), in der weiteren Region an diejenigen von Amasra, Sinop, Samsun, Giresun, Trabzon und Çankırı (vgl. Ireland 1996: 115; Casey 2010; dazu Çizmeli 2006: 156; Dalaison 2008: 8, 182).

84) Vgl. Dalaison 2008: 181f. und besonders Çizmeli 2006: 155-157, 167f.; Amandry, Rémy, Özcan 1994; Ireland 2000.

85) Çizmeli 2006: 158-170; Dalaison 2008: 185f. In Antiocheia am Orontes wurde eine von Sebastopolis geprägte Münze gefunden (Amandry, Rémy 1998: 51; Amandry, Rémy 1999: 63), in Ankara (Çankırıkapı) eine von Neokaisareia geprägte (Çizmeli $2006: 163-$ 165; Dalaison 2008: 186), in Chersonesos auf der Krim zwei von Neokaisareia und eine von Sebastopolis geprägte (Gilevitsch 1968; Çizmeli 2006: 165f.), in Erenköy (am Euphrat) und Sadak (ant. Satala) jeweils eine von Amaseia geprägte (Çizmeli 2006: 156f.; Dalaison 2008: 186), in Augst (Schweiz) das von Pompeiopolis geprägte Medaillon (Dalaison 2010: 71; zur genauen Fundlage vgl. Cahn 1968: 62). Wohl aus kilikischem Gebiet stammt eine Münze von Zela, die sich heute im Museum von Adana befinden (Cox 1941; Çizmeli 2006: 166f.).

86) Von einer Ausnahme abgesehen allesamt in den Jahren 205/6 und 206/7 emittiert, teils in Horten, teils einzeln gefunden. Vgl. Dalaison 2008: 185-188; Çizmeli 2006: 158-163; Dalaison, Rémy, Amandry 2009: 49; Amandry, Rémy 1999: 63; Amandry, Rémy 1998: 51. Zu den Münzfunden von Doura Europos insgesamt: Bellinger 1939; 1943; 1949.

87) Dalaison 2008: 185-188, bes. 187; vgl. auch oben S. 172f. Zu betonen ist freilich - worauf Dalaison mit Nachdruck hinweist -, daß nicht zuletzt mangels vergleichbarer archäologischer Untersuchungen an anderen Orten insbesondere die Wertung dieses Befundes als Sonderfall nicht als vollkommen gesichert gelten kann.

88) Abgesehen von den lateinischen Legenden der Münzen der Colonia Iulia Felix gilt dies auch für die Münzlegenden der Städte der weiteren Region.

89) Çizmeli 2006 Nr. 380, 392, 402-403. Freilich kombiniert mit der griechischen Angabe ЄТ РПH für das Jahr 188 der städtischen Ära (251/2 n.Chr.). Die Vorderseiten zeigen - mit griechischer Legende - Trebonianus Gallus (Nr. 380, 392) bzw. Trebonianus Gallus und Volusianus (Nr. 402f.), auf die sich der Plural in der Bezeichnung genius Augustorum nostrorum bezieht. (GEN als Sigular aufzulösen, legt das Rückseitenbild nahe, das einen Genius zeigt.) Einleuchtend ist die Erklärung, die Çizmeli 2006: 130 für diesen exzeptionellen Gebrauch der lateinischen Sprache gibt: „on aurait préféré utiliser le latin parce que le Genius est un concept romain.“ Offenkundig ist freilich, daß man in diesem Jahr überhaupt Rom in den Vordergrund stellte: Von den insgesamt 32 bekannten Rückseitenstempeln dieser Emission zeigen 25 Roma Nikephoros, vier den Genius Augustorum, und lediglich drei andere Motive (Tyche der Stadt, Demeter). Die Legenden der Roma-Nikephoros-Münzen verzichten ebenfalls in exzeptioneller Weise auf die Nennung der emittierenden Stadt bzw. Bürgerschaft (vgl. unten Anm. 140) und schreiben abgesehen vom Jahr der Prägung lediglich, das Münzbild erklärend, PWMH. Die Koinzidenz , lateinische Legende auf einem Teil - Roma Nikephoros auf einem anderen Teil der Münzen - beides unter Verzicht auf die Nennung des Stadtnamens“ wurde bereits 1917 von Friedrich Imhoof-Blumer festgestellt. Daß man Rom derart in den Vordergrund rückte, dürfte aber eher vor dem Hintergrund der äußeren Bedrohungen dieser Zeit zu sehen sein (vgl. oben Anm. 24) und weniger damit zu tun haben ,dass zur Zeit der Prägung das römische Element in den Gemeindebehörden das überwiegende war“", wie Imhoof-Blumer 1917: 27f. zu überlegen gab. - Außerdem finden sich auf einem Teil der Münzen von Neokaisareia aus der Emission des Jahres 100/1 die Buchstaben SC (senatus consulto) gleichsam als Rückseitenbild, umgeben von der zweizeiligen Legende

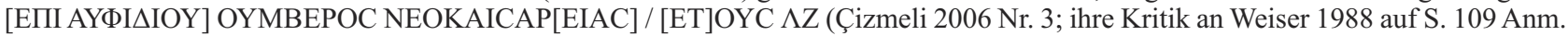
123 beruht auf einem grundlegenden Mißverständnis). Vorbild dieser Münzgestaltung dürften unter Titus und Nerva geprägte Restitutions-Sesterzen gewesen sein (Weiser 1988: 12). Auch wenn diese Emission, anders als Weiser meinte, nicht die erste Emission, sondern lediglich die erste nicht-,pseudoautonome' Emission der Stadt gewesen ist, so ist seine Interpretation doch bestechend: Die Bürger von Neokaisareia wollten mit dieser engen Anlehnung an ein römisches Vorbild und mit der ihr innewohnenden Bezugnahme auf den römischen Senat gerade in ihrer, ersten` Emission ihre Verbundenheit mit Rom hervorheben. 
kaisareia, Sebastopolis und Zela transkribierten in der Zeit des Septimius Severus jedoch die Titel Augustus bzw. Augusta lediglich, anstatt sie mit Sebastos bzw. Sebaste zu übersetzen..$^{90}$

Auffallenderweise wandelte sich die Form bestimmter Buchstaben, insbesondere des Epsilon und des Omega, und die Schreibweise bestimmter Wörter $^{91}$ in den innerpontischen Städten nicht in gleicher Weise:

- Beim Epsilon geht die Entwicklung von der eckigen zur lunaren Form (vgl. Tabelle 3) ${ }^{92}$ Tendenziell ist festzustellen, daß die eckige Form in hadrianischer Zeit aus der Mode gekommen ist. ${ }^{93}$ In Amaseia freilich war die lunare Form bereits seit vespasianischer, in Nikopolis und Sebasteia seit traianischer Zeit üblich. Gleichsam umgekehrt benutzte man in Pompeiopolis noch unter M. Aurel, in Zela noch unter Septimius Severus neben der lunaren Form auch noch die eckige. ${ }^{94}$ - Beim Omega ist in vortraianische Zeit und dann wieder in der Zeit nach Septimius Severus die traditionelle Form $\Omega$ üblich (vgl. Tabelle 4). ${ }^{95}$ Ausnahmen stellen Komana und Neokaisareia dar: In Komana wurde in der Zeit des Caligula meist die kursive Form $\omega$ verwendet; in Neokaisareia wurde in der Zeit des Trebonianus Gallus nochmals auf die kursive Form zurückgegriffen, nun aber eckig, wie ein $\mathrm{W}$ geschrieben. ${ }^{96} \mathrm{In}$ der Zeit zwischen Traian und Septimius Severus variiert der Gebrauch der beiden Formen von Stadt zu Stadt und von Zeit zu Zeit. So verwendet Sebasteia $\Omega$ und auch in Neoklaudiopolis bleibt $\Omega$ vorherrschend, wobei unter Antoninus Pius und insbesondere unter Commodus aber auch $\omega$ vorkommt. In Pompeiopolis wird zunächst $\Omega$ verwendet, dann beide Formen, in Komana und Zela zunächst $\Omega$, dann grundsätzlich $\omega$. In Nikopolis wurde, von einer Ausnahme unter Traian abgesehen, $\omega$ verwendet. Auch in Sebastopolis wurde unter Traian $\omega$ verwendet, aber bereits unter Septimius Severus wieder $\Omega$. In Amaseia war unter Traian und Hadrian $\omega$ üblich, unter Antoninus Pius treten beide Formen auf, bereits ab M. Aurel dann wieder vornehmlich $\Omega$. In Neokaisareia schließlich wurden in dieser Zeit beide Formen verwendet, nur unter Commodus ist ausschließlich $\omega$ nachgewiesen.

- Das lateinische v im Namen Severus wurde bezogen auf Septimius Severus - in Amaseia, Neokaisareia, Sebastopolis und, von einem einzigen Stempel abgesehen, auch in Zela mit ov wiedergegeben, in Neoklaudiopolis und Pompeiopolis jedoch lediglich mit $v$. Auf den Münzen von Komana findet sich neben der Schreibweise ov die zusätzliche Variante vov. Bezogen auf Severus Alexander blieb man in Neokaisareia bei der Schreibweise ov, in Amaseia finden sich dagegen sowohl ov als auch $v$. - Der Name bzw. Titel ,Caesar ${ }^{6}$ wurde grundsätzlich KAICAP transkribiert. Bezieht er sich freilich auf Geta, schreiben Amaseia, Neoklaudiopolis und Sebastopolis - anders als Komana, Neokaisareia und Zela - nicht KAICAP, sondern KECAP. ${ }^{97}$

90) Vgl. Amandry, Rémy 1999: 69 (Komana); Çizmeli 2006: 114 (Neokaisareia); Amandry, Rémy 1998: 56 (Sebastopolis); Dalaison, Rémy, Amandry 2009: 51 (Zela). In der weiteren Region ist dieses Phänomen bei Abonouteichos, Amastris, Germanikopolis und Trapezous zu beobachten. Hier ist es aber nicht nur für die Zeit des Septimius Severus (Abonouteichos: Dalaison, Delrieux, Ferriès 2015 Nr. 33; Germanikopolis: Bricault, Delrieux 2014: GG/1, 4-8, 30[34], 31[35], 37[48], 38-40, 42[54-55], 43-47, 64, 69, 73-76, 78, 85[105], 86, 87[107], 96-98, 99[126]; Amastris: Rec. 177* Nr. 137f.; 178* Nr. 143-148; 179* Nr. 150, 152-155; Trapezous: Wojan 2006 Nr. 51f.) nachzuweisen, sondern auch für die des Elagabal (Trapezous: Wojan 2006 Nr. 63), des Severus Alexander (Abonouteichos: Dalaison, Delrieux, Ferriès 2015 Nr. 34, 36; Trapezous: Wojan 2006 Nr. 75, 89, 104, 106-108, 111-114), des Maximinus Thrax (Amastris: Rec. 180* Nr. 159-161) und des Gordian (Abonouteichos: Dalaison, Delrieux, Ferriès 2015 Nr. 39; Amastris: Rec. 181* Nr. 162). Amastris, Germanikopolis und Trapezous waren dabei in der Zeit des Septimius Severus wenig konsequent: Neben der Transkription kommt auch die Übersetzung vor (Amastris: Rec. 177* Nr. 136, 139; Germanikopolis: Bricault, Delrieux 2014: GG/9-18, 41, 42[53], 48, 7172, 77, 90[114], 91-95; Trapezous: Wojan 2006 Nr. 33, 36f., 47-49).

91) Vgl. auch Çizmeli 2006: 113, 130; Dalaison 2008: 148, 155 f.

92) Die Aussagen, die hier zu Neokaisareia, Sebastopolis und Amaseia getroffen werden, stehen freilich unter einem gewissen Vorbehalt, da Çizmeli 2006, Amandry, Rémy 1998 und auch Dalaison 2008 die Buchstabenform nicht explizit ausweisen, man also auf die Abbildungen angewiesen ist; vgl. aber Dalaison 2008: 148, 155.

93) Aus hadrianischer Zeit selbst sind jedoch nur Münzen von Neoklaudiopolis und Amaseia bekannt. Auf den entsprechenden Münzen von Neoklaudiopolis hat das Epsilon eckige, auf denen von Amaseia lunare Form.

94) Zudem mischen die Stempel R15 und D26 von Komana nach Ausweis von Amandry, Rémy 1999 beide Formen; die beigegebenen Photos lassen dies allerdings nicht erkennen.

95) Hier stehen die Aussagen zu Sebastopolis unter einem gewissen Vorbehalt, da Amandry, Rémy 1998 die Buchstabenform nicht explizit ausweisen.

96) Erwähnt sei, daß die kursive Form auch in Prägungen anderer Städte hin und wieder eckig geschrieben wurde.

97) Ihren Namen ,Neocaesarea' schrieb Neokaisareia seit der Zeit des Septimius Severus sowohl mit $\alpha 1$ als auch mit $\varepsilon$. Sieht man von der Zeit des Severus Alexander ab, ist die Version $\alpha$ häufiger. Für die Jahren 204/5, 226/7, 234/5, 255/6 und 262/3 sind beide Versionen simultan belegt. 
Tabelle 3 : Formen des Epsilon.

(1) Die Datierung in die Zeit des Tiberius ist nicht ganz sicher; Alternativen: Augustus oder Caligula (vgl. Dalaison 2008: 24).

- Der Buchstabe Epsilon kommt in den Legenden nicht vor.

* mit einer Ausnahme.

(*) eventuell mit Ausnahmen.

\begin{tabular}{|c|c|c|c|c|c|c|c|c|c|}
\hline & Komana & Amaseia & Neokaisareia & $\begin{array}{l}\text { Neoklau- } \\
\text { diopolis }\end{array}$ & Nikopolis & $\begin{array}{l}\text { Sebasto- } \\
\text { polis }\end{array}$ & Zela & Sebasteia & $\begin{array}{l}\text { Pompeio- } \\
\text { polis }\end{array}$ \\
\hline Tiberius & - & $\mathrm{E}^{(1)}$ & & & & & & & \\
\hline Caligula & $\mathrm{E}$ & & & & & & & & \\
\hline Claudius & - & & & & & & & & \\
\hline Nero & - & & & & & & & & \\
\hline Vespasian & & $\epsilon$ & & & & & & & \\
\hline Domitian & & $\epsilon$ & $\mathrm{E}$ & & & & & & \\
\hline Nerva & $\mathrm{E}$ & & & & & & & & \\
\hline Traian & $\mathrm{E}$ & $\epsilon$ & $\mathrm{E}$ & $\mathrm{E}$ & $\epsilon^{*}$ & $\mathrm{E}$ & $\mathrm{E}$ & $\epsilon$ & \\
\hline Hadrian & & $\epsilon$ & & $\mathrm{E}$ & & & & & \\
\hline Antoninus Pius & & $\epsilon$ & & $\epsilon$ & & & & & $\epsilon$ \\
\hline M. Aurel, L. Verus & & $\epsilon$ & $\epsilon$ & & $\epsilon$ & & & $\epsilon$ & E und $\epsilon$ \\
\hline Commodus & & $\epsilon$ & $\epsilon$ & $\epsilon$ & & & & & \\
\hline Septimius Severus & $\epsilon^{(*)}$ & $\epsilon$ & $\epsilon$ & $\epsilon$ & & $\epsilon$ & E und $\epsilon$ & & $\epsilon$ \\
\hline Severus Alexander & & $\epsilon$ & $\epsilon$ & & & & & & \\
\hline Gordian III. & & & $\epsilon$ & & & & & & \\
\hline Philippus Arabs & & & $\epsilon$ & & & & & & \\
\hline $\begin{array}{l}\text { Trebonianus Gallus, } \\
\text { Volusianus }\end{array}$ & & & $\epsilon$ & & & & & & \\
\hline Valerian, Gallienus & & & $\epsilon$ & & & & & & \\
\hline Gallienus & & & $\epsilon$ & & & $\epsilon$ & & & \\
\hline
\end{tabular}

- Das i im Namen Antoninus wurde sowohl mit $\varepsilon 1$ als auch lediglich mit 1 transkribiert (vgl. Tabelle 5). Grob gesprochen geht dabei die Tendenz von der Version el zur Version 1. Bezogen auf Antoninus Pius und M. Aurel finden sich beide Versionen: für Antoninus Pius $\varepsilon 1$ in Neoklaudiopolis, $\mathrm{l}$ in Pompeiopolis, beide Versionen in Amaseia, für M. Aurel $\varepsilon \iota$ in Nikopolis und Pompeiopolis, 1 in Amaseia, beide Versionen in Neokaisareia. Bezogen auf Commodus und Caracalla findet sich, von je einem Stempel in Amaseia abgesehen, ausschließlich die Version 1.

- Bemerkenswert ist, daß das i im Namen Faustina d.J., der Frau des M. Aurel - sie spielt lediglich in der Münzprägung von Amaseia und Pompeiopolis eine Rolle - in Amaseia mit $\varepsilon 1$ wiedergegeben wurde, obwohl man zeitgleich konsequent ANT $\Omega$ NINOC schrieb. In Pompeiopolis schrieb man sowohl ФAYCTEINA als auch ФAYCTINA, aber nur ANTSNEINOC, wobei sich der Name des M. Aurel freilich nur auf einem einzigen Stempel findet. Im Fall der Faustina d. Ä., der Frau des Antoninus Pius - sie figuriert lediglich in der Münzprägung von Pompeiopolis -, wird das i hingegen als Eta transkribiert. Dieselbe Tendenz von $\varepsilon 1 \mathrm{zu} \iota$ ist bei der Schreibung des Namens der Prägeherren zu verzeichnen (vgl. Tabelle 6). Hier fällt freilich folgendes auf: Neoklaudiopolis bleibt konsequent bei der ersten Variante, Sebastopolis schreibt bereits in traianischer Zeit CEBACTOПO $\Lambda$ IT $\omega \mathrm{N}$, Neokaisareia kehrt in der Zeit des Trebonianus Gallus bzw. des Volusianus bei einem Teil der Stempel zur Schreibweise NEEOKAICAP€IAC zurück. 
Tabelle 4 : Formen des Omega.

(1) Die Datierung in die Zeit des Tiberius ist nicht ganz sicher; Alternativen: Augustus oder Caligula (vgl. Dalaison 2008: 24).

- Der Buchstabe Omega kommt in den Legenden nicht vor oder ist nicht lesbar.

* mit einer Ausnahme.

** mit Ausnahmen.

\begin{tabular}{|c|c|c|c|c|c|c|c|c|c|}
\hline & Komana & Amaseia & Neokaisareia & $\begin{array}{l}\text { Neoklau- } \\
\text { diopolis }\end{array}$ & Nikopolis & $\begin{array}{l}\text { Sebasto- } \\
\text { polis }\end{array}$ & Zela & \begin{tabular}{|c|} 
Sebas- \\
teia
\end{tabular} & $\begin{array}{l}\text { Pompeio- } \\
\text { polis }\end{array}$ \\
\hline Tiberius & $\Omega$ & $\Omega^{(1)}$ & & & & & & & \\
\hline Caligula & $\omega^{*}$ & & & & & & & & \\
\hline Claudius & $\Omega$ & & & & & & & & \\
\hline Nero & $\Omega$ & & & & & & & & \\
\hline Vespasian & & - & & & & & & & \\
\hline Domitian & & $\Omega$ & - & & & & & & \\
\hline Nerva & $\Omega$ & & & & & & & & \\
\hline Traian & $\Omega$ & $\omega$ & - & $\Omega$ & $\omega^{*}$ & $\omega$ & $\Omega$ & - & \\
\hline Hadrian & & $\omega$ & & - & & & & & \\
\hline Antoninus Pius & & $\Omega$ und $\omega$ & & $\Omega^{* *}$ & & & & & $\Omega$ \\
\hline M. Aurel, L. Verus & & $\Omega$ & $\Omega$ und $\omega$ & & $\omega$ & & & $\Omega$ & $\Omega$ und $\omega$ \\
\hline Commodus & & $\Omega^{* *}$ & $\omega$ & $\Omega$ und $\omega$ & & & & & \\
\hline Septimius Severus & $\omega^{*}$ & $\Omega^{* *}$ & $\Omega$ und $\omega$ & $\Omega$ & & $\Omega$ & $\omega$ & & - \\
\hline Severus Alexander & & $\Omega$ & $\Omega$ & & & & & & \\
\hline Gordian III. & & & $\Omega$ & & & & & & \\
\hline Philippus Arabs & & & - & & & & & & \\
\hline $\begin{array}{l}\text { Trebonianus Gallus, } \\
\text { Volusianus }\end{array}$ & & & W & & & & & & \\
\hline Valerian, Gallienus & & & $\Omega$ & & & & & & \\
\hline Gallienus & & & - & & & - & & & \\
\hline
\end{tabular}

\section{Tabelle 5 : Transkription des Namens Antoninus.}

- $\quad$ Der Name Antoninus wird in den Legenden nicht verwendet. eine Ausnahme.

\begin{tabular}{|c|c|c|c|c|c|c|c|c|}
\hline & Amaseia & Komana & Neokaisareia & Neoklaudiopolis & Nikopolis & Pompeiopolis & $\begin{array}{c}\text { Sebasto- } \\
\text { polis }\end{array}$ & Zela \\
\hline $\begin{array}{l}\text { Antoninus } \\
\text { Pius }\end{array}$ & $\varepsilon 1$ und 1 & & & $\varepsilon 1$ & & 1 & & \\
\hline M. Aurel & 1 & & El und $\mathrm{l}$ & & $\varepsilon 1$ & $\varepsilon 1$ & & \\
\hline Commodus & $1^{*}$ & & 1 & - & & & & \\
\hline Caracalla & $\imath^{*}$ & 1 & 1 & 1 & & & 1 & 1 \\
\hline
\end{tabular}


Tabelle $6: \varepsilon 1 / 1$ im Namen von Prägeherren.

(1) Die Datierung in die Zeit des Tiberius ist nicht ganz sicher; Alternativen: Augustus oder Caligula (vgl. Dalaison 2008: 24).

- Die Varianten $\varepsilon 1$ oder 1 sind nicht feststellbar, da die Prägeherren abgekürzt oder in anderer Form (Nominativ statt Genitiv, Bürger- statt Stadtname) angegeben werden.

* mit zwei Ausnahmen.

\begin{tabular}{|c|c|c|c|c|c|c|c|}
\hline & $\begin{array}{l}\text { Amaseia, } \\
\text {-as }\end{array}$ & $\begin{array}{c}\text { Neokaisareia, } \\
\text {-as }\end{array}$ & Zeleiton & Sebasteias & Sebastopoleiton & Neikopoleiton & $\begin{array}{l}\text { Neoklaudiopo- } \\
\text { leiton }\end{array}$ \\
\hline Tiberius & $-^{(1)}$ & & & & & & \\
\hline Vespasian & $\varepsilon 1$ & & & & & & \\
\hline Domitian & $\varepsilon 1$ & $\varepsilon 1$ & & & & & \\
\hline Traian & - & $\varepsilon 1$ & $\varepsilon 1$ & - & 1 & - & $\varepsilon 1$ \\
\hline Hadrian & $\varepsilon 1$ & & & & & & - \\
\hline Antoninus Pius & 1 & & & & & & $\varepsilon 1$ \\
\hline M. Aurel & - & - & & El und $\mathrm{l}$ & & 1 & \\
\hline Commodus & $i^{*}$ & - & & & & & $\varepsilon 1$ \\
\hline Septimius Severus & 1 & - & 1 & & - & & $\varepsilon 1$ \\
\hline Severus Alexander & 1 & 1 & & & & & \\
\hline Gordian III. & & 1 & & & & & \\
\hline Philippus Arabs & & 1 & & & & & \\
\hline $\begin{array}{l}\text { Trebonianus Gallus, } \\
\text { Volusianus }\end{array}$ & & $\imath$ und $\varepsilon l$ & & & & & \\
\hline Valerian, Gallienus & & 1 & & & & & \\
\hline Gallienus & & 1 & & & - & & \\
\hline
\end{tabular}

Was Formensprache und Stil der Münzbilder anbelangt, unterschieden sich die Prägungen weder von Stadt zu Stadt, noch zwischen den Städten und der reichsrömischen Prägung in signifikanter Weise. ${ }^{98}$ Zumindest in einem Fall - dem des Kaiserportraits mit Strahlenkrone - wurde ein Bedeutung tragendes Zeichen jedoch gleichsam kopiert ohne daß dessen Bedeutung selbst übernommen worden wäre: In der reichsrömischen Prägung zeigt die Strahlenkrone an, daß die Münze doppelten Wert hat, daß es sich nicht um ein As, sondern um einen Dupondius handelt. ${ }^{99}$ In der Prägung der ,innerpontischen' Städte ist die Strahlenkrone jedoch nicht an das Diassarion gekoppelt. ${ }^{100}$

\section{PORTRAIT, NAME UND TITEL DES KAISERS, SEINER FRAU, SEINER SÖHNE}

Auf der Vorderseite zeigen die Münzen der ,innerpontischen' Städte üblicherweise das Portrait des Kaisers oder eines Mitglieds der kaiserlichen Familie und nennen Namen und Titel der abgebildeten Person. Komana und Neokaisareia prägten anfangs jedoch auch sogenannte pseudoautonome Münzen: anstelle des Kaisers, seiner Frau, seines Mitregenten oder seines Sohnes zeigen sie eine Gottheit. ${ }^{101}$

Wenn eine Stadt nicht nur das Portrait des Kaisers, sondern auch Portraits von Mitgliedern der kaiserlichen Familie prägte, übertraf die Zahl der

98) Vgl. Çizmeli 2006: 110-112, 117-130; Dalaison 2007: 230-233; 2008: 149-152, 159-180; 2010: 65-71; Dalaison, Delrieux 2014: 186-191; vgl. auch unten die Abschnitte 4 und 6.

99) Im Bereich der Silberprägung diente die Strahlenkrone seit der Einführung des Doppeldenars im Jahr 215 auch zur Kennzeichnung dieses modern ,Antoninianus' genannten Nominals.

100) Für Neokaisareia hat dies Çizmeli 2006: 112 gezeigt, für Amaseia Dalaison 2008: 150f., für Neoklaudiopolis Dalaison, Delrieux 2014: 187. Für Sebastopolis gilt zweifellos dasselbe, da Münzen ein und desselben Nominals den Kaiser teils mit Strahlenkrone, teils mit Lorbeerkranz zeigen. Verwendet wurde das Portrait mit Strahlenkrone in Amaseia und Neoklaudiopolis für Caracalla, in Neokaisareia für Caracalla, Severus Alexander, Philippus Arabs, Trebonianus Gallus, Volusianus, Valerianus und Gallienus und in Sebastopolis für Gallienus.

101) Komana: Ma in den Jahren 35/6, 36/7, 39/40, 46/7 und 56/7 (Amandry, Rémy 1999 Nr. 1f., 8-12); Neokaisareia: Zeus im Jahr 92/3 (Çizmeli 2006 Nr. 1; vgl. auch Nr. 2: Büste mit Schleier). Deutlich umfangreicher und nicht nur auf die Anfangsphase beschränkt ist in der weiteren Region die ,pseudoautonome' Prägung von Amastris und Amisos. Amastris: Dionysos (Rec. 169* Nr. 28), Helios 
Stempel, und daher mit größter Wahrscheinlichkeit auch die Zahl der geprägten Münzen, die einen Sohn oder Mitregenten oder auch die Frau des Kaisers zeigten, nicht selten die Zahl der Stempel bzw. der Münzen, die den Kaiser selbst zeigten (vgl. Tabelle 7). Besonders eklatant ist dies im Fall von Amaseia, wo 22 Stempel des L. Verus fünf Stempeln des M. Aurel und 42 Stempel des Caracalla 16 Stempeln des Septimius Severus gegenüberstehen. Fast ebenso auffallend ist dies bei Zela und Neokaisareia, wo man Caracalla gegenüber Septimius Severus mit 14 zu 7 bzw. 22 zu 15 Stempeln den Vorzug gab. Im Fall von Pompeiopolis ist Faustina d.J. mit fünf, M. Aurel aber nur mit einem Stempel vertreten, und im Fall von Sebasteia wurden zwar Münzen geprägt, die L. Verus zeigen (vier Stempel), mit einiger Wahrscheinlichkeit aber keine, die M. Aurel zeigen. In anderen Städten ist das Verhältnis ausgewogener, so in Komana zur Zeit des Septimius Severus; oder aber der Kaiser dominiert gleichsam, wie in Sebastopolis, ebenfalls zur Zeit des Septimius Severus oder in Neokaisareia zur Zeit Gordians III. ${ }^{102}$ Eine Erklärung für die Prominenz Faustinas d.J., des L. Verus und des Caracalla in der Münzprägung eines Teils Städte der Region zu finden, gelingt am ehesten im Fall von Pompeiopolis und Faustina: Julie Dalaison gibt zu überlegen, ob ihre auffallend deutliche Präsenz in der Münzprä- gung gerade dieser Stadt damit zu erklären ist, daß man hier die kaiserliche Familie - Dank der Ehe des aus Pompeiopolis stammenden Cn. Claudius Severus mit einer Tochter M. Aurels und Faustinas durch den Bezug auf die Frauen des Kaiserhauses in besonderer Weise ehren konnte. ${ }^{103}$ Nicht ausgeschlossen ist, daß die überproportionale Häufigkeit, mit der insbesondere in Amaseia und auch in Sebasteia auf L. Verus Bezug genommen wurde, mit der Aktualität seiner Person im Osten des Römischen Reiches in den Jahren 161/2 und 162/3 in Zusammenhang steht: ${ }^{104}$ die profectio des L. Verus in den Partherkrieg, der unter seiner Leitung geführt werden sollte, war im Frühjahr 162 erfolgt. ${ }^{105}$

Die Gestaltung der Portraits der Kaiser und der Mitglieder der kaiserlichen Familie in der Münzprägung der ,innerpontischen ' Städte entsprach üblicherweise sehr genau deren Gestaltung in der Reichsprägung; es sind jedoch auch Abweichungen und Sonderentwicklungen zu beobachten. ${ }^{106}$ So hat im Fall der Münzen von Neokaisareia Tranquillina, die Frau Gordians III., eine gleichsam individuelle Frisur, die, anders als in der Reichsprägung, aber der Haartracht der Iulia Mamaea und der Orbiana, der Mutter bzw. der Frau des Severus Alexander, näher steht als derjenigen der Otacilia Severa, der Frau des Philippus Arabs (vgl. Abb. 2). ${ }^{107}$ Zudem trägt Tranquillina auf einem Teil der Münzen eine Hals-

(Rec. 170* Nr. 29), Kore (Rec. 170* Nr. 31), Tyche (RPC-online temp. no. 4911), Zeus Strategos (Rec. 169* Nr. 23-27; RPC-online temp. no. 4895; 4897-4900) und Homer (Rec. 170* Nr. 32-37; 171* Nr. 38-44; 172* Nr. 45; RPC-online temp. no. 4902f., 4905, 4907, 4913, 6477, 10959; zur Bedeutung Homers für Amastris vgl. Sauer 2014: 114). Amisos: Aphrodite (Rec. 74 Nr. 52), Apollon (Rec. 74, Nr. 50b; 77 Nr. 67b), Athena (Rec. 73 Nr. 49; 74 Nr. 53, 53a; RPC I Nr. 2151), Dionysos (Rec. 74 Nr. 51; 75 Nr. 60; 76 Nr. 61, 61a-c, 62-66), Hermes (Rec. 74 Nr. 50; 75 Nr. 59, 59a-b; RPC I Nr. 2152), Roma (Rec. 75 Nr. 58; 77 Nr. 67c), Tyche (Rec. 75 Nr. $54 \mathrm{a}$, $57 ; 76$ Nr. 67, 67a) und Antinoous in Gestalt des Hermes (Rec. 74 Nr. 54). Zum Phänomen der sogenannten pseudoautomen Prägungen allgemein vgl. Johnston 1985.

102) Im Fall von Amaseia ist diese Aussage sehr zuverlässig, da man so gut wie alle in der Zeit des M. Aurel und des Septimius Severus benutzten Vorderseitenstempel kennt (vgl. Dalaison 2008: 40f.); entsprechendes gilt für Neokaisareia in der Zeit des Septimius Severus und Gordians III. (vgl. Çizmeli 2006: 143 - aus dieser Tabelle läßt sich der jeweilige charakteroskopische Index leicht errechnen; vgl. aber oben Tabelle 1b, Anm. (2) zu Fehlern in der Tabelle). Auch im Fall von Zela (vgl. Dalaison, Rémy, Amandry 2009: 45f.), Komana (vgl. Amandry, Rémy 1999: 57f.) und Sebastopolis (vgl. Amandry, Rémy 1998: 47) hat man recht sicheren Boden unter den Füßen. Unter größerem Vorbehalt ist der Befund zu Pompeiopolis (vgl. Dalaison 2010: 62) und Sebasteia (soweit ich sehe, sind mittlerweile 9 Münzen bekannt, die mit 5 Vorderseitenstempeln geschlagen wurden; der charakteroskopische Index ist also 1,8) zu sehen. Zum charakteroskopischen Index vgl. Callatä̈, Depeyrot, Villaronga 1993: 8f.; Dalaison 2008: 39.

103) Dalaison 2010: 64: „la forte présence des frappes de Faustine pourrait en outre être un moyen de rendre plus spécifiquement hommages à la famille impériale, via les femmes, puisque c'est grâce à une fille de Marc Aurèle que la cité, et surtout son patron (sc. Cn. Claudius Severus), ont acquis une certaine importance et renommée dans l'empire.“

104) In den ,innerpontischen' Städten wurde zur Zeit M. Aurels offenbar ausschließlich in diesen beiden Jahren geprägt. Dies bedeutet freilich nicht notwendigerweise, daß der bevorstehende Krieg auch der Anlaß der Prägung gewesen ist (vgl. oben S. 173f.).

105) In dieser Frage und insbesondere in der nach der Prominenz Caracallas mag etwa der Vergleich mit der Prägepraxis von Städten außerhalb der pontischen Region, aber auch der Vergleich mit den Usancen der Reichsprägung weiterführen; dies würde freilich den Rahmen der vorliegenden Untersuchung sprengen.

106) Allgemein zur Verbreitung und Bedeutung offizieller Portraits des Kaisers und seiner Familie in den Provinzen vgl. etwa Ando 2000: 206-273.

107) In der Münzdarstellung von Neokaisareia sind die Haare der Tranquillina - am Kopf onduliert - im Nacken und im seitlichen Halsbereich unterhalb des Ohres zu einer flachen, aber breiten, möglicherweise aus einem geschlungenen Zopf gebildeten Struktur zusammengefaßt (am deutlichsten zu sehen bei Çizmeli 2006 Nr. 358a, planche 28). Im Fall der Iulia Mamaea und der Orbiana findet sich im Nacken- und Halsbereich üblicherweise ein ähnliches Gebilde, das aber aus einer dicken an Hals und Nacken drapierten Haar- 
Tabelle 7 : Zahl der Vorderseitenstempel, die den Kaiser bzw. Mitglieder seiner Familie zeigen.

Es sind nur die Fälle aufgeführt, in denen - anders als bei Tiberius, Caligula, Claudius, Nero, Vespasian, Domitian, Nerva, Traian, Hadrian, Commodus, Severus Alexander, Gallienus - nicht ausschließlich der Kaiser selbst abgebildet wurde.

(1) jedoch Medaillonprägung (1 Stempel).

\begin{tabular}{|c|c|c|c|c|c|c|c|c|c|}
\hline & Amaseia & Komana & Pompeiopolis & $\begin{array}{c}\text { Neokai- } \\
\text { sareia }\end{array}$ & $\begin{array}{c}\text { Neoklau- } \\
\text { diopolis }\end{array}$ & $\begin{array}{l}\text { Niko- } \\
\text { polis }\end{array}$ & $\begin{array}{c}\text { Sebas- } \\
\text { teia }\end{array}$ & $\begin{array}{c}\text { Sebasto- } \\
\text { polis }\end{array}$ & Zela \\
\hline Antoninus Pius & 8 & & 1 & & 5 & & & & \\
\hline Faustina d.Ä. & 0 & & 1 & & 0 & & & & \\
\hline M. Aurel & 5 & & 1 & 1 & & 2 & 0 & & \\
\hline Faustina d.J. & 4 & & 5 & 0 & & 0 & 0 & & \\
\hline L. Verus & 22 & & 2 & 1 & & 3 & 4 & & \\
\hline Lucilla & 0 & & 1 & 0 & & 0 & 0 & & \\
\hline M. Aurel und L. Verus & 0 & & $0^{(1)}$ & 0 & & 0 & 0 & & \\
\hline Septimius Severus & 16 & 8 & 1 & 15 & 2 & & & 7 & 7 \\
\hline Iulia Domna & 3 & 1 & 0 & 4 & 1 & & & 4 & 4 \\
\hline Caracalla & 42 & 9 & 0 & 22 & 2 & & & 3 & 14 \\
\hline Geta & 8 & 1 & 0 & 11 & 1 & & & 2 & 3 \\
\hline $\begin{array}{l}\text { Septimius Severus und } \\
\text { Caracalla }\end{array}$ & 0 & 0 & 0 & 0 & 0 & & & 0 & 1 \\
\hline Gordian III. & & & & 9 & & & & & \\
\hline Tranquillina & & & & 2 & & & & & \\
\hline Philippus Arabs & & & & 3 & & & & & \\
\hline $\begin{array}{l}\text { Philippus Arabs und } \\
\text { Philippus II. }\end{array}$ & & & & 1 & & & & & \\
\hline Trebonianus Gallus & & & & 2 & & & & & \\
\hline Volusianus & & & & 1 & & & & & \\
\hline $\begin{array}{l}\text { Trebonianus Gallus und } \\
\text { Volusianus }\end{array}$ & & & & 2 & & & & & \\
\hline Valerianus & & & & 2 & & & & & \\
\hline Gallienus & & & & 1 & & & & & \\
\hline
\end{tabular}



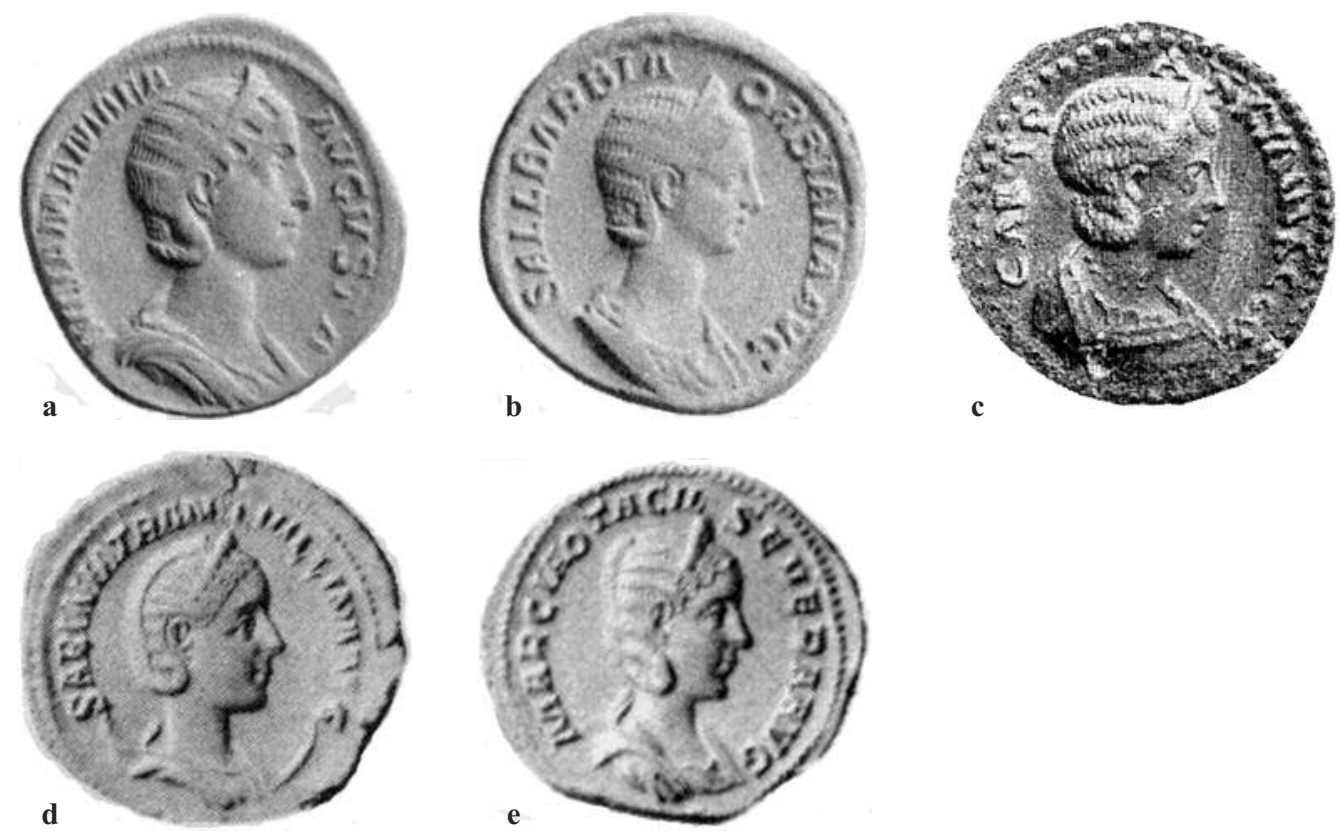

Abb. 2 : Portraits der Tranquillina im Vergleich.

a Iulia Mamaea: Rom, Sestertius; RIC IV.2, 126 Nr. 701, plate 9 Nr. 5.

b Orbiana: Rom, Sestertius; RIC IV.2, 122 Nr. 657, plate 9 Nr. 1.

c Tranquillina: Neokaisareia; Çizmeli 2006 Nr. 358a, planche 28.

d Tranquillina: Antiocheia, Antoninian; RIC IV.3, 42 Nr. 250, plate 3 Nr. 19.

e Otacilia Severa: Rom, Aureus; RIC IV.3, 83 Nr. 120a, plate 7 Nr. 9.

kette, ${ }^{108}$ was nicht nur eine Abweichung von ihrem in der Reichsprägung üblichen Portrait darstellt, sondern für die Portraits von Kaiserfrauen in vorconstantinischer Zeit generell ungewöhnlich ist. ${ }^{109}$ Auch die Portraits des Gallienus unterscheiden sich auf Münzen von Neokaisareia deutlich von in der Reichsprägung üblichen. In seinem Fall betrifft dies aber nicht nur Details der Darstellung, sondern auch den Gesamteindruck der Portraits (vgl. Abb. 3a-e). ${ }^{110}$ Entsprechendes gilt für das Portrait dieses Kaisers in der Münzprägung von Sebastopolis (vgl. Abb. 3a$\mathrm{c}$ und f). Bemerkenswerterweise hat sein hier übliches Portrait aber deutliche Ähnlichkeit zumindest mit einer Variante der in Neokaisareia geprägten

strähne besteht, die mit einem kleinen Knoten im Nacken abschließt (vgl. Bastien 2, 1993: 601-603; 3, 1994: pl. 88f.). Im Fall der Otacilia Severa hingegen wird das Haar nach ähnlicher Anordnung im Hals- und Nackenbereich in einem Zopf am Hinterkopf entlang bis auf den Scheitel hinaufgeführt (vgl. Bastien 2, 1993: 605f.; 3, 1994: pl. 95). Diese Frisur der Otacilia Severa ist derjenigen der Tranquillina auf den Münzen der Reichsprägung (vgl. Bastien 2, 1993: 604f.; 3, 1994: pl. 93) fast zum Verwechseln ähnlich. Zu einer zweiten Variante der Frisur Tranquillinas auf Münzen von Neokaisareia, die sich ebenfalls von der Reichsprägung erheblich unterscheidet wiederum führt kein Zopf auf den Scheitel hinauf, das Haar ist aber auch in der Nackenpartie onduliert -, vgl. Çizmeli 2006 Nr. 370 , planche 29. Allgemein zu Portraits der Tranquillina und der Otacilia Severa vgl. auch Bergmann 1977: 39-41.

108) Wiederum am deutlichsten zu erkennen bei Çizmeli 2006 Nr. 358a, planche 28 (vgl. oben Abb. 2c).

109) Bastien 2, 1993: 643.

110) Vgl. etwa die allerdings unterschiedlich gut erhaltenen Münzen Cizmeli 2006 Nr. 479a, planche 36 (aus dem Jahr 263/4; unten Abb. 3d) und Çizmeli 2006 Nr. 459a, planche 35 (aus dem Jahr 262/3; unten Abb. 3e) mit RIC V.1, 130 Nr. 2 , plate 2 Nr. 29 (Aureus, Rom, 263 n.Chr.; unten Abb. 3 b), RIC V.1, 185 Nr. 615, plate 3 Nr. 46 (Antoninian, Asia, 266 n.Chr.; unten Abb. $3 c$ ) und auch RIC V.1, 74 Nr. 77, plate 2 Nr. 20 (Aureus, Rom, undatiert; unten Abb. 3a) hinsichtlich des Profils (Stirn, Nase, Kinn), des Haaransatzes, der Form der Haarsträhnen und der Bartlocken, der Linienführung des Bartes an Unterkiefer und Kinn bzw. am Hals, der Glattheit bzw. Faltigkeit der Gesichtszüge und hinsichtlich des Gesamteindrucks des Portraits. Zu bedenken ist freilich, daß für Gallienus in Plastik und Münzprägung eine Vielzahl offizieller Portraittypen entwickelt wurde. So ist zu überlegen, ob deren Unterschiedlichkeit (vgl. etwa RIC V.1 74 Nr. 77 und 130, Nr. 2 unten Abb. 3 a und b) einerseits zu einer gewissen Unsicherheit hinsichtlich des Aussehens des Kaisers geführt haben kann, andererseits aber auch dazu, daß man sich bei dessen Darstellung etwas größere Freiheiten nahm. Allgemein zu Portraits des Gallienus vgl. Bergmann 1977, 47-50 und besonders Tafeln 12-14. - So mag man Zeynep Çizmeli, die - allerdings ohne dies näher zu erläutern - für Neokaisareia feststellt, daß die Portraits bis einschließlich desjenigen des Commodus dem römischen Vorbild sehr ähnlich waren, sich danach aber von diesem Vorbild entfernten (Çizmeli 2006: 111), bis zu einem gewissen Grad zustimmen. Insbesondere in Bezug auf die Münzprägung der severischen Zeit und - wenigstens in ihrer Grundsätzlichkeit - überhaupt für die Münzprägung in der Zeit vor Gallienus, ist Çizmelis These m.E. jedoch nicht zutreffend. 

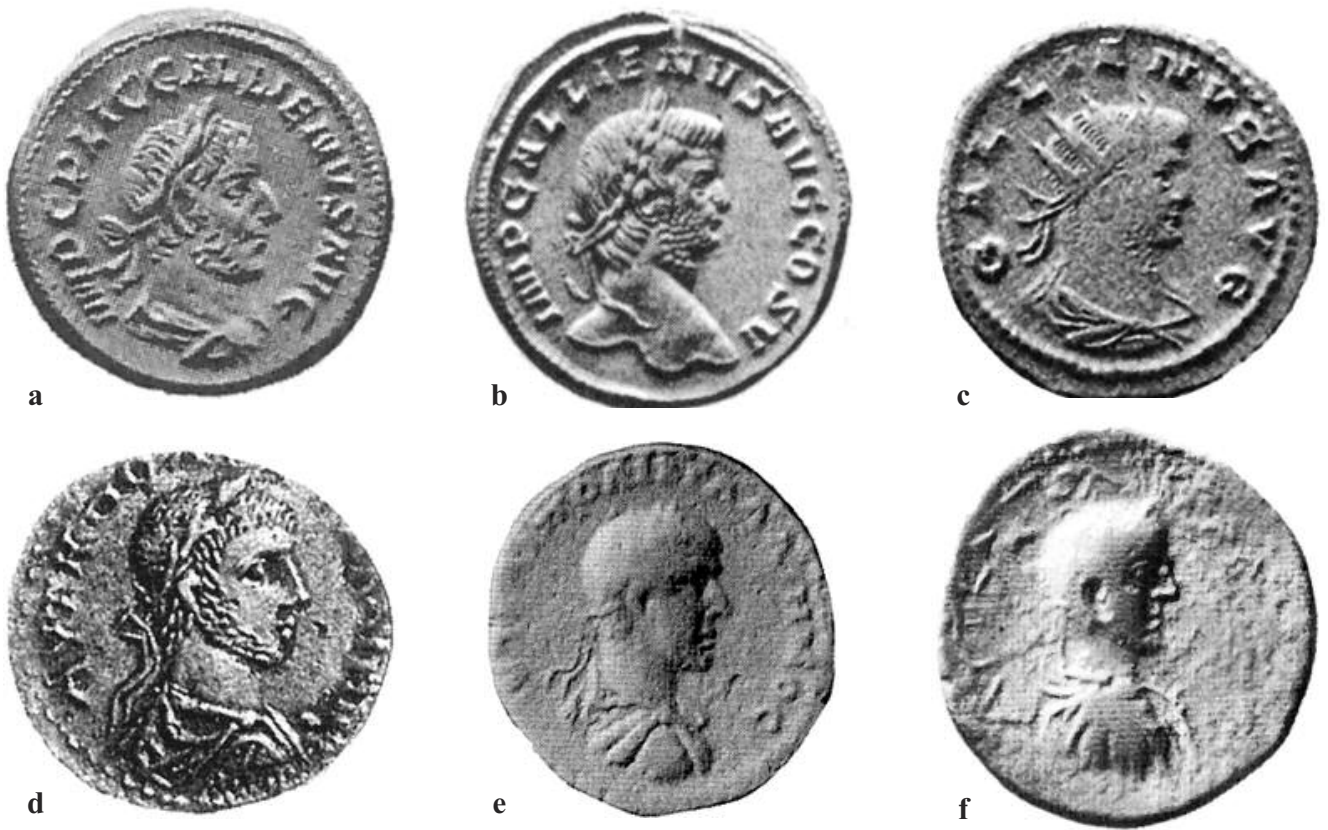

Abb. 3 : Portraits des Gallienus.

a Rom, Aureus, undatiert; RIC V.1, 74 Nr. 77, plate 2 Nr. 20.

b Rom, Aureus, 263 n.Chr.; RIC V.1, 130 Nr. 2, plate 2 Nr. 29.

c Kleinasiatische Münzstätte, Antoninian, 266 n.Chr.; RIC V.1, 185 Nr. 615, plate 3 Nr. 46.

d Neokaisareia, 263/4 n.Chr.; Çizmeli 2006 Nr. 479a, planche 36.

e Neokaisareia, 262/3 n.Chr.; Çizmeli 2006 Nr. 459a, planche 35.

f Sebastopolis, 263/4 n.Chr.; Amandry, Rémy 1998 Nr. 64b, planche 6.

Portraits. ${ }^{111}$ Im Fall der Münzen von Amaseia ist die Gestaltung des Portraits des Septimius Severus in gewisser Weise konservativer als in der Reichsprägung. Während der Kaiser auf einem Teil der Münzen der Reichsprägung bereits mit in die Stirn fallenden Korkenzieherlocken abgebildet wird, bleibt man in Amaseia konsequent bei der älteren Frisur mit kurzen, kräftigen Locken in der Stirnpartie (vgl. Abb. 4). ${ }^{112}$ Außerdem fand in der Münzprägung von Amaseia für Severus Alexander neben konventionellen Porträts auch ein Typus Verwendung, der für diesen Kaiser m.E. lediglich in der Münzprägung von Byzantion ${ }^{113}$ und von Kaisareia in Kappadokien $^{114}$ eine Parallele hat, in der Reichsprägung jedoch nicht nachgewiesen ist ${ }^{115}$ und der zudem für Kaiser in der Zeit vor Gallienus generell sehr selten ist: ${ }^{116} \mathrm{Er}$ zeigt die Büste des Kaisers mit Schild und Lanze (vgl. Abb. 5). ${ }^{117}$

111) Vgl. etwa Amandry, Rémy 1998 Nr. 64b, planche 6 (Sebastopolis, 263/4 n.Chr.; oben Abb. 3f) mit Çizmeli 2006 Nr. 459 a, planche 35 (Neokaisareia, 262/3 n.Chr.; oben Abb. 3e).

112) Dalaison 2008: 150. Vgl. etwa Dalaison 2008 Nr. 291b aus dem Jahr 205/6 (kurze, kräftige Locken in der Stirnpartie) mit RIC IV.1, 196 Nr. 770, plate 10 Nr. 3 aus dem Jahr 206 (Rom, Sestertius; in die Stirn fallende lange Korkenzieherlocken).

113) Vgl. Schönert-Geiss 1972 Nr. 1738-1742. Hier trägt der Kaiser freilich nicht einen Lorbeerkranz, sondern eine Strahlenkrone.

114) So bereits Bastien 2, 1993: 471 Anm. 6, der auf SNG Aulock Nr. 6509 verweist. Diese Münze ist freilich schlecht erhalten, der Schild - anders als bei den Münzen von Amaseia und Byzantion in der rechten Bildhälfte - nur in Umrissen, die Lanze, soweit ich sehe, gar nicht zu erkennen.

115) Dalaison 2008: 151.

116) Bastien 2, 1993: 462. In der Zeit vor Severus Alexander ist er in der Reichsprägung überhaupt nur für Septimius Severus und Caracalla, in Städteprägungen nur für Caracalla, Geta und Elagabal nachgewiesen; vgl. Bastien 2, 1993: 468-471; Dalaison 2008: 151; Bricault, Delrieux 2014: 88f.

117) Dalaison 2008 Nr. 588-589, 604, 606, 609 (alle mit Stempel D 147 geschlagen). - Julie Dalaison zufolge weichen auch die Frisuren Faustinas d.J. von reichsrömischen Mustern ab (vgl. Dalaison 2008: 152: „les graveurs se sont sans doute contentés de s'inspirer vaguement de la coiffure en chignon de l'impératrice"). M.E. lassen sich die von Dalaison konstatierten Differenzen (Grad der Ondulierung des am Kopf anliegenden Haares, Volumen des Knotens) jedoch teils mit dem Erhaltungszustand der Münzen von Amaseia erklären, teils aber auch nicht recht nachvollziehen. Jedenfalls finden Dalaison 2008 Nr. 98-99 Fittschen 1982, Tafel 1 Nr. 3-8 (Typ 1) und auch Bastien 3, 1994: planche 66 Nr. 2, 4 zufolge und Dalaison 2008 Nr. 100-101 Fittschen 1982: Tafel 3 Nr. 6-7, 10-12; Tafel 4 

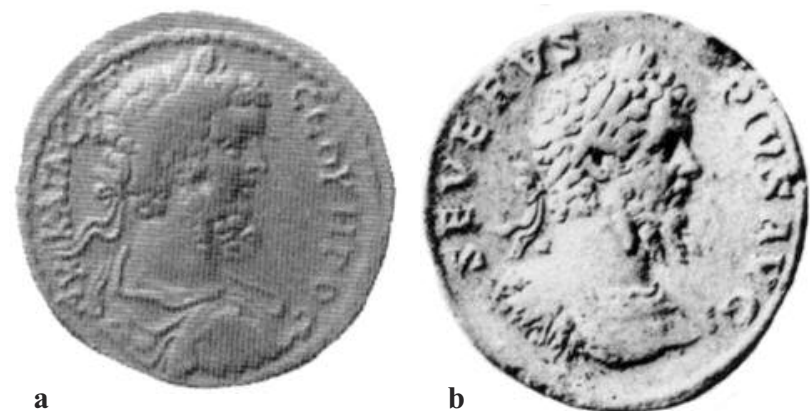

Abb. 4 : Portraits des Septimius Severus.

a Amaseia, 205/6 n.Chr.; Dalaison 2008 Nr. 291b, planche 30.

b Rom, Sestertius, 206 n.Chr.; RIC IV.1, 196 Nr. 770, plate 10 Nr. 3.
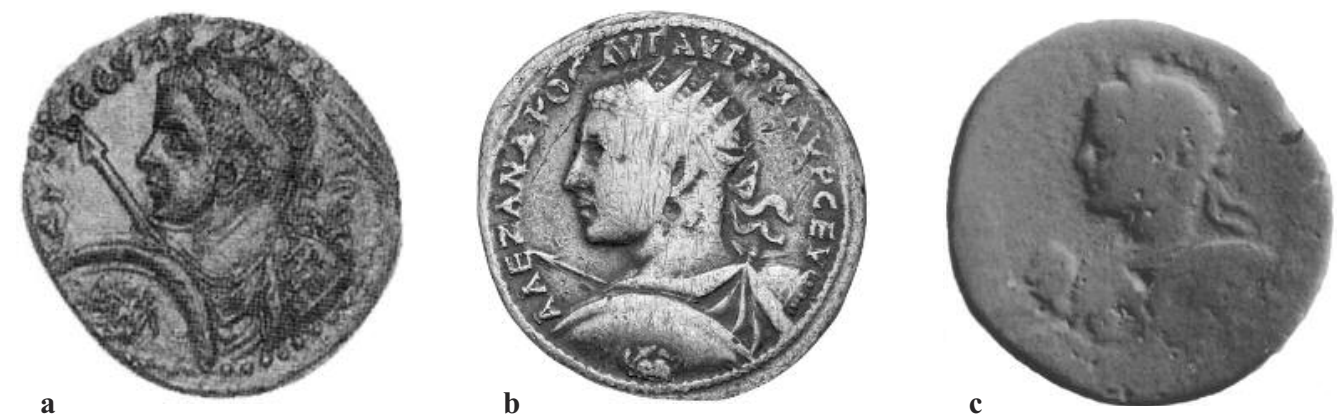

Abb. 5 : Portraits des Severus Alexander.

a Amaseia, 231/232 n.Chr.; Dalaison 2008 Nr. 589b, planche 62.

b Byzantion, undatiert; Schönert-Geiss 1972 Nr. 1741.1; Münzkabinett der Staatlichen Museen zu Berlin, Objektnummer 18235869; Photo: Münzkabinett der Staatlichen Museen zu Berlin, Aufnahme durch

Reinhard Saczewski.

c Kaisareia in Kappadokien, 222 n.Chr. (?); SNG Aulock 6509.

Die Gestaltung der Namen und Titel der Kaiser, ihrer Frauen und Söhne auf den Münzen der ,innerpontischen' Städte unterschied sich in Details recht deutlich sowohl von den Gepflogenheiten der Reichsprägung als auch von Stadt zu Stadt. ${ }^{118}$
So ist die Titulatur grundsätzlich weniger umfangreich als in der Reichsprägung. ${ }^{119}$ Die Namen und Titel werden zuweilen in einer von der Reichsprägung abweichenden Reihenfolge genannt. ${ }^{120}$ Der Titel ,Augustus' fehlt häufig

Nr. 1-4; Tafel 5 Nr. 1-8 (Typen 5-7) zufolge enge Parallelen. Zu den vielgestaltigen Frisuren Faustinas d.J. allgemein vgl. Fittschen 1982; Bastien 2, 1993: 586-588 (mit Lit.).

118) Dies gilt auch für die Städte der weiteren Region. - Abweichungen, die dem Platzmangel auf Münzen mit kleinem Durchmesser geschuldet sind und also lediglich eine technische Ursache haben, bleiben im Folgenden selbstredend unberücksichtigt.

119) Weder findet die tribunicia potestas (zu einer einzigen denkbaren Ausnahme vgl. unten Anm. 136) oder der Oberpontifikat des Kaisers Berücksichtigung, noch der Titel pater patriae oder die Bekleidung des Konsulats. Siegerbeinamen werden dagegen bis einschließlich der Zeit M. Aurels konsequent genannt. Das betrifft den Titel Germanicus im Fall Domitians (Amaseia) und Traians (Amaseia, Komana, Neokaisareia, Neoklaudiopolis, Nikopolis, Sebastopolis, Zela, wohl auch Sebasteia) und den Titel Dacicus im Fall Traians (Amaseia, Komana, Neoklaudiopolis, Nikopolis, Sebastopolis, Zela, wohl auch Sebasteia). Daß andere Siegerbeinamen und Siegerbeinamen anderer Kaiser nicht genannt werden, ist damit zu erklären, daß die Kaiser sie in den Jahren, in denen in den ,innerpontischen' Städten geprägt wurde, noch nicht geführt haben, im Fall des Domitian und der Münzprägung von Neokaisareia auch damit, daß es sich um ,pseudoautonome‘ Prägungen handelte. Ab der Zeit des Commodus fehlen die Siegerbeinamen dagegen ebenso konsequent.

120) So liest man auf den Münzen von Amaseia im Fall des Hadrian, des M. Aurel, des L. Verus, des Septimius Severus und des Caracalla ganz konventionell Autokrator Kaisar $<$ Name $>$ Sebastos, im Fall des Vespasian aber Autokrator Kaisar Sebastos $<$ Name $>$, im Fall des Domitian und des Traian Autokrator $<$ Name $>$ Kaisar Sebastos und im Fall des Commodus neben Autokrator $<$ Name $>$ und $<$ Name $>$ Sebastos auch <Name $>$ Autokrator (vgl. Dalaison 2008: 149, 200f.). Vergleichbares ist in den Legenden der Münzen von Neoklaudiopolis, Sebastopolis und Zela zu beobachten. 
(vgl. Tabelle 8), ${ }^{121}$ und man kann den Eindruck gewinnen, ,Autokrator' (lat. Imperator) habe nach Auffassung der Städte den Herrscher eher als solchen charakterisiert als ,Sebastos'. ${ }^{122}$ Das Cognomen ,Pius' des Antoninus Pius erscheint nie - sieht man von einem einzigen in Amaseia verwendeten Stempel ab. ${ }^{123}$ Möglicherweise ist das damit zu erklären, daß der Verweis auf die besondere pietas dieses Kaisers seinem Vorgänger Hadrian gegenüber in den ,innerpontischen' Städten keinen allzu großen Wiederhall hatte. ${ }^{124}$ Neoklaudiopolis gab Geta zusätzlich den Namen Kommodos, ${ }^{125}$ was lediglich in den Prägungen von Tavion und von Antiocheia in Pisidien eine Parallele hat. ${ }^{126}$ Vermutlich spiegelt diese Namensgebung, wie die Städte rezipierten, daß Septimius Severus im Jahr 195 seine Adoption durch M. Aurel behauptet und seinen ,Bruder' Commodus hatte konsekrieren lassen, indem sie Geta hier nach seinem ,Onkel' benannt haben - ohne daß es dafür in der offiziellen Namensgestaltung des Geta ein Vorbild gegeben hätte. ${ }^{127}$ Neokaisareia gab grundsätzlich in ein und derselben Legende beide Vornamen - Publius und Lucius - an, die Geta im Lauf der Zeit getragen hat;: ${ }^{128}$ Amaseia nannte Geta auf einem Teil der Münzen des Jahres 205/6 Sebastos, obwohl Geta den Augustus-Titel damals noch nicht geführt hat. ${ }^{129}$ Während im ersten Fall der Fehler wohl damit zu erklären ist, daß man aus einer gewissen Verwirrung heraus gleichsam überkorrekt sein wollte, ${ }^{130}$ ist im zweiten Fall zu fragen, ob tatsächlich ein - etwa aus unachtsamer Routine heraus entstandener - Fehler vorliegt, oder ob es sich nicht eher um ein Zeugnis gleichsam vorauseilenden Gehorsams handelt oder gar um den Ausdruck eines Wunsches. ${ }^{131}$ Pompeiopolis bezeichnete Faustina d.J. auf einem Teil der Münzen als $N e a,{ }^{132}$ was in der Prägung der Städte des Ostens - abweichend

121) Im Fall des Antoninus Pius, des Severus Alexander und des Gallienus nannte keine der Städte, die unter diesen Kaisern prägte, den Titelbestandteil Sebastos bzw. Augoustos in ihren Münzlegenden. Commodus wurde auf einem Teil der Münzen von Amaseia mit diesem Titel bedacht, nicht jedoch in Neokaisareia und Neoklaudiopolis. Im Fall des Septimius Severus und des Caracalla fällt die Bilanz gemischt aus: In den Legenden der Münzen von Komana und Neokaisareia fehlt der Titel grundsätzlich, während er in denjenigen von Amaseia, Neoklaudiopolis, Sebatopolis und Zela zumindest in einem Teil der Prägungung, sei es nur im Fall des Septimius Severus (Sebastopolis, Zela) oder nur des Caracalla (Neoklaudiopolis) oder aber bei beiden Augusti (Amaseia) Verwendung findet. In der Zeit bis einschließlich Hadrian und in der Zeit des M. Aurel war die Verwendung des Titels offenbar jedoch die Regel - vgl. insbesondere die Konsequenz, mit der er im Fall des Traian zur Anwendung kam - sieht man von den Ausnahmen der Münzprägung von Komana (Caligula, Nerva) und Pompeiopolis (M. Aurel, L. Verus) ab.

122) So bereits Julie Dalaison in Bezug auf Amaseia: „Il semblerait donc que pour les graveurs et les habitants d'Amaseia, ce soit plus le titre d'Imperator qui fasse l'empereur que celui d'Augustus ..." (Dalaison 2008: 149). Bemerkenswerter und schwer erklärlicher Weise verzichtete man freilich im Fall des Commodus in Neoklaudiopolis wohl konsequent und in Amaseia immerhin teilweise darauf, den Titel Autokrator zu verwenden. Anders dagegen in Neokaisareia: hier findet sich Autokrator auf allen identifizierbaren Stempeln dieses Kaisers (Çizmeli 2006 Nr. 13-17, drei Stempel). Zu Neoklaudiopolis vgl. Dalaison, Delrieux 2014: 187 und Nr. 19-22 (weder Autokrator noch Sebastos; zwei Stempel), Nr. 23 (wohl ebenso, Legende aber nur teilweise lesbar; ein Stempel). Zu Amaseia vgl. Dalaison 2008: 149 und Nr. 183-185, 204 (weder Autokrator noch Sebastos; zwei Stempel), Nr. 154-162, 173-182, 186-189, 191-202 und wohl auch 190 und 203 (nur Sebastos; 12 Stempel), Nr. 163-172 (nur Autokrator; zwei Stempel).

123) Dalaison 2008 Nr. 49: AYT KAI A $\triangle$ PI ANTWNINOC EYCEB. Anders als noch im Corpus der Münzen von Amaseia notiert

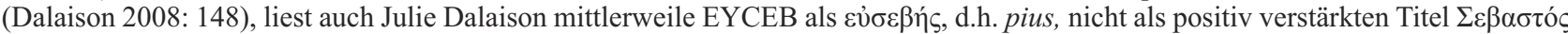
(persönliche Mitteilung).

124) Städte in anderen Regionen, beispielsweise in Bithynien, Galatien, Kilikien und Syrien, nannten das Cognomen ,Pius' des Kaisers dagegen durchaus (vgl. RPC-online). - Auch die gleichsam allgemeine pietas der Kaiser wurde von den ,innerpontischen` Städten nur höchst selten thematisiert: Lediglich Münzen von Amaseia, die den Kaiser bei der Libation zeigen (Dalaison 2008 Nr. 282, 464472; 6 Stempel) und Münzen von Neokaisareia, auf denen der Kaiser Tyche bekränzt (Çizmeli 2006 Nr. 211; 1 Stempel), kann man mit pietas in Verbindung bringen.

125) Dalaison, Delrieux 2014 Nr. 37

126) Dalaison, Delrieux 2014: 187. Zumindest die Prägung von Tavion ist früher zu datieren als diejenige von Neoklaudiopolis.

127) Dalaison, Delrieux 2014: 188 unter Verweis auf eine Überlegung von Leschhorn 1992: 325.

128) Cizmeli 2006 Nr. 189-207, 211-239. Die Legende der Nummern 208-210 verzichtet ganz auf Vornamen, bei den Nummern 188 und 240-242 sind die entsprechenden Partien nicht lesbar. Das Praenomen Lucius trug Geta vorübergehend in der Zeit von 195 bis wohl 205 (Kienast 1996: 166); die Münzen von Neokaisareia datieren - mit Ausnahme einer einzigen aus dem Jahr 204/5, deren Vorderseitenlegende jedoch nicht lesbar ist - in das Jahr 205/6.

129) Dalaison 2008 Nr. 537-544, 546, 549-552. Geta Augustus: seit 209 oder 210 (Kienast 1996: 166).

130) Vgl. Çizmeli 2006: 113.

131) Julie Dalaison weist darauf hin, daß die Hierarchie zwischen den Augusti Septimius Severus und Caracalla auf der einen und dem Caesar Geta auf der anderen Seite aber insofern gewahrt blieb, als man für Geta nie den Imperator-Titel verwandte (Dalaison 2008: 149; zur besonderen Bedeutung des Imperator-Titels in der Münzprägung der ,innerpontischen“ Städte vgl. auch oben S. 189f.). Zu bedenken ist freilich, daß man in Amaseia - wenn auch 20 Jahre zuvor - Commodus häufig Sebastos, nicht aber Autokrator genannt hatte.

132) Dalaison 2010 Nr. 10-11, nicht aber Nr. 4-9. 
Tabelle 8 : Verwendung des Titels Augustus/Sebastos.

(1) Die Datierung in die Zeit des Tiberius ist nicht ganz sicher; Alternativen: Augustus oder Caligula (vgl. Dalaison 2008: 24).

(2) Mit der Ausnahme eines Stempels.

(3) Vgl. aber die Legende AYT M AYP ANTSN€I $\Lambda$ AYP OYHPOC C€B der Medaillonprägung (dazu Dalaison 2010: 66).

(4) Die Legende auf der einzig erhaltenen Münze ist an der entscheidenden Stelle nicht erkennbar.

- Der Kaiser ist in der Münzprägung nicht vertreten, sei es weil in seiner Zeit in der jeweiligen Stadt nicht geprägt wurde, sei es weil es sich um ,pseudoautonome' Münzen handelte.

\begin{tabular}{|c|c|c|c|c|c|c|c|c|c|}
\hline & Amaseia & Komana & $\begin{array}{c}\text { Neokai- } \\
\text { sareia }\end{array}$ & $\begin{array}{c}\text { Neoklau- } \\
\text { diopolis }\end{array}$ & Nikopolis & Pompeiopolis & Sebasteia & Sebastopolis & Zela \\
\hline Tiberius & $\mathrm{ja}^{(1)}$ & - & - & - & - & - & - & - & - \\
\hline Caligula & - & nein & - & - & - & - & - & - & - \\
\hline Claudius & - & - & - & - & - & - & - & - & - \\
\hline Nero & - & - & - & - & - & - & - & - & - \\
\hline Vespasian & ja & - & - & - & - & - & - & - & - \\
\hline Domitian & ja & - & - & - & - & - & - & - & - \\
\hline Nerva & - & nein & - & - & - & - & - & - & - \\
\hline Traian & ja & $\mathrm{ja}$ & ja & $\mathrm{ja}$ & ja & - & ja & $\mathrm{ja}$ & ja \\
\hline Hadrian & ja & - & - & ja & - & - & - & - & - \\
\hline Antoninus Pius & nein & - & - & nein & - & nein & - & - & - \\
\hline M. Aurel & ja & - & ja & - & ja & nein & - & - & - \\
\hline L. Verus & ja & - & ja & - & ja & nein $^{(3)}$ & ja & - & - \\
\hline Commodus & teils & - & nein & nein & - & - & - & - & - \\
\hline $\begin{array}{l}\text { Septimius } \\
\text { Severus }\end{array}$ & teils & nein & nein & nein & - & $?^{(4)}$ & - & teils & teils \\
\hline Caracalla & teils & nein $^{(2)}$ & nein & teils & - & - & - & nein & nein \\
\hline $\begin{array}{l}\text { Severus } \\
\text { Alexander }\end{array}$ & nein & - & nein & - & - & - & - & - & - \\
\hline Gordian & - & - & teils & - & - & - & - & - & - \\
\hline Philippus Arabs & - & - & nein & - & - & - & - & - & - \\
\hline $\begin{array}{l}\text { Trebonianus } \\
\text { Gallus }\end{array}$ & - & - & ja & - & - & - & - & - & - \\
\hline Volusianus & - & - & ja & - & - & - & - & - & - \\
\hline Valerian & - & - & nein & - & - & - & - & - & - \\
\hline Gallienus & - & - & nein & - & - & - & - & - & - \\
\hline Gallienus & - & - & nein & - & - & - & - & nein & - \\
\hline
\end{tabular}


vom Usus der Reichsprägung - üblich gewesen ist. ${ }^{133}$ Amaseia verzichtete jedoch auf diesen Zusatz. ${ }^{134}$

Grundsätzlich beziehen sich die Münzlegenden der ,innerpontischen' Städte nicht auf die Herrschaftsjahre der Kaiser; ${ }^{135}$ anders jedoch die in der Herrschaftszeit des Nerva geprägten Münzen von Komana und die in der Zeit des Traian geprägten Münzen von Nikopolis. ${ }^{136} \mathrm{Im}$ Fall von Nikopolis ist es verführerisch, darin ein Anknüpfen an gleichsam vorrömische Usancen $\mathrm{zu}$ sehen, ${ }^{137}$ wurden doch höchst wahrscheinlich in Nikopolis die Münzen des Aristoboulos geprägt - und diese verzeichneten das jeweilige Herrschaftsjahr des Königs. ${ }^{138}$ Der Blick auf die Münzprägung von Komana, in der dasselbe Phänomen auftritt, ohne daß dafür jedoch ältere lokale Prägetraditionen Vorbild gewesen sein können, macht deutlich, daß ebenso gut auch der entspre- chende Usus in der Münzprägung anderer Städte Pate gestanden haben kann. ${ }^{139}$

\section{NAME UND TITEL DER STADT, DAS JAHR DER STÄDTISCHEN ÄRA}

Die ,innerpontischen' Städte gaben sich auf der Rückseite ihrer Münzen in aller Regel ausdrücklich als Prägeherren zu erkennen ${ }^{140}$ - sei es mit dem Namen der Stadt, sei es mit dem ihrer Bürger, ${ }^{141}$ sei es mit dem Namen im Nominativ, sei es im Genitiv $^{142}$ - und führten dabei mehrheitlich Titel bzw. ehrende Beinamen an, sofern sie über solche verfügten. So nannten sich im Lauf der Zeit Pompeiopolis metropolis, Amaseia metropolis, neokoros, prote tou Pontou, Hadriane, Severiane Antoniniane und Severiane Alexandriane, Neokaisareia metropolis, neokoros, dis neokoros, prote tou pontou und Hadriane. ${ }^{143}$ Anders verfuhr jedoch Nikopolis und

133) Dalaison 2010: 66 Anm. 64.

134) Vgl. Dalaison 2008 Nr. 98-101. So könnte man fragen, ob sich Amaseia schlicht an der offiziellen Namensgestaltung etwa der Reichsprägung orientiert, oder aber die explizite Erklärung, um welche Faustina es sich handelte, für überflüssig gehalten hat. Angesichts der geradezu familiären Kontakte zwischen Pompeiopolis und dem Kaiserhaus wäre letzteres freilich viel eher für diese Stadt zu erwarten gewesen.

135) Vgl. auch oben Anm. 119.

136) Amandry, Rémy 1999 Nr. 13 bzw. Dalaison 2007 Nr. 10-24. Ebenso die in traianischer Zeit - mit größter Wahrscheinlichkeit ebenfalls in Nikopolis geprägten (Dalaison 2007: 203) - Münzen des kleinarmenischen koinon: Dalaison 2007 Nr. 25-31. Die Formel , $\tau$ ò + Zahl', die sich in der Vorderseitenlegende, dem Namen und den Titeln des Kaisers nachgestellt, findet, ist wörtlich zu verstehen als ,zum ... mal', wird vor allem in Münzlegenden aber auch anstelle der Formel ,ětovৎ + Jahreszahl' verwendet (Leschhorn 1993: 126f., 148). Wolfgang Leschorn konnte zeigen, daß man damit in Nikopolis mit größter Wahrscheinlichkeit nicht auf die tribunicia potestas des Kaisers, sondern auf seine Regierungsjahre rekurrierte, wobei als erstes Regierungsjahr der Zeitraum zwischen dem dies imperii des Kaisers und dem Jahresende des lokalen Kalenders gegolten haben dürfte (Leschhorn 1993: 146-149). Im Fall von Komana ist dagegen nicht auszuschließen, daß man sich tatsächlich auf das Datum der Verleihung und auf die Zählung der tribunicia potestas bezog (Leschhorn 1993: 126-128)

137) So auch Leschhorn 1993: 148

138) Dalaison 2007: 203 und Nr. 1-8. Dies geschah in der Form ,ětov + Zahl', die im Fall der unter Aristoboulos geprägten Münzen anders als im Fall der unter Traian geprägten (vgl. Leschhorn 1993: 148) nicht durch die Angabe des Prägejahres nach der städtischen Ära in der Rückseitenlegende besetzt war.

139) Insbesondere in der Münzprägung der Städte der Provinz Cappadocia (etwa in Kaisareia, Kybistra und Tyana), zu der zur fraglichen Zeit auch Komana und Nikopolis gehörten, „war die Angabe des Regierungsjahres des Kaisers die übliche Datierungsform“ (Leschhorn 1993: 148). In Kappadokien hatte „diese Art der Zeitrechnung“ allerdings tatsächlich insofern lokale bzw. regionale Tradition, als sie „,vom letzten kappadokischen König übernommen und dann fortgeführt worden war“ (Leschhorn, 1.c.). Vgl. auch Leschhorn 1993: 18-20 mit Quellen und Lit.

140) Die einzig echte Ausnahme stellen im Jahr 251/2 n.Chr. geprägte Münzen von Neokaisareia dar: 29 der 32 Rückseitenstempel weisen die Stadt nicht als Prägeherrn aus; vgl. dazu oben Anm. 89. Im Fall der Münzen von Zela aus dem Jahr 113/4 n.Chr. (Dalaison,

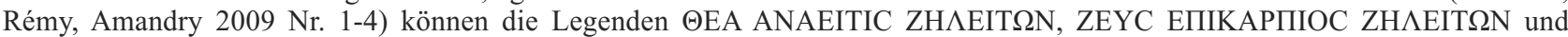

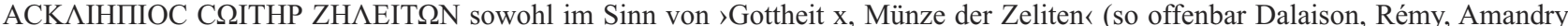
2009: 37) als auch im Sinn von >Gottheit x der Zeliten` verstanden werden; im zweiten, m.E. wahrscheinlicheren Fall würden die Zeliten streng genommen nicht ausdrücklich als Prägeherren figurieren.

141) Ausnahmslos mit dem Namen der Stadt: Neokaisareia, Pompeiopolis und wohl auch Sebasteia. Meist mit dem Namen der Stadt: Amasaeia (Ausnahmen: Dalaison 2008 Nr. 1-4, 20-38). Immerhin häufig mit dem Namen der Stadt: Nikopolis und Sebastopolis. Ausnahmslos mit dem Namen der Bürger: Zela und wohl auch Komana. Überwiegend mit dem Namen der Bürger: Neoklaudiopolis (Ausnahme: Dalaison, Delrieux 2014 Nr. 5-7). - Die Unsicherheit im Fall von Sebasteia und Komana rührt daher, daß der Name abgekürzt oder die grammatische Form nicht eindeutig ist.

142) Soweit der Grad der Abkürzung dies erkennen läßt, verwandte Pompeiopolis konsequent den Nominativ, Komana, Nikopolis, Sebasteia, Zela und wohl auch Amaseia (vgl. Dalaison 2008: 155f.) konsequent den Genitiv. Neoklaudiopolis verwandte fast immer den Genitiv (Ausnahme: Dalaison, Delrieux 2014 Nr. 5). Sebastopolis bevorzugte wohl den Nominativ, Neokaisareia den Genitiv; oft ist der Name dieser beiden Städte aber so stark abgekürzt, daß der Kasus nicht bestimmbar ist.

143) Vgl. Cizmeli 2006: 133-136 (Neokaisareia); Dalaison 2008: 201-207 (Amaseia); 2010: 67 (Pompeiopolis). Zur Bedeutung der Titel metropolis und neokoros vgl. oben Anm. 69; zu prote tou Pontou vgl. Dalaison 2008: 158; 2014: 132; zu Hadriane, Severiane Antoniniane und Severiane Alexandriane vgl. Dalaison 2008: 156f.; 2014: 131f. 
erwähnte in den Legenden ihrer Münzen nicht einen ihrer Titel bzw. Beinamen. ${ }^{144}$ Dies mag damit in $\mathrm{Zu}-$ sammenhang stehen, daß Nikopolis als einzige $p o-$ liteia der eparchia und des koinon Armenias in diesen Institutionen gleichsam eine Monopolstellung hatte, während Neokaisareia und Amaseia in der Eparchie Pontus Mediterraneus und im koinon Pontou um den Vorrang wetteiferten und in der eparchia und dem koinon Paphlagonias Germanikopolis mit Pompeiopolis konkurrierte. ${ }^{145}$ Auffallenderweise war Amaseia aber bei der Nennung ihrer Titel und Beinamen viel konsequenter als Neokaisareia. ${ }^{146} \mathrm{Neo}-$ kaisareia wiederum nutzte, anders als Amaseia, in einem Großteil ihrer Emissionen auch die Rückseitenbilder, um ihre Titel neokoros bzw. dis neokoros zu propagieren. ${ }^{147}$
Die Nennung des Jahres, in dem die Münzen geprägt wurden - datiert nach der städtischen Ära -, war ebenfalls weit verbreitetes Element der Rückseitenlegenden. ${ }^{148}$ Pompeiopolis verzichtete freilich konsequent darauf, ${ }^{149}$ Amaseia und Neoklaudiopolis in Einzelfällen. ${ }^{150} \mathrm{Im}$ Fall von Neoklaudiopolis dürfte der ausnahmsweise Verzicht technisch bedingt gewesen sein: er ist nur bei den Münzen mit dem kleinsten für Prägungen dieser Stadt dokumentierten Durchmesser zu beobachten. ${ }^{151}$ Im Fall von Amaseia mag der Verzicht damit in Zusammenhang gestanden haben, daß man in den Rückseitenlegenden der betreffenden Münzen ${ }^{152}$ auf den Statthalter verwies. ${ }^{153}$

144) Nach Ausweis der Inschriften war Nikopolis metropolis, neokoros, dis nekoros, Hadriane und italike kolonia. Aus chronologischer Sicht hätten der metropolis-Titel, die erste Neokorie und der Beiname Hadriane in der Münzprägung in Erscheinung treten können; die zweite Neokorie und der höchst wahrscheinlich erst kaiserzeitliche Kolonietitel sind dagegen frühestens für die Zeit Gordians III. belegt, in der Nikopolis nicht mehr prägte (vgl. oben Anm. 69 mit Lit.; zum Kolonietitel außerdem Marek 1993: 37; Esch 2011, 40).

145) Vgl. hierzu neuerlich oben Anm. 69. Germanikopolis führte zwar keinen Titel wie metropolis oder neokoros und trug keinen auf den Kaiser bezogenen Beinamen, nannte sich in den Legenden ihrer Münzen aber archaiotate Paphlagonias und hestia theon und rekurrierte auch mit der Bezeichnung Germanikopolis pros Gangra auf ihre Seniorität (vgl. Dalaison 2010: 47, 51-53; Sauer 2014: 118, 123f.; vgl. auch Bricault, Delrieux 2014: 93f.).

146) Amaseia führte in aller Regel sämtliche ihrer Titel und Beinamen an (Hadriane nannte sie sich freilich erst, als auch Neokaisareia dies tat: Dalaison 2008: 156f.; Severiane Alexandriane löste Severiane Antoniniane gleichsam ab: Dalaison 2008: 157). Neokaisareia nannte nur den metropolis-Titel durchgängig (wenn auch genau genommen erst ab der Zeit des Septimius Severus); der Neokorie-Titel fehlt in den Legenden ihrer Münzen dagegen in der Zeit des Septimius Severus auf fast allen Stempeln (Ausnahmen: Çizmeli 2006 Nr. 22, 42, 168), wird in der Zeit des Severus Alexander häufiger, um dann, von seltensten Ausnahmen in den Jahren 241/2 und 255/6 abgesehen (Çizmeli 2006 Nr. 306, 308 bzw. Nr. 420, 431), zu verschwinden. Prote tou Pontou nannte Neokaisareia sich nur in der Zeit des M. Aurel und des Commodus und dann wieder in der des Severus Alexander, und dies auch nur auf wenigen Stempeln (Çizmeli 2006 Nr. 10-11, 13-15, 17-18, 256-257). Der Beiname Hadriane kommt ab dem Jahr 205/6 überhaupt nicht mehr vor. Vgl. dazu auch Çizmeli 2006: 130-132; Dalaison 2008: 154-159; 2014, 130-133.

147) Dargestellt wurden ein bzw. zwei Tempel, außerdem Kronen, die als Siegespreis von Wettkämpfen zu denken sind, die mit dem Kaiserkult in Verbindung standen. Diese Rückseitenmotive sind auf den Münzen von Neokaisareia von der Zeit des Septimius Severus an mit Abstand am häufigsten vertreten. Vgl. Çizmeli 2006: 118-123; Dalaison 2014: 141f.; vgl. auch unten Anm. 157, 204 und S. 195. - Überhaupt ist festzustellen, daß sowohl die Art und Weise als auch die Verve, mit der die Städte in der Münzprägung ihren Status zu demonstrieren und ihr Prestige zu steigern suchten, deutlich unterschiedlich war. Es würde aber den Rahmen dieses Beitrags sprengen, wollte man hier ins Detail gehen. Vgl. zu den Themenbereichen ,Münzprägung und Selbstvergewisserung, Selbstdarstellung, Identität' die Lit. oben Anm. 11.

148) Lediglich Neokaisareia gab in der frühesten bekannten Emission - einer ,pseudoautonomen“ Prägung -, das Jahr auf der Vorderseite an (Çizmeli 2006 Nr. 1-2). Zu den städtischen Ären vgl. Tabelle 2.

149) In der weiteren Region taten dies auch Abonouteichos und - in der Kaiserzeit anders als noch in republikanischer Zeit - Amastris.

150) In der weiteren Region verzichteten auch Amisos (Rec. 76 Nr. 67, 67a; 77 Nr. 67b-c, 68f.; 86 Nr. 110; 92 Nr. 130c, 130 e; 95 Nr. 144-145, 145a; 97 Nr. 149, 149a-d, 150-151, 151a; 98 Nr. 152-153, 153a, 154, 154a-d; 99 Nr. 155-156; RPC-online temp. no. 5330) und Germanikopolis (Bricault, Delrieux 2014: GG/60-110) und auch die Colonia Iulia Felix (Rec. 208 Nr. 73a; 205* Nr. 98; 201** Nr. 114a-b; 203** Nr. 124; $205^{* *}$ Nr. 134-135; $206^{* *}$ Nr. 135b, 140-141; 207** Nr. 142; RPC I 2107, 2140, 2142; RPC-online temp. no. 4938, 5481, 9579, 9679) teilweise darauf, das Jahr der Prägung anzugeben. Zumindest im Fall von Germanikopolis ist der Anteil der undatierten Münzen erheblich (vgl. Bricault, Delrieux 2014: 51-54, 68).

151) Dalaison, Delrieux 2014 Nr. 35-36.

152) Dalaison 2008 Nr. 1-4.

153) T. Helvius Basila. Dies geschah in der Form غ̇лì + Name im Genitiv, stellte also auch eine Datierung dar (>in der Zeit des Basila<; die Statthalterschaft des T. Helvius Basila ist in die Zeit des Augustus, des Caligula oder - wahrscheinlicher - in die des Tiberius zu datieren: Dalaison 2008: 24). Derartige Erwähnungen von Statthaltern finden sich erneut in traianischer Zeit auf Münzen von Sebasteia (L. Catilius Severus Iulianus Claudius Reginus [PIR ${ }^{2}$ C 558]: Schulz 1989 Nr. 1; Weiser 1998: 283), Sebastopolis (P. Calvisius Ruso Iulius Frontinus [PIR² C 350]: Amandry, Rémy 1998 Nr. 1) und Neokaisareia (Q. Orfitasius Aufidius Umber [PIR² A 1395]: Çizmeli 2006 Nr. 3-6 [das Cognomen OYMBEPOC wurde von Çizmeli irrtümlich zu OYMEPOC verkürzt]), freilich ohne daß in diesen Fällen auf die Datierung nach der städtischen Ära verzichtet worden wäre. Zur viel diskutierten Frage, weshalb Statthalter auf Münzen genannt wurden, vgl. etwa RPC I: 2f.; RPC II: 3; Weiß 2005: 60f. 
Weshalb Pompeiopolis generell auf die Datierung ihrer Münzen verzichtete, muß dagegen - soweit ich sehe - offen bleiben. ${ }^{154}$

\section{THEMENKREISE DER REVERSDARSTELLUNGEN, BILDMOTIVE}

Die Rückseitendarstellungen der Münzen der ,innerpontischen' Städte können so gut wie ausnahmslos drei Themenkreisen zugeordnet werden: (1) ,Götter, Kult und Mythos', (2) ,Kaiser und Militärisches', (3) ,die Stadt selbst'. Münzbilder, die dem ersten Themenkreis zuzuorden sind, zeigen Gotthei- ten, ${ }^{155}$ Szenen des Göttermythos, ${ }^{156}$ mit Gottheiten und Kulten in Verbindung stehende Gegenstände und Tiere, ${ }^{157}$ Tempel (zuweilen samt Kultbild) und Altäre. ${ }^{158}$ Münzbilder, die dem zweiten Themenkreis zuzuorden sind, zeigen etwa den genius Augustorum, ${ }^{159}$ den Kaiser bei einer Libation, zu Pferd oder in einer Quadriga, wie er von Tyche bekränzt wird oder wie er dem Mitregenten oder dem Caesar die Hand reicht, ${ }^{160}$ außerdem signa militaria. ${ }^{161}$ Münzbilder, die dem dritten Themenkreis zuzuorden sind, spielen etwa auf die natürliche Umgebung der Stadt ${ }^{162}$ oder ihr Erscheinungsbild an. ${ }^{163}$ Selbstredend sind diese Themenkreise nicht streng voneinander getrennt, sondern überschneiden

154) Vermuten kann man allenfalls, daß das Vorbild der Nachbarstädte Amastris und Abonouteichos eine gewisse Rolle gespielt haben könnte. Angesichts der grundsätzlichen Bedeutung, die Ären für das Selbstverständnis und die Selbstdarstellung von vielen Städten hatten (vgl. dazu Leschhorn 1993, 2: 428-432), speziell auch angesichs der Tatsache, daß die Städte der östlich an Pompeiopolis anschließenden Region ihre Münzen, anders als Amastris und Abonouteichos, nach der jeweiligen städtischen Ära datierten und auch die südliche Nachbarstadt Germanikopolis dies in severischer Zeit grundsätzlich tun würde, schließlich auch angesichts der Tatsache, daß in Pompeiopolis die Nutzung der städtischen Ära in öffentlichen wie in privaten Inschriften durchaus üblich war (vgl. Marek 1993: 130f.), hat es sich aber sicherlich um eine bewußt getroffene Entscheidung der polis gehandelt.

155) Vgl. dazu auch unten Abschnitt 7

156) So Europe auf dem Stier (Amaseia: Dalaison 2008 Nr. 583, 604 mit S. 167), Aphrodite und Ares (Amaseia: Dalaison 2008 Nr. 67-69, 82-85, 102, 127-129 mit S. 163), Aphrodite mit dem goldenen Apfel (Neoklaudiopolis: Dalaison, Delrieux 2014 Nr. 37 mit S. 189), Taten des Herakles (Sebastopolis: Amandry, Rémy 1998 Nr. 7, 26, 34, 60-64 [nemeischer Löwe]; 15, 30 [erymanthischer Eber]; 16, 71-72 [kerynithische Hirschkuh]; 17 [kretischer Stier]; 22 [lernäische Hydra]; 33 [Äpfel der Hesperiden]; 46 [Kerberos]), Telephos, Sohn des Herakles, der von der Hirschkuh gesäugt wird (Sebastopolis: Amandry, Rémy 1998 Nr. 45, 57). Vgl. auch dazu unten Abschnitt 7.

157) Siegeskronen von Agonen, die im Rahmen des Kaiserkults stattfanden (Neokaisareia: Çizmeli 2006 Nr. 250, 253-254, 258, 264-267, 269-272, 275-282, 286, 288, 290-298, 301-305, 307, 309-315, 319-348, 350-354, 356-368, 372-373, 411-418, 424-430, 433441, 445-446, 448-454, 459-471, 473-477, 479-480, 482, 484-488, 490-495 mit S. 120-122). - Die mit Asklepios verbundene Schlange (Amaseia: Dalaison 2008 Nr. 20-22, 52, 64, 418; Neokaisareia: Çizmeli 2006 Nr. 6; Neoklaudiopolis: Dalaison, Delrieux 2014 Nr. 35 ; Nikopolis: Dalaison 2007 Nr. 23-24; Zela: Dalaison, Rémy, Amandry 2009 Nr. 4). Sie ist zumindest im Fall von Zela freilich wohl

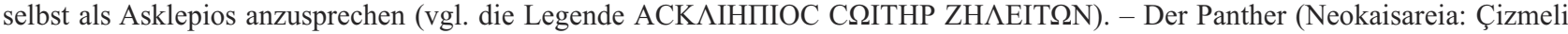
2006 Nr. 371) und die aus einer cista herauskriechende Schlange des Dionysos (Amaseia: Dalaison 2008 Nr. 608). - Die Keule bzw. die Keule und das Löwenfell des Herakles (Sebastopolis: Amandry, Rémy 1998 Nr. 23 bzw. Nr. 2-4). - Die Keule, der baitylos und der Adler der Ma (Komana: Amandry, Rémy 1999 Nr. 1-2, 8-13 bzw. 21 bzw. 22-23). - Der Adler des Zeus Nikephoros (Amaseia: Dalaison 2008 Nr. 66, 238-239, 361-364, 548 mit S. 171). Der zwischen Feldzeichen auf einer Basis sitzende und einen Kranz im Schnabel haltende Adler auf Münzen von Neoklaudiopolis (Dalaison, Delrieux 2014 Nr. 24-27, 32) weist sicherlich ebenfalls auf den siegbringenden Iuppiter bzw. Zeus. - Die aus drei Ähren bestehende Garbe auf Münzen von Zela (Dalaison, Rémy, Amandry 2009 Nr. 127-128) dürfte Anaïtis (so Dalaison, Rémy 2013: 35) oder Zeus Epikarpios zuzuordnen sein: Beide Gottheiten werden auf Münzen der Stadt mit diesem Attribut dargestellt (vgl. etwa Dalaison, Rémy, Amandry 2009: planche 1 Nr. 1a bzw. planche 5 Nr. $57 \mathrm{c}$ ).

158) Tempel: Amaseia (Dalaison 2008 Nr. 25-38, 346, 413), Komana (Amandry, Rémy 1999 Nr. 14-16, 19-20, 24-59, 61-63), Neokaisareia (Çizmeli 2006 Nr. 21-50, 54-111, 113-210, 212-214, 217-243, 245-248, 251-252, 255-257, 259-263, 268, 273-274, 283-285, 287, 289, 306, 308, 316-318, 349, 369-370, 421, 455), Neoklaudiopolis (Dalaison, Delrieux 2014 Nr. 28, 34, 36; http://www.aeruginis.de/aeruginis/Sammlung/ Detail.php?page=889), Sebastopolis (Amandry, Rémy 1998 Nr. 8-13, 19-21, 27-28, 3543, 48-55, 65-67), Zela (Dalaison, Rémy, Amandry 2009 Nr. 9-16, 18-31, 33-43, 65-103, 106-107, 109-125, 130-131, 133-137). Altäre: Amaseia (Dalaison 2008 Nr. 23-24, 50-51, 59-63, 65, 158-162, 240-272, 291-296, 301-306, 365-412, 506-530, 533-534, 536, 549-560, 566-579, 584-586, 609-652, vgl. auch Nr. 580), Zela (Dalaison, Rémy, Amandry 2009 Nr. 104-105). Vgl. dazu Sauer 2014: 114-118 (auch zur weiteren Region).

159) Vgl. oben Anm. 89.

160) Bei einer Libation: Amaseia (Dalaison 2008 Nr. 282, 464-472); zu Pferd: Amaseia (Dalaison 2008 Nr. 154-157, 230-232, 360, 547), Neokaisareia (Çizmeli 2006 Nr. 481), Zela (Dalaison, Rémy, Amandry 2009 Nr. 129); in einer Quadriga: Zela (Dalaison, Rémy, Amandry 2009 Nr. 7-8, 17, 60-64); von Tyche bekränzt: Neoklaudiopolis (Dalaison, Delrieux 2014 Nr. 6f.); dem Mitregenten oder dem Caesar die Hand reichend: Amaseia (Dalaison 2008 Nr. 70-79, 86-93, 95-97, 103-121, 130-151, 233-237, 283-290, 473-505). Vgl. Sauer 2014: 120

161) Auf Münzen von Neoklaudiopolis: Dalaison, Delrieux 2014 Nr. 24-27, 32. Vgl. Sauer 2014: 121.

162) So zeigen Münzen von Amaseia den Fluß Iris in Gestalt eines anthropomorphen Flußgottes (Dalaison 2008 Nr. 100, 355); auf Münzen von Neokaisareia begleitet der personifizierte Fluß Lykos die Tyche der Stadt (Çizmeli 2006 Nr. 51). Vgl. Sauer 2014: 111114.

163) Meist durch die Darstellung sakraler Gebäude (vgl. oben zu, Tempel und Altäre`); Amaseia präsentiert auf einigen ihrer Münzen aber auch die Ansicht der Stadt insgesamt (Dalaison 2008 Nr. 16-19, 580-582, 587). Vgl. ausführlicher Sauer 2014: 114-118. 
Tabelle 9 : Zahl der Rückseitenstempel, die dem ersten Themenkreis zugeordnet werden können.

(1) In persona, nicht aber als Figur des Mythos; Kultbild, sei es isoliert oder in einer aedicula o.ä. stehend, nicht aber in einem Tempel oder in einer zwei Tempel verbindenden Arkade.

(2) Vgl. dazu oben Anm. 157

(3) Von zwei Ausnahmen abgesehen, zeigen alle diese Stempel Siegeskronen.

(4) Sei es mit oder ohne Kultbild.

(5) In allen Fällen Zeus Stratios repräsentierend.

\begin{tabular}{|c|c|c|c|c|c|}
\hline & Götter ${ }^{(1)}$ & $\begin{array}{c}\text { mit Göttern oder Kulten in Verbin- } \\
\text { dung stehende Gegenstände oder } \\
\text { Tiere }^{(2)}\end{array}$ & Tempel $^{(4)}$ & Altäre & Göttermythos \\
\hline Pompeiopolis & 14 & & & & \\
\hline Sebasteia & 3 & & & & \\
\hline Nikopolis & 24 & 2 & & & \\
\hline Amaseia & 196 & 13 & 10 & $166^{(5)}$ & 10 \\
\hline Komana & 7 & 11 & 34 & & \\
\hline Neoklaudiopolis & 23 & 6 & 4 & & 1 \\
\hline Neokaisareia & 57 & $115^{(3)}$ & 190 & & \\
\hline Sebastopolis & 14 & 4 & 28 & & 14 \\
\hline Zela & 19 & 3 & 63 & 2 & \\
\hline
\end{tabular}

sich partiell. ${ }^{164}$ Der Themenkreis ,Götter, Kult und Mythos' ist in der Münzprägung aller, innerpontischen' Städte mit Abstand am populärsten. Komana, Pompeiopolis, Nikopolis und Sebastopolis beschränken sich gar völlig auf Darstellungen aus diesem Bereich. ${ }^{165}$

Die thematische Vielfalt innerhalb der Themenkreise variiert von Stadt zu Stadt erheblich. Besonders deutlich wird dies am Beispiel des ersten Themenkreises. ${ }^{166}$ So finden sich auf den Münzen von Pompeiopolis und Sebasteia lediglich Götterdarstellungen; auf Münzen von Nikopolis kommt immerhin die Schlange des Asklepios hinzu. Auf den Münzen von Amaseia, Komana, Neokaisareia, Neoklaudiopolis, Sebastopolis und Zela werden dagegen neben Göttern und mit ihnen bzw. ihrem Kult in Verbindung stehenden Gegenständen oder Tieren auch Tempel gezeigt, auf Münzen von Amaseia und Zela zudem Altäre. Im Fall von Amaseia, Neoklaudiopo- lis und Sebastopolis kommen schließlich noch Szenen des Göttermythos hinzu.

Dabei variiert von Stadt zu Stadt insbesondere, welches Gewicht man der Darstellung von Göttern, der Darstellung besagter Gegenstände und der Darstellung von Tempeln oder Altären gab. So sind in der Münzprägung von Neoklaudiopolis und Nikopolis und - selbstredend - in derjenigen von Pompeiopolis und Sebasteia Götterdarstellungen am häufigsten. Dies gilt auch für die Münzprägung von Amaseia, wobei hier jedoch die Darstellung von Altären - es handelt sich ausnahmslos um Altäre des Zeus Stratios - fast ebenso häufig ist. In den Prägungen von Komana und Zela, und auch von Neokaisareia und Sebastopolis sind dagegen Tempeldarstellungen am häufigsten. In Neokaisareia hat freilich insbesondere auch die Darstellung der Siegeskronen, die bei Agonen verliehen wurden, die im Rahmen des Kaiserkults stattfanden, großes Gewicht. Und in Seba-

164) Beispielsweise überschneiden sich der erste und der zweite Themenkreis bei der Darstellung von Siegesgöttern. Im Fall von Nikopolis dürfte die Darstellung von Nike und Zeus Nikephoros zudem dem dritten Themenkreis zuzuordenen sein, handelt es sich hier doch mit einiger Wahrscheinlichkeit auch um eine Anspielung auf die Geschichte und den Namen der Stadt (24 der 27 bekannten Rückseitenstempel zeigen eine dieser beiden Gottheiten). Bei der Darstellung der Tyche der Stadt, bei der Darstellung von Flußgöttern und bei der Darstellung von Tempeln überschneiden sich der erste und dritte Themenkreis, da es hier nicht nur um ,Kult', sondern auch um die Personifizierung, um die natürliche Umgebung oder um das Erscheinungsbild der Stadt geht. Handelt es sich um Tempel, die mit dem Kaiserkult in Verbindung stehen, kommt hier zudem der zweite Themenkreis ins Spiel.

165) Die Prägung von Pompeiopolis, die aller Wahrscheinlichkeit nach als Medaillon anzusprechen ist, weicht - man ist geneigt zu sagen: bezeichnenderweise - von diesem Muster ab; vgl. dazu oben S. 172. - Auch in der Münzprägung sämtlicher Städte der weiteren Region ist der erste Themenkreis mit Abstand am häufigsten vertreten; hier beschränken sich Abonouteichos und Trapezous ganz auf ihn.

166) Vgl. hierzu auch Tabelle 9 und unten Abschnitt 7. 
stopolis würde die Darstellung von Göttern - es handelt sich fast ausnahmslos um Herakles - mit der Darstellung von Tempeln gleichauf liegen, würde man die Darstellungen mythischer Szenen - es handelt es sich fast ausnahmslos um die Darstellung der Taten des Herakles - zu den Götterdarstellungen zählen. ${ }^{167}$

Die meisten Motive, mit denen die ,innerpontischen' Städte die Rückseiten ihrer Münzen gestalteten, begegnen auch in der Reichsprägung und in Prägungen anderer Städte. In einigen Fällen entwickelte man aber auch eigenständige Münzbilder. Dies gilt natürlich für Münzbilder, die Dinge zeigen, die bereits an sich einzigartig gewesen sind, wie etwa die Stadtansicht von Amaseia oder der Altar des Zeus Stratios. Untersuchungen von Julie Dalaison und Fabrice Delrieux machen es jedoch wahrscheinlich, daß dies in einigen, wenn auch wenigen Fällen auch für Münzbilder gilt, deren Singularität nicht auf die Einzigartigkeit des Dargestellten zurückgeführt werden kann: ${ }^{168}$ So ist für die Büste des Asklepios und für Europe auf dem Stier auf Münzen von Amaseia, für den Schild mit der Aufschrift $\triangle \mathrm{AKIKOC}$ vor gekreuzten Lanzen und für die den Kaiser bekränzende Tyche auf Münzen von Neoklaudiopolis, außerdem für die beiden Kaiser, die gemeinsam einen Feind niederwerfen auf dem Medaillon von Pompeiopolis, keine direkte Parallele nachgewiesen. ${ }^{169}$ Entsprechendes gilt auch für die Göttin Ma und ihren baitylos auf Münzen von Komana. ${ }^{170}$

\section{DIE PANTHEA DER MÜNZEN}

Bei den Göttern, auf welche die Münzprägung der ,innerpontischen' Städte Bezug nimmt, herrschen Gottheiten vor, die in der griechisch-römischen Vorstellungswelt der Kaiserzeit geradezu Gemeingut und deren Kult in aller Regel weit verbreitet war: ${ }^{171}$ Aphrodite, ${ }^{172}$ Apollon, ${ }^{173}$ Asklepios, ${ }^{174}$ Athena, ${ }^{175}$ Demeter, ${ }^{176}$ Dionysos, ${ }^{177}$ die Dioskuren, ${ }^{178}$ Helios, ${ }^{179}$ Herakles, ${ }^{180}$ Hygieia, ${ }^{181}$ Kybele, ${ }^{182}$ Nemesis, ${ }^{183}$ Nike, ${ }^{184}$

167) Vgl. zu der Differenzierung Götterdarstellungen aus der kultischen bzw. aus der mythischen Sphäre auch unten S. 198.

168) Julie Dalaison und Fabrice Delrieux vergleichen jeweils mit der Reichsprägung und mit der Prägung anderer Städte der Umgebung. Städtische Prägungen anderer Regionen nicht in den Vergleich mit einzubeziehen, ist angesichts des in der Regel räumlich recht beschränkten Münzumlaufs städtischer Prägungen (vgl. dazu oben S. 179f.) sicherlich gerechtfertigt, da es wenig wahrscheinlich ist, daß ein Motiv auf einer in einer weit entfernten Stadt geprägten Münze als Vorbild gedient haben könnte.

169) Büste des Asklepios: Dalaison 2008 Nr. 48 mit S. 164; Europe auf dem Stier: Dalaison 2008 Nr. 583, 604 mit S. 167; Schild vor gekreuzten Lanzen: Dalaison, Delrieux 2014 Nr. 1 mit S. 188; Tyche den Kaiser bekränzend: Dalaison, Delrieux 2014 Nr. $6 f$. mit S. 188 Anm. 121; Kaiser, die Feinde niederwerfen: Dalaison 2010 Nr. 15 und S. 69f.

170) Ma: Amandry, Rémy 1999 Nr. 1-2, 8-12 (Av.); 3-7, 14-18, 60(?) (Rv.). Baitylos: Amandry, Rémy 1999 Nr. 20-21, 24-41, 4558, 61-63. Die Münzen von Komana bieten überhaupt die einzigen von der Göttin bekannten Darstellungen auf Münzen (vgl. Dalaison, Rémy 2013: 36); zu den wenigen anderen Darstellungen der Göttin vgl. Nade Proeva, Ma, in: LIMC 6.1, 1992: 330f.; 6.2, 1992: 169f. Von Komana-Hierapolis in Kappadokien, dem ursprünglichen Kultzentrum der Göttin, sind, von RPC I Nr. 3661 (Av. Nero, Rv. Berg) abgesehen, keine Münzen bekannt (vgl. Robert 1964: 19). Von der römischen Göttin Bellona, mit der seit Sulla Ma identifiziert wurde, gibt es weder in der republikanischen noch in der kaiserzeitlichen römischen Münzprägung eine Darstellung, deren Identifizierung als Bellona bzw. Ma-Bellona unumstritten ist (vgl. José M. Blázquez, Bellona, in: LIMC 3.1, 1986: 92f.; 3.2, 1986: 71f.).

171) Vgl. auch Tabelle 10 Nr. 37)

172) Amaseia (zusammen mit Ares: Dalaison 2008 Nr. 67-69, 82-85, 102, 127-129); Neoklaudiopolis (Dalaison, Delrieux 2014

173) Amaseia (Dalaison 2008 Nr. 203-204, 308, 354).

174) Amaseia (Dalaison 2008 Nr. 48, 166-172, 414-417, 532, 535, 545; zusammen mit Hygieia: Nr. 565; Schlange: Nr. 20-22, 52, 64, 418; Schlange in Tempel: Nr. 413); Neokaisareia (Schlange: Çizmeli 2006 Nr. 6); Neoklaudiopolis (Dalaison, Delrieux 2014 Nr. 24, 14-16; Schlange: Nr. 35); Nikopolis (Schlange: Dalaison 2007 Nr. 23-24); Pompeiopolis (Dalaison 2010 Nr. 1); Zela (Schlange: Dalaison, Rémy, Amandry 2009 Nr. 4).

175) Athena: Amaseia (Dalaison 2008 Nr. 223-225, 347, 456, 543); Neokaisareia (Çizmeli 2006 Nr. 13, 15-20); Neoklaudiopolis (Dalaison, Delrieux 2014 Nr. 11-13). - Athena Nikephoros: Neoklaudiopolis (Dalaison, Delrieux 2014 Nr. 29); Neokaisareia (Çizmeli 2006 Nr. 14, 456). - Athena Promachos: Amaseia (Dalaison 2008 Nr. 42-45, 47); Neokaisareia (Çizmeli 2006 Nr. 4); Zela (Dalaison, Rémy, Amandry 2009 Nr. 45-49).

176) Neokaisareia (Çizmeli 2006 Nr. 379, 394); Pompeiopolis (Dalaison 2010 Nr. 5-7); Sebasteia (Schulz 1989 Nr. 4).

177) Amaseia (Dalaison 2008 Nr. 98-99, 605; Schlange aus cista: Nr. 608); Neokaisareia (Panther: Çizmeli 2006 Nr. 371 ); Pompeiopolis (Dalaison 2010 Nr. 8-11).

178) Neokaisareia (Çizmeli 2006 Nr. 8-12).

179) Zela (Dalaison, Rémy, Amandry 2009 Nr. 5, 50-52).

180) Neokaisareia (Çizmeli 2006 Nr. 423, 444, 457); Pompeiopolis (Dalaison 2010 Nr. 16); Sebastopolis (Amandry, Rémy 1998 Nr. 14, 18, 29, 58, 68-70; in aedicula: Nr. 5-6, 24-25, 47, 59; in Arkade, die zwei Tempel verbindet: Nr. 8-13, 27-28, 35-41, 48-54, 6567; Keule: Nr. 23; Keule und Löwenfell: Nr. 2-4; Taten: Nr. 7, 15-17, 22, 26, 30, 33-34, 46, 60-64, 71-72; Telephos: Nr. 45, 57).

181) Neoklaudiopolis (Dalaison, Delrieux 2014 Nr. 33).

182) Pompeiopolis (Dalaison 2010 Nr. 4).

183) Pompeiopolis (Dalaison 2010 Nr. 14).

184) Amaseia (Dalaison 2008 Nr. 101, 226-227, 348-353, 544); Neoklaudiopolis (Dalaison, Delrieux 2014 Nr. 8, 30); Nikopolis (Dalaison 2007 Nr. 12-22); Sebasteia (Schulz 1989 Nr. 5). 
Tabelle 10 : Zahl der Stempel mit explizitem Bezug auf eine Gottheit - sei es, daß die Gottheit selbst dargestellt ist, ein mit ihr verbundener Gegenstand, ein entsprechendes Tier, ein erkennbar ihr zugeordneter Tempel o.ä. (Der Kaiser bleibt in dieser Tabelle jedoch unberücksichtigt; vgl. dazu unten Anm. 204).

(1) Iris auf Münzen von Amaseia, Lykos - die Tyche begleitend - auf Münzen von Neokaisareia.

(2) Amaseia: Dalaison 2008 Nr. 228 mit S. 163 (vielleicht Hera); Neoklaudiopolis: Dalaison, Delrieux 2014 Nr. 28 (Artemis Ephesia oder Anaïtis; vgl. dazu unten Anm. 191), 31 mit S. 190 (vielleicht Demeter); Pompeiopolis: Dalaison 2010 Nr. 2 mit S. 68 (vielleicht Demeter oder Hera).

(3) In Gestalt des Stiers, der Europe entführt.

(4) Repräsentiert durch seinen Altar.

(5) Davon sind vier Avers-Stempel ,pseudoautonomer‘ Münzen (Çizmeli 2006 Nr. 1-2, 8-12).

(6) Vgl. aber Çizmeli 2006: 127f. zu der Schwierigkeit Athena und Roma bzw. Athena Nikephoros und Roma Nikephoros vonein ander zu unterscheiden, wenn die Göttin nicht durch eine Legende identifiziert ist. Hier werden nur die Münzbilder mit der

Beischrift PWMH Roma Nikephoros zugeordnet.

(7) Avers-Stempel ,pseudoautonomer‘ Münzen (Çizmeli 2006 Nr. 1).

(8) Avers-Stempel ,pseudoautonomer“ Münzen (Çizmeli 2006 Nr. 2: „,buste voilé“).

(9) Je nachdem, ob die Garbe Anaitis oder Zeus Epikarpios zuzuordnen ist (vgl. dazu oben Anm. 157).

\begin{tabular}{|c|c|c|c|c|c|c|c|c|c|}
\hline & Amaseia & Komana & $\begin{array}{c}\text { Neokai- } \\
\text { sareia }\end{array}$ & $\begin{array}{l}\text { Neoklau- } \\
\text { diopolis }\end{array}$ & $\begin{array}{l}\text { Niko- } \\
\text { polis }\end{array}$ & $\begin{array}{l}\text { Pompeio- } \\
\text { polis }\end{array}$ & $\begin{array}{l}\text { Sebas- } \\
\text { teia }\end{array}$ & $\begin{array}{l}\text { Sebasto- } \\
\text { polis }\end{array}$ & Zela \\
\hline Anaïtis & & & & & & & & & 7 od. $9^{(9)}$ \\
\hline Aphrodite & & & & 1 & & & & & \\
\hline mit Ares & 8 & & & & & & & & \\
\hline Apollon & 4 & & & & & & & & \\
\hline Asklepios & 18 & & 1 & 7 & 2 & 1 & & & 1 \\
\hline mit Hygieia & 1 & & & & & & & & \\
\hline Athena & 6 & & $5^{(6)}$ & 2 & & & & & \\
\hline Nikephoros & & & $2^{(6)}$ & 1 & & & & & \\
\hline Promachos & 4 & & 1 & & & & & & 4 \\
\hline Demeter & & & 1 & & & 2 & 1 & & \\
\hline Dionysos & 4 & & 1 & & & 4 & & & \\
\hline Dioskuren & & & 5 & & & & & & \\
\hline Flußgott $^{(1)}$ & 2 & & 1 & & & & & & \\
\hline Helios & & & & & & & & & 4 \\
\hline Herakles & & & 2 & & & 1 & & 51 & \\
\hline Hygieia & & & & 1 & & & & & \\
\hline Kybele & & & & & & 1 & & & \\
\hline $\mathrm{Ma}$ & & $54^{(5)}$ & & & & & & & \\
\hline Men Pharnakou & & & 3 & & & & & & \\
\hline Nemesis & & & & & & 1 & & & \\
\hline Nike & 9 & & & 2 & 11 & & 1 & & \\
\hline Roma Nikephoros & & & 25 & & & & & & \\
\hline Serapis & & & & 3 & & & & & \\
\hline Hades-Serapis & 14 & & & & & & & & \\
\hline Tyche der Stadt & 137 & & 18 & 5 & & 3 & & 3 & 2 \\
\hline ,Fortuna ‘ & & & & 2 & & & & & \\
\hline Zeus & $2^{(3)}$ & & $1^{(7)}$ & & & & 1 & & \\
\hline Epikarpios & & & & & & & & & 7 od. $9^{(9)}$ \\
\hline Nikephoros & 11 & & & 5 & 13 & & & & 1 \\
\hline Stratios & $167^{(4)}$ & & & & & & & & \\
\hline $\begin{array}{l}\text { Göttin, nicht sicher } \\
\text { bestimmbar }^{(2)}\end{array}$ & 1 & & $1^{(8)}$ & 2 & & 1 & & & \\
\hline
\end{tabular}


Roma Nikephoros, ${ }^{185}$ Serapis ${ }^{186}$ und Zeus, ${ }^{187}$ außerdem Flußgötter ${ }^{188}$ und Tyche ${ }^{189}$ - Tyche in aller Regel verstanden als Tyche der jeweiligen Stadt. ${ }^{190}$ Von diesen Gottheiten können Asklepios, Zeus (in verschiedenen Spielarten) und die Tychen als in der Münzprägung der ,innerpontischen' Städte insofern besonders verbreitet gelten, als sie auf den Münzen von jeweils sechs Städten in Erscheinung treten. Apollon, die Dioskuren, Helios, Kybele, Nemesis und Roma Nikephoros finden sich dagegen lediglich auf den Münzen jeweils einer, Aphrodite, Hygieia, Serapis (in zwei Spielarten) und auch Flußgötter auf den Münzen von jeweils nur zwei Städten. Demeter, Dionysos und Herakles, Athena (in verschiedenen Spielarten) und Nike rangieren insofern gleichsam im Mittelfeld als Demeter, Dionysos und Herakles in der Münzprägung von jeweils drei, Athena und Nike in der Münzprägung von jeweils vier Städten präsent sind.

Neben diesen in der griechisch-römischen Welt allgemein üblichen Gottheiten nimmt die Münzprägung einiger ,innerpontischer' Städte jedoch auch auf speziellere Gottheiten iranischen und anatolischen Ursprungs Bezug, deren Kult, wenn auch nicht ausschließlich, so doch ganz wesentlich von mehr oder minder ausgedehnter regionaler Bedeutung gewesen ist. Dabei handelt es sich um Anaïtis, Ma, Men Pharnakou und Zeus Stratios. Anaïtis ist auf Münzen von Zela, ${ }^{191}$ Ma auf Münzen von Komana, ${ }^{192}$ Men Pharnakou auf Münzen von Neokaisareia $^{193}$ und Zeus Stratios auf Münzen von Amaseia, ${ }^{194}$ und damit in der Münzprägung genau der Städte präsent, auf deren Territorium einer der bedeutendsten Kultorte der jeweiligen Gottheit lag. ${ }^{195}$

Meist sind die Gottheiten in persona dargestellt ${ }^{196}$ oder sie sind gleichsam aus der kultischen Sphäre genommen - sei es, daß ihr Kultbild, ihr Altar oder Tempel abgebildet wird. Daß sie in der Rolle gezeigt werden, die sie im Mythos spielen, begegnet dagegen - sieht man von der Darstellung der Taten des Herakles in der Münzprägung von Sebastopolis $\mathrm{ab}^{197}$ - nur höchst selten. ${ }^{198}$

185) Neokaisareia (Çizmeli 2006 Nr. 375-376, 381-391, 395-401, 404-410).

186) Amaseia (Hades-Serapis: Dalaison 2008 Nr. 49, 53-58, 457-462, 606-607; Hades-Serapis in Arkade: Nr. 281, 463); Neoklaudiopolis (Dalaison, Delrieux 2014 Nr. 17, 21-22).

187) Zeus: Amaseia (in Gestalt des Stiers der Europe entführt: Dalaison 2008 Nr. 583, 604); Sebasteia (Schulz 1989 Nr. 2-3; RPConline temp. nr. 5454). - Zeus Epikarpios: Zela (Dalaison, Rémy, Amandry 2009 Nr. 3, 6, 32, 53-58, 108, 132; möglicherweise auch Nr. 127-128 [Garbe; vgl. dazu oben Anm. 157]). - Zeus Nikephoros: Amaseia (Dalaison 2008 Nr. 39-41, 229, 356, 546); Neoklaudiopolis (Adler: Dalaison, Delrieux 2014 Nr. 24-27, 32); Nikopolis (Dalaison 2007 Nr. 10-11, 32-42); Zela (Dalaison, Rémy, Amandry 2009 Nr. 59).

188) Zu den Flußgöttern auf Münzen von Amaseia und Neokaisareia vgl. oben Anm. 162.

189) Amaseia (Dalaison 2008 Nr. 1-15, 80-81, 94, 122-126, 152-153, 163-165, 173-202, 205-222, 273-280, 297-300, 307, 309345, 419-455, 537-541, 561-564, 588-603; in Tempel: Nr. 346; in Arkade: 542); Neokaisareia (Çizmeli 2006 Nr. 7, 299-300, 355, 374, 377-378, 393, 419-420, 442; in Nymphaeum: Nr. 244; in Arkade: Nr. 249; umgeben von fünf anderen Tychen: Nr. 51-53, 215-216; mit Men und wohl dem Kaiser: Nr. 211); Neoklaudiopolis (Dalaison, Delrieux 2014 Nr. 5, 9-10, 19-20); Pompeiopolis (Dalaison 2010 Nr. 3, 12-13); Sebastopolis (Amandry, Rémy 1998 Nr. 31-32, 44, 56); Zela (in Tempel: Dalaison, Rémy, Amandry 2009 Nr. 29, 75-76, 131, 135).

190) Auf zwei Stempeln von Neoklaudiopolis, die zeigen, wie Tyche den Kaiser bekränzt, ist Tyche allerdings als Äquivalent der römischen Fortuna zu verstehen (Dalaison, Delrieux 2014 Nr. 6-7 mit S. 188f.).

191) Dalaison, Rémy, Amandry 2009 Nr. 1-2, 44. Mit der Darstellung eines auf Felsen stehenden Altars (Nr. 104-105) und eines auf Felsen stehenden Tempels (Nr. 106-107) sind sicherlich Altar und Tempel der Anaïtis gemeint (vgl. Strab. 11,8,4). Die auf zwei Stempeln abgebildete Garbe ist möglicherweise als Attribut dieser Gottheit zu verstehen (Nr. 127-128; vgl. dazu oben Anm. 157). - Zu überlegen ist, ob es sich außerdem auch bei einer in einem Tempel stehend dargestellten Gottheit auf Münzen von Neoklaudiopolis (Dalaison, Delrieux 2014 Nr. 28) um Anaïtis handelt: vgl. die Variante der stehenden Anaïtis auf Münzen von Zela (Dalaison, Rémy, Amandry 2009 Nr. 44) unten Abb. 8. Dalaison, Delrieux 2014: 190 favorisieren zwar die Identifizierung als Artemis Ephesia, geben aber zu bedenken, daß es sich auch um eine ander Göttin „représentée sous la forme de la ,célèbre“ Artémis d'Éphèse“ handeln könnte (freilich ohne Anaïtis namentlich ins Spiel zu bringen). Zur ikonographischen Nähe von Anaïtis und Artemis Ephesia vgl. Fleischer 1973: bes. 185-187, 386-407.

192) Abgesehen von mit zwei Stempeln geschlagenen Münzen (Amandry, Rémy 1999 Nr. 19, 43-44, 59), die einen Tempel ohne Kultbild zeigen, beziehen sich alle Münzen von Komana explizit auf Ma.

193) Çizmeli 2006 Nr. 211 (mit Tyche und vermutlich dem Kaiser) und wohl auch Nr. 316-317, 370 (in Tempel); vgl. dazu Çizmeli 2006: 122-124.

194) Repräsentiert durch seinen Altar (vgl. die Referenzen oben Anm. 158); vgl. dazu Dalaison 2008: 174-177.

195) Vgl. zu diesen Gottheiten und ihren Kultstätten jüngst Dalaison, Rémy 2013: 34-39, $42-45$ (mit Lit.), zu Zeus Stratios außerdem Williamson 2014; Summerer 2014: 207-209.

196) Oder auch durch ein Attribut repräsentiert.

197) Vgl. dazu auch Sauer 2014: 123.

198) Vgl. oben Anm. 156. 

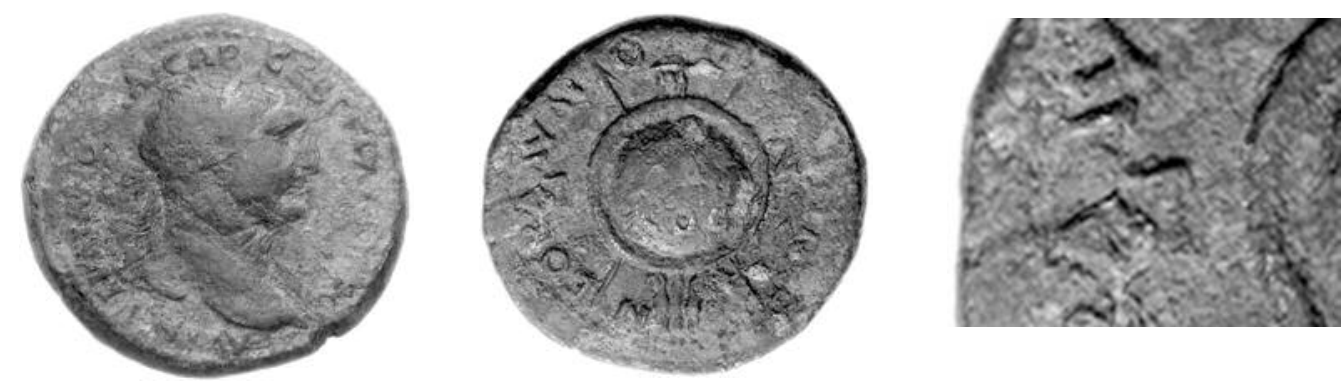

Abb. 6 : Traianos Dakikos.

Dalaison, Delrieux 2014 Nr. 1 (Photo: www.cngcoins.com/Coin.aspx?CoinID=101261).
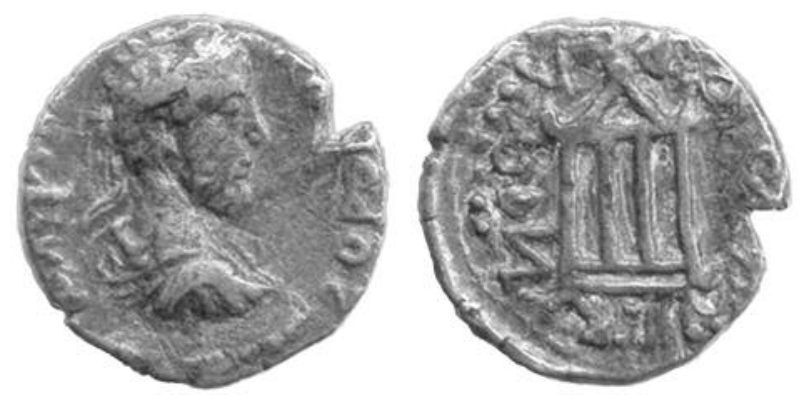

Abb. 7 : Eine weitere von Neoklaudiopolis geprägte Münze.

Diese Münze wurde auf der Website „Aeruginis - architectura in nummis“ mit diesem Photo und den Angaben 23mm, 8,58g, 7h publik gemacht (http://www.aeruginis.de/aeruginis/Sammlung/

Detail.php?page=889; Lizenz: http://creativecommons.org/licenses/by-sa/3.0/de/legalcode; Hintergrund retuschiert). Sie ist ein zweites Exemplar zu der von Dalaison, Delrieux 2014 unter der Nummer 23 geführten. Die Ärenangabe ist auch hier nicht lesbar.
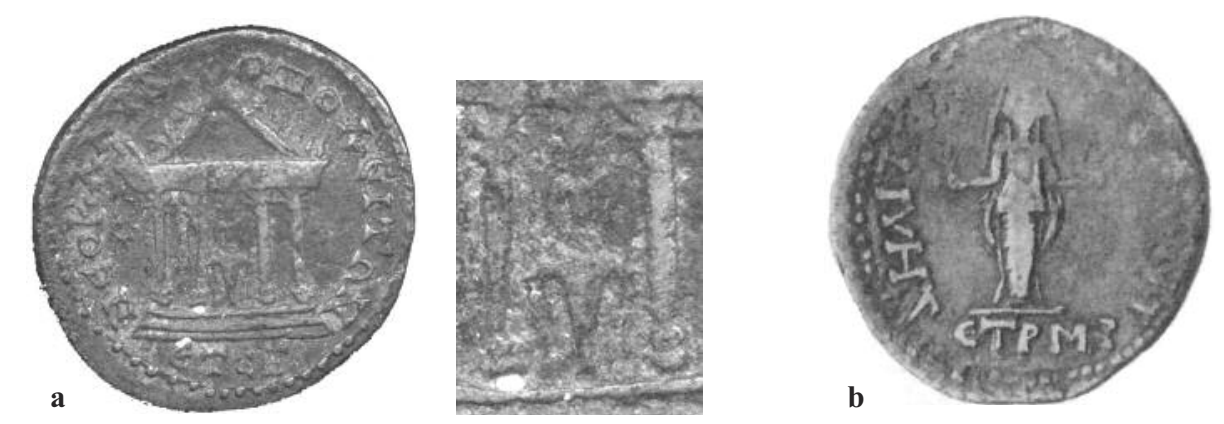

Abb. 8 : ,Artemis Ephesia' und Anaïtis.

a Göttin in Gestalt der Artemis Ephesia: Neoklaudiopolis; Dalaison, Delrieux 2014 Nr. 28b (Numismatic Collection of the National Museum, Prague, Czech Republic, Inv.-no. H5-250378; Photo: National Museum) b Anaïtis: Zela; Dalaison, Rémy, Amandry 2009 Nr. 44a, planche 4. 
In der Münzprägung der meisten Städte fand eine relativ große Zahl von Göttern Berücksichtigung. ${ }^{199}$ Nikopolis thematisierte dagegen nur drei, Sebastopolis lediglich zwei, Komana gar nur eine einzige Gottheit. Dabei zeigen die Prägung von Pompeiopolis und Sebasteia und auch diejenigen von Neoklaudiopolis und Zela keine besondere Präferenz für eine bestimmte Gottheit. ${ }^{200}$ Dagegen favorisieren neben Komana, deren Münzprägung vollständig auf Ma fokussiert ist, Sebastopolis, Nikopolis und Amaseia bestimmte Gottheiten ganz deutlich: Bei Sebastopolis ist es Herakles, ${ }^{201}$ bei Nikopolis Zeus Nikephoros und Nike, ${ }^{202}$ bei Amaseia Zeus Stratios und die Tyche der Stadt. Und in der Münzprägung von Neokaisareia ist die Zahl der Stempel, die Roma Nikephoros ${ }^{203}$ oder auch die Tyche der Stadt zeigen, deutlich größer als die Zahl der Stempel, die sich auf andere Gottheiten beziehen; sie wird ihrerseits aber bei weitem übertroffen von der Zahl der Stempel, die Motive zeigen, die mit dem Kaiserkult in Verbindung stehen, ${ }^{204}$ die sich also auf den Kaiser als Gottheit beziehen.

Auffallenderweise zählen die Gottheiten, die sich in der Prägung vieler Städte finden, in aller
Regel nicht zu den in den Prägungen dieser Städte prominentesten Gottheiten. ${ }^{205}$ Anders als Amaseia und, noch intensiver, Komana, rekurriert Neokaisareia kaum auf ihre spezielle Gottheit und auch Zela tut dies, jedenfalls in eindeutiger Weise, nur in mäßigem Umfang. Bezüge auf den Kaiserkult stellt lediglich Neokaisareia her, nicht jedoch die beiden anderen neokoroi Amaseia und Nikopolis. ${ }^{206}$ Insgesamt ist festzustellen, daß kein ,Münz-Pantheon“ einer Stadt dem einer anderen gleicht. ${ }^{207}$

\section{ABSCHLIESSENDE BEMERKUNGEN}

1. Die Prägungen der, innerpontischen' Städte erweisen sich als zugleich konventionell und individuell - so paradox dies zunächst klingen mag. Einerseits sind die Prägungen recht uniform und dabei eng an der reichsrömischen Münzprägung orientiert, andererseits hat die Prägung einer jeden Stadt individuelle Züge, die nicht etwa nur marginal sind. ${ }^{208}$

2. Beide Aspekte, derjenige der Konventionalität ebenso wie derjenige der Individualität, betreffen sowohl die eher formal-technische, als auch die thematisch-inhaltliche Seite der Münzprägung. Kon-

199) Vgl. erneut Tabelle 10. Zählt man bei den Götterpaaren Aphrodite/Ares und Asklepios/Hygieia jeweils beide Gottheiten und bei Tyche, Athena und Zeus jede Spielart der Gottheit, so begegnen auf den Münzen von Amaseia 16, auf den Münzen von Neokaisareia 14, auf den Münzen von Neoklaudiopolis zwölf, auf den Münzen von Pompeiopolis acht und auf den Münzen von Zela sieben Gottheiten. Gemessen an der geringen Zahl der aus der Münzprägung von Sebasteia bekannten Stempel, ist auch die Zahl von drei Gottheiten auf den Münzen dieser Stadt relativ groß. In der weiteren Region ist freilich der Kreis der in der Münzprägung bedachten Gottheiten zumindest im Fall von Germanikopolis, Amisos und Amastris deutlich umfangreicher.

200) Daß im Fall von Neoklaudiopolis Asklepios zwar nicht mit einer herausragenden, doch aber mit einer etwas größeren Stempelzahl vertreten ist, spiegelt sicherlich die relativ große Bedeutung, die dieser Gott hier aufgrund der Tatsache gehabt haben dürfte,

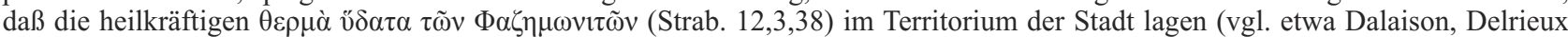
2014: 171f.). - Im Fall von Zela liegen Anaitis und Zeus Epikarpios sozusagen gleichauf. Angesichts der Prominenz, die der Tempel der Anaïtis zumindest bis in das 1. Jh. n.Chr. nachweislich hatte (zu den Quellen vgl. Dalaison, Rémy, Amandry 2009: 7-12), ist es zugegebenermaßen verführerisch, die Tempeldarstellungen, die sich auf einer Vielzahl von Stempeln finden (insgesamt 63 Stück), auf den Tempel dieser Göttin zu beziehen. Die Münzbilder bieten von der Ausnahme zweier Stempel abgesehen (vgl. dazu oben Anm. 191), jedoch keinen sicheren Anhaltspunkt für die Zuordnung - sei es zu Anaïtis, sei es zu Zeus Epikarpios, sei es zu einer anderen Gottheit (ähnlich zurückhaltend, wenngleich mit anderer Argumentation, Dalaison, Rémy, Amandry 2009: 11; anders aber jetzt Dalaison, Rémy 2013: 36).

201) Abgesehen von mit sechs Stempeln geschlagenen Münzen (Amandry, Rémy 1998 Nr. 19-21, 42-43, 55), die einen Tempel ohne Kultbild zeigen, beziehen sich insbesondere auch alle Münzen von Sebastopolis mit Tempeldarstellungen explizit auf Herakles: Sie zeigen eine Statue des Gottes in einer zwischen zwei Tempeln gelegenen Arkade. Die enge Verbindung der Stadt mit Herakles spiegelt sich auch in ihrer Benennung eindrucksvoll: Seit hadrianischer Zeit führte sie den Doppelnamen Sebastopolis-Herakleopolis (vgl. Amandry, Rémy 1998: 8).

202) Vgl. dazu oben Anm. 164

203) Sie stammen freilich allesamt aus einer einzigen Emission; vgl. dazu auch oben Anm. 89.

204) Dabei handelt es sich um die erwähnten Siegeskronen von Agonen, die im Rahmen des Kaiserkults stattfanden (113 Stempel) und um mit dem Kaiserkult in Verbindung stehende Tempel (188 Stempel). Daß beide Motive tatsächlich auf Aspekte des Kaiserkults weisen, zeigt Çizmeli 2006: 118-123.

205) Mit Ausnahme des Falls von Amaseia gilt dies bemerkenswerterweise auch für die Stadttychen. - Die relative Prominenz des Asklepios in der Prägung von Neoklaudiopolis stellt eine Ausnahme dar (vgl. dazu aber oben Anm. 200).

206) Anders als Nikopolis erwähnt Amaseia freilich in den Legenden ihrer Münzen die Neokorie. Vgl. dazu oben S. 192f.

207) Wenigstens in dieser Fußnote sei darauf hingewiesen, daß man vom Kreis der Gottheiten, auf welche die Münzprägung einer Stadt Bezug nimmt, nicht unbedingt auf das ,reale' Pantheon schließen kann, d.h. auf den Kreis der Götter, für die von oder zumindest in der betreffenden Stadt ein Kult eingerichtet war. Davor warnt etwa das Beispiel von Pompeiopolis und Sebastopolis: Nach Ausweis der Inschriften - zu Pompeiopolis vgl. Marek 2011: 190, zu Sebastopolis vgl. Amandry, Rémy 1998: 13f. - wurden in beiden Städten auch Gottheiten verehrt, die in der Münzprägung überhaupt nicht in Erscheinung treten. - Mit der Begriffsbildung ,Münz-Pantheon' operieren beispielsweise auch Dalaison, Rémy 2013 (panthéon, monetaire).

208) Dies gilt, soweit es sich bislang beurteilen läßt, ebenso für die Städte der weiteren Region. 
ventionell war etwa der Usus, Münzen zu prägen, an sich, der Usus, dies lediglich sporadisch zu tun, das Nominalsystem der assaria zu verwenden, in erster Linie für den Eigenbedarf der polis zu prägen, für die Legenden die griechische Schrift und Sprache zu nutzen, sich, was die Formensprache und den Stil der Münzbilder anbelangt, eng an die Usancen der reichsrömischen Prägung anzuschließen, sich namentlich als Prägeherr erkennen zu geben, die Münzen nach der städtischen Ära zu datieren, die städtischen Titel zu propagieren, auf der Vorderseite der Münzen Portraits des Kaisers und der Mitglieder seiner Familie zu zeigen, die Rückseitenmotive aus den Themenkreisen ,Götter, Kult und Mythos', ,Kaiser und Militärisches', ,die Stadt selbst' zu wählen und dabei dem erstgenannten Themenkreis den Vorzug zu geben. Individuell waren dagegen punktuelle Abweichungen von diesem Muster, außerdem der Zeitpunkt, zu dem die Städte die Münzprägung aufnahmen und schließlich auch wieder einstellten, grundsätzlich auch die jeweiligen eine Emission auslösenden Momente, die Gesamtzahl, die Frequenz und das Volumen der Emissionen, der Wandel von Buchstabenformen und Schreibweisen, der Umgang mit der kaiserlichen Titulatur, die Gewichtung der Präsenz des Kaisers, seiner Frau, des Mitregenten und des präsumptiven Nachfolgers auf den Vorderseiten der Münzen, bei der Gestaltung der Rückseiten der Grad der Vielfalt der Bilder, die Präferenz für bestimmte Bildthemen, der Umfang der Entwicklung eigenständiger Bildmotive, deren Inhalte und last but not least die Art und Weise und die Intensität der Propagierung städtischer Besonderheiten und des städtischen Prestiges in Bild und Legende.

3. Offenkundig nutzten die Städte die Münzprägung sowohl, um ihrer Identität als polis Ausdruck zu verleihen, als auch, um diese zu stärken - freilich ihre Identität als polis, die Teil des Römischen Reichs ist. Die individuellen Züge der Prägungen spiegeln gleichsam die innere Autonomie, welche die Städte - bis zu einem gewissen Grad - besaßen. Daß sie nie den ,Rahmen des Üblichen“ sprengten, daß die Individualität konventionell geblieben ist, geht damit einher, daß es, wie Julie Dalaison treffend betont, gerade diese Autonomie mit ihrer ,marge de manœuvre" gewesen ist, welche die poleis auf das Engste an die römische Herrschaft gebunden hat. ${ }^{209}$
4. So zahlreich die in der vorliegenden Untersuchung identifizierten individuellen Züge der Münzprägung der ,innerpontischen' Städte auch sind, ließen sich sicherlich weitere finden, würde man beispielsweise untersuchen, ob ein Zusammenhang zwischen Vorder- und Rückseitentypen besteht, ob der Rangunterschied der auf den Münzvorderseiten portraitierten Personen oder auch die Wahl bestimmter Rückseitenmotive zur Kenntlichmachung von Nominalen genutzt wurde, ${ }^{210}$ oder, ob Rückseitenmotive, die in der Prägung der jeweiligen Stadt durch viele Stempel vertreten sind, in allen Zeiten der Prägung auftreten oder aber gleichsam Modeerscheinungen gewesen sind.

5. Einige der hier vorgestellten Befunde sollten in die Diskussion eingebracht werden, die sich um die insbesondere von Konrad Kraft initiierte Vorstellung von Werkstätten der Stempel- bzw. Münzproduktion entwickelt hat, die mehrere Städte beliefert haben sollen. ${ }^{211}$ Was die ,innerpontischen' Städte anbelangt, ist der von Konrad Kraft abgesteckte Tätigkeitsbereich der Werkstatt „Amaseia“ von Interesse, der in der Zeit des Septimius Severus bestanden und die Städte Amaseia, Komana, Neokaisareia, Sebastopolis, Zela, Amisos, Germanikopolis und Amastris umfaßt haben soll. ${ }^{212}$ Während wohl nicht zu bezweifeln ist, daß in einem Fall Münzen von Neokaisareia und von Amastris, in einem anderen Fall Münzen von Neokaisareia und Komana mit demselben Vorderseitenstempel geschlagen worden sind, ${ }^{213}$ ist zu fragen, welche Konsequenzen es für die Vorstellung, die wir uns von der Arbeitsweise einer Werkstätte „Amaseia“ machen sollten, beispielsweise hat, daß nur Neokaisareia in ein und derselben Legende beide Vornamen angab, die Geta im Lauf der Zeit getragen hat, daß Komana, Neokaisareia und Zela KAICAP schreiben, wenn sich der Name bzw. Titel ,Caesar' auf Geta bezieht, Amaseia und Sebastopolis aber KECAP, daß das Omega in den Legenden der Münzen von Amaseia und Sebastopolis in der fraglichen Zeit die Form $\Omega$ hat, während Komana und Zela $\omega$ schreiben und sich in Neokaisareia beide Formen finden, daß Amaseia die Titel Augustus bzw. Augusta mit Sebastos bzw. Sebaste übersetzt, Komana, Neokaisareia, Sebastopolis und Zela diese dagegen lediglich transkribieren. ${ }^{214}$

210) Vgl. zu dieser Diskussion etwa Çizmeli 2006: 148f.; Dalaison 2008: 33f.

211) Vgl. dazu etwa auch Çizmeli 2006: 137-141; Dalaison 2008: 52-54; Bricault, Delrieux 2014: 81f. (jeweils mit Lit.).

212) Kraft 1972: $70 \mathrm{f}$.

213) Çizmeli 2006 Nr. 189-204 (Neokaisareia) und Rec. 179* Nr. 151 (Amastris) bzw. Çizmeli 2006 Nr. 21-24, 36-50 (Neokaisareia) und Amandry, Rémy 1999 Nr. 18 (Komana). Vgl. dazu Kraft 1972: 67; Çizmeli 2006: 138; Dalaison 2008: 52.

214) Vgl. dazu oben S. 180f., $189 f$. 
ANHANG 1

Prägevolumen Neokaisareia

\begin{tabular}{|c|c|c|c|c|c|c|c|c|c|}
\hline Zeit des Kaisers & Jahr & Nominal & $\mathrm{n}$ & $\mathrm{d}$ & IC & $\mathrm{D}$ & $\mathrm{s}$ & \multicolumn{2}{|c|}{ Assaria } \\
\hline \multirow[t]{2}{*}{ Domitian } & \multirow[t]{2}{*}{$92 / 3$} & A & 1 & 1 & 1 & - & - & 20.000 & \multirow[t]{2}{*}{30.000} \\
\hline & & $1 / 2 \mathrm{~A}$ & 1 & 1 & 1 & - & - & 10.000 & \\
\hline \multirow[t]{3}{*}{ Traian } & $100 / 1$ & $\mathrm{~T}$ & 2 & 1 & 2 & 1,6 & 2,0 & 160.000 & \multirow[t]{3}{*}{280.000} \\
\hline & \multirow[t]{2}{*}{$101 / 2$} & $\mathrm{~T}$ & 1 & 1 & 1 & - & - & 80.000 & \\
\hline & & $\mathrm{D}$ & 3 & 1 & 3 & 1,3 & 0,7 & 40.000 & \\
\hline M. Aurel, L. Verus & $161 / 2$ & $\mathrm{D}$ & 8 & 2 & 4 & 2,3 & 0,5 & 80.000 & 80.000 \\
\hline Commodus & $184 / 5$ & $\mathrm{D}$ & 13 & 4 & 3,25 & 4,9 & 0,9 & 200.000 & 200.000 \\
\hline \multirow[t]{3}{*}{ Septimius Severus } & $204 / 5$ & $\mathrm{~T}$ & 12 & 4 & 3 & 5,1 & 1,0 & 400.000 & \multirow[t]{3}{*}{4.360 .000} \\
\hline & \multirow[t]{2}{*}{$205 / 6$} & $\mathrm{~T}$ & 360 & 47 & 7,7 & 49,0 & 1,0 & 3.920 .000 & \\
\hline & & $\mathrm{A}$ & 2 & 1 & 2 & 1,6 & 2,0 & 40.000 & \\
\hline \multirow[t]{3}{*}{ Severus Alexander } & \multirow[t]{2}{*}{$226 / 7$} & $\mathrm{~T}$ & 40 & 7 & 5,7 & 7,6 & 0,5 & 640.000 & \multirow[t]{3}{*}{1.060 .000} \\
\hline & & A & 1 & 1 & 1 & - & - & 20.000 & \\
\hline & $234 / 5$ & $\mathrm{~T}$ & 76 & 5 & 15,2 & 4,9 & 0,1 & 400.000 & \\
\hline Gordian III. & $241 / 2$ & $\mathrm{~T}$ & 197 & 11 & 17,9 & 10,8 & 0,2 & 880.000 & 880.000 \\
\hline Philippus Arabs & $248 / 9$ & A & 8 & 4 & 2 & 6,5 & 2,4 & 140.000 & 140.000 \\
\hline $\begin{array}{l}\text { Trebonianus Gallus, } \\
\text { Volusianus }\end{array}$ & $251 / 2$ & $\mathrm{~T}$ & 79 & 5 & 15,8 & 4,9 & 0,1 & 400.000 & 400.000 \\
\hline Valerian, Gallienus & $255 / 6$ & $\mathrm{~T}$ & 85 & 3 & 28,3 & 2,9 & 0,1 & 240.000 & 240.000 \\
\hline \multirow[t]{4}{*}{ Gallienus } & $262 / 3$ & $\mathrm{~T}$ & 67 & 11 & 6,1 & 11,8 & 0,6 & 960.000 & \multirow[t]{4}{*}{2.400 .000} \\
\hline & $263 / 4$ & $\mathrm{~T}$ & 19 & 9 & 2,1 & 14,0 & 2,9 & 1.120 .000 & \\
\hline & $264 / 5$ & $\mathrm{~T}$ & 5 & 2 & 2,5 & 2,8 & 1,2 & 240.000 & \\
\hline & $265 / 6$ & $\mathrm{~T}$ & 7 & 1 & 7 & 1,1 & 0,2 & 80.000 & \\
\hline & & & & & & & & $\approx 629$ & $\begin{array}{l}10.070 .000 \\
375 \text { Denare }\end{array}$ \\
\hline
\end{tabular}

A: Assarion, D: Diassarion, T: Tetrassarion

$\mathrm{n}$ : Anzahl der in der Kalkulation berücksichtigten Münzen

$\mathrm{d}$ : Anzahl der verschiedenen Vorderseitenstempel, mit denen diese Münzen geprägt wurden

IC: Charakteroskopischer Index; $I C=\frac{n}{d}$

D: Ursprüngliche Zahl der Vorderseitenstempel; $D=\frac{n d}{1,214 n-1,197 d}$ falls $n<2 d ; D=\frac{n d}{1,124 n-1,016 d}$ falls $2 d \leq n \leq 3 d$;

$D=\frac{n d}{1,069 n-0,843 d}$ falls $n>3 d$

s: Standardabweichung für die errechnete ursprüngliche Zahl von Vorderseitenstempeln; $s=\frac{D \sqrt{D}}{n-1}$ 
ANHANG 2

Prägevolumen Kerasous

\begin{tabular}{|c|c|c|c|c|c|c|c|c|c|}
\hline Zeit des Kaisers & Jahr & Nominal & $\mathrm{n}$ & $\mathrm{d}$ & $\mathrm{IC}$ & $\mathrm{D}$ & $\mathrm{s}$ & \multicolumn{2}{|c|}{ Assaria } \\
\hline \multirow[t]{2}{*}{ Hadrian } & \multirow[t]{2}{*}{$137 / 8$} & $\mathrm{D}$ & 1 & 1 & 1 & - & - & 40.000 & \multirow[t]{2}{*}{60.000} \\
\hline & & A & 1 & 1 & 1 & - & - & 20.000 & \\
\hline \multirow[t]{7}{*}{ Antoninus Pius } & \multirow[t]{2}{*}{$(137) / 138$} & $\mathrm{~T}$ & 1 & 1 & 1 & - & - & 80.000 & \multirow[t]{7}{*}{300.000} \\
\hline & & A & 2 & 1 & 2 & 1,6 & 2,0 & 40.000 & \\
\hline & \multirow[t]{2}{*}{$141 / 2$} & $\mathrm{D}$ & 1 & 1 & 1 & - & - & 40.000 & \\
\hline & & $\mathrm{A}$ & 1 & 1 & 1 & - & - & 20.000 & \\
\hline & $144 / 5$ od. $147 / 8$ & A & 2 & 1 & 2 & 1,6 & 2,0 & 40.000 & \\
\hline & $145 / 6$ & $\mathrm{D}$ & 1 & 1 & 1 & - & - & 40.000 & \\
\hline & $151 / 2$ & $\mathrm{D}$ & 1 & 1 & 1 & - & - & 40.000 & \\
\hline \multirow[t]{2}{*}{ M. Aurel, L. Verus } & \multirow[t]{2}{*}{$161 / 2$} & $\mathrm{D}$ & 1 & 1 & 1 & - & - & 40.000 & \multirow[t]{2}{*}{60.000} \\
\hline & & A & 1 & 1 & 1 & - & - & 20.000 & \\
\hline \multirow[t]{3}{*}{ Commodus } & $184 / 5$ & A & 2 & 1 & 2 & 1,6 & 2,0 & 40.000 & \multirow[t]{3}{*}{200.000} \\
\hline & $186 / 7$ & $\mathrm{D}$ & 2 & 1 & 2 & 1,6 & 2,0 & 80.000 & \\
\hline & $?$ & $\mathrm{~T}$ & 1 & 1 & 1 & - & - & 80.000 & \\
\hline \multirow[t]{3}{*}{ Elagabal } & $218 / 9$ & $\mathrm{D}$ & 2 & 2 & 1 & - & - & 80.000 & \multirow[t]{3}{*}{900.000} \\
\hline & \multirow[t]{2}{*}{$219 / 20$} & $\mathrm{D}$ & 17 & 10 & 1,7 & 19,6 & 7,2 & 800.000 & \\
\hline & & A & 3 & 1 & 3 & 1,3 & 0,4 & 20.000 & \\
\hline Severus Alexander & $225 / 6$ & $\mathrm{D}$ & 13 & 1 & 13 & 1,0 & 0,1 & 40.000 & 40.000 \\
\hline & & & & & & & & $\approx 97$. & $\begin{array}{l}1.560 .000 \\
\text { Denare }^{(1)}\end{array}$ \\
\hline
\end{tabular}

D15 wurde in zwei Jahren verwendet; der Stempel wird hier doppelt gezählt.

(1) Bricault, Delrieux 2014: 69 haben einen leicht abweichenden Wert errechnet: 92.500 . 
ANHANG 3

Prägevolumen Trapezous

\begin{tabular}{|c|c|c|c|c|c|c|c|c|c|}
\hline Zeit des Kaisers & Jahr & Nominal & $\mathrm{n}$ & $\mathrm{d}$ & IC & $\mathrm{D}$ & $\mathrm{s}$ & \multicolumn{2}{|c|}{ Assaria } \\
\hline \multirow[t]{2}{*}{ Traian } & \multirow[t]{2}{*}{$113 / 4$} & $\mathrm{~T}$ & 6 & 3 & 2 & 4,9 & 2,2 & 400.000 & \multirow[t]{2}{*}{560.000} \\
\hline & & $\mathrm{A}$ & 17 & 6 & 2,8 & 7,8 & 1,4 & 160.000 & \\
\hline Antoninus Pius & $?$ & A & 1 & 1 & 1 & - & - & 20.000 & 20.000 \\
\hline \multirow[t]{3}{*}{ M. Aurel, L. Verus } & $161 / 2$ & $\mathrm{D}$ & 4 & 2 & 2 & 3,2 & 1,9 & 120.000 & \multirow[t]{3}{*}{280.000} \\
\hline & $163 / 4$ & A & 3 & 2 & 1,5 & 4,8 & 5,3 & 100.000 & \\
\hline & $?$ & A & 6 & 2 & 3 & 2,5 & 0,8 & 60.000 & \\
\hline \multirow[t]{2}{*}{ Commodus } & $183 / 4$ & $\mathrm{D}$ & 5 & 1 & 5 & 1,1 & 0,3 & 40.000 & \multirow[t]{2}{*}{240.000} \\
\hline & $188 / 9$ & $\mathrm{D}$ & 13 & 4 & 3,3 & 4,9 & 0,9 & 200.000 & \\
\hline \multirow[t]{4}{*}{ Septimius Severus } & $194 / 5$ & $\mathrm{~T}$ & 8 & 4 & 2 & 6,5 & 2,4 & 560.000 & \multirow[t]{4}{*}{920.000} \\
\hline & \multirow[t]{2}{*}{$198 / 9$} & $\mathrm{~T}$ & 2 & 1 & 2 & 1,6 & 2,0 & 160.000 & \\
\hline & & $\mathrm{D}$ & 4 & 1 & 4 & 1,2 & 0,4 & 40.000 & \\
\hline & $204 / 5$ & $\mathrm{~T}$ & 2 & 2 & 1 & - & - & 160.000 & \\
\hline Caracalla & $216 / 7$ & $\mathrm{~T}$ & 13 & 4 & 3,3 & 4,9 & 0,9 & 400.000 & 400.000 \\
\hline \multirow[t]{4}{*}{ Elagabal } & \multirow[t]{3}{*}{$218 / 9$} & $\mathrm{~T}$ & 13 & 5 & 2,6 & 6,8 & 1,5 & 560.000 & \multirow[t]{4}{*}{740.000} \\
\hline & & A & 3 & 1 & 3 & 1,3 & 0,7 & 20.000 & \\
\hline & & $\mathrm{D}$ & 2 & 1 & 2 & 1,6 & 2,0 & 80.000 & \\
\hline & $219 / 20$ & $\mathrm{D}$ & 16 & 2 & 8 & 2,1 & 0,2 & 80.000 & \\
\hline \multirow[t]{4}{*}{ Severus Alexander } & $224 / 5$ & $\mathrm{D}$ & 2 & 2 & 1 & - & - & 80.000 & \multirow[t]{4}{*}{980.000} \\
\hline & $225 / 6$ & $\mathrm{D}$ & 26 & 3 & 8,7 & 3,1 & 0,2 & 120.000 & \\
\hline & \multirow[t]{2}{*}{$226 / 7$} & $\mathrm{D}$ & 31 & 13 & 2,4 & 18,6 & 2,7 & 760.000 & \\
\hline & & $\mathrm{A}$ & 1 & 1 & 1 & - & - & 20.000 & \\
\hline \multirow[t]{3}{*}{ Gordian III. } & $238 / 9$ & $\mathrm{~T}$ & 20 & 2 & 10 & 2,0 & 0,1 & 160.000 & \multirow[t]{3}{*}{720.000} \\
\hline & $242 / 3$ & $\mathrm{~T}$ & 4 & 1 & 4 & 1,2 & 0,4 & 80.000 & \\
\hline & $243 / 4$ & $\mathrm{~T}$ & 22 & 5 & 4,4 & 5,7 & 0,6 & 480.000 & \\
\hline Philippus Arabs & $244 / 5$ & $\mathrm{~T}$ & 35 & 9 & 3,9 & 10,6 & 1,0 & 880.000 & 880.000 \\
\hline & & & & & & & & $\approx 358.7$ & $\begin{array}{r}5.740 .000 \\
\text { Denare }^{(1)}\end{array}$ \\
\hline
\end{tabular}

D64 wurde in zwei Jahren verwendet; der Stempel wird hier doppelt gezählt.

(1) Bricault, Delrieux 2014: 69 haben einen abweichenden Wert errechnet: 336.250. 


\section{ANHANG 4 \\ Dalaison, Delrieux 2014 Nr. 1}

Bislang wurde die Münze, die Dalaison, Delrieux 2014 in ihrem Corpus der Münzen von Neoklaudiopolis als Nr. 1 führen, anstandslos in das Jahr 107 der städtischen Ära und damit in das Jahr 101/2 n.Chr. datiert. ${ }^{215}$ Dankenswerterweise hat mich Herr Professor Ruprecht Ziegler darauf aufmerksam gemacht, daß diese Datierung höchst wahrscheinlich nicht aufrechterhalten werden kann. Zumindest gibt das von dieser Münze bekannte, recht qualitätvolle Photo (oben neuerlich als Abb. 6 abgedruckt) Anlaß zu erheblichen Zweifeln an der Lesung der Jahreszahl PZ im Feld der Rückseite. Tatsächlich ist hier kein Rho zu erkennen; viel eher handelt es sich um ein Iota. So dürfte die Rückseitenlegende nicht wie bislang gedacht als N-EOK $\Lambda$ AY $\Delta \mathrm{I}-\mathrm{O}-\Pi-[\mathrm{O} \Lambda \mathrm{EIT}]$ $\Omega \mathrm{N}$ mit $[\triangle \mathrm{AKI}] / \mathrm{KOC}$ auf dem Schild und $\mathrm{P}$ und $\mathrm{Z}$ links bzw. rechts neben dem Schild im Feld zu lesen sein,

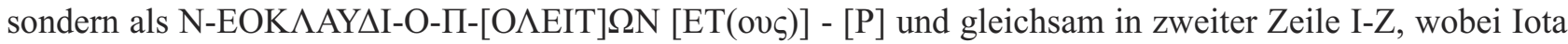
und Zeta jedoch wie die auf dem Schild befindlichen Buchstaben orientiert sind, auf dem - unverändert $[\triangle \mathrm{AKI}] / \mathrm{KOC}$ zu lesen ist. Folgt man diesem Vorschlag, so ist die Münze in das Jahr 117 der städtischen Ära und damit in das Jahr 111/2 n.Chr. zu datieren.

Die hier vorgeschlagene Korrektur hat nicht unerhebliche Konsequenzen: So können lediglich acht Emissionen als sicher für Neoklaudiopolis belegt gelten, wobei die Prägung des Jahres 109/10 als erste anzusehen ist. Vor allem aber kann die Rückseitendarstellung der Münze nicht als - gemessen an den Usancen der Münzprägung der ,innerpontischen' Städte - exzeptionelle Bezugnahme auf ein aktuelles Ereignis, den Sieg des Traian über die Daker und die Verleihung des Titels Dacicus an den Kaiser gegen Ende des Jahres 102 n.Chr., gewertet werden. ${ }^{216}$ Damit sind auch alle Überlegungen, ob diese Münze zur Bestimmung des Jahresbeginns des lokalen Kalenders herangezogen werden kann, ${ }^{217}$ hinfällig. Weiterhin gilt hingegen, daß dieses Münzbild insofern eine Ausnahme darstellt, als es sich auf ein konkretes und eindeutig identifizierbares Ereignis bezieht. Was die für die Münzprägung in Neoklaudiopolis zuständigen Entscheidungsträger dazu führte, zehn Jahre nach dem Geschehen an dieses zu erinnern, muß hingegen offen bleiben: Der zweite Triumph über die Daker, den Traian im Jahr 107 gefeiert hatte, lag bereits einige Zeit zurück und der Feldzug des Kaisers gegen die Parther, der in den Jahren 114-117 erfolgen sollte, und dessen Erfolg man durch die Erinnerung an einen Erfolg der Vergangenheit möglicherweise hätte ,beschwören“ können, zeichnete sich im Jahr 111/2 noch nicht mit Deutlichkeit ab. ${ }^{218}$ 


\section{LITERATUR}

Alston 1994: R. Alston, Roman Military Pay from Caesar to Diocletian, in: Journal of Roman Studies 84, 1994: 113-123.

Amandry 2011: Michel Amandry, La production monétaire des cités pontiques à l'époque impériale. Synchronismes et quantifications, in: François de Callataÿ (Hg.), Quantifying monetary supplies in Greco-Roman times, Bari (Pragmateiai 19): 303-310.

Amandry, Rémy 1998: Michel Amandry, Bernard Rémy, Pontica II. Les monnaies de l'atelier de Sebastopolis du Pont, Paris (Varia Anatolica 10).

Amandry, Rémy 1999: Michel Amandry, Bernard Rémy, Comana du Pont sous l'Empire romain. Etude historique et corpus monétaire, Milano (Glaux 14).

Amandry, Rémy, Özcan 1994: Michel Amandry, Bernard Rémy, Birsel Özcan, La circulation monétaire dans le Pont à l'époque impériale à travers les collections numismatiques du Musée de Tokat, in: Michel Amandry, Georges Le Rider (Hg.), Trésors et circulation monétaire en Anatolie antique, Paris: 119-130, pl. 27-34.

Ando 2000: Clifford Ando, Imperial ideology and provincial loyalty in the Roman Empire, Berkeley/Los Angeles/London.

Arslan 1995: Melih Arslan, Ancient hoards: no. 10 Near Zile (Zela), Turkey, 1991 or before, in: The Numismatic Chronicle 155: 330-332, pl. 55-56.

Bastien 1992/3/4: Pierre Bastien, Le buste monétaire des empereurs romains, $3 \mathrm{Bd}$., Wetteren (Numismatique Romaine 19).

Bekker-Nielsen 2014: Tønnes Bekker-Nielsen, To be or not to be Paphlagonian? A question of identity, in: Bekker-Nielsen (Hg.) 2014: 63-74.

Bekker-Nielsen (Hg.) 2014: Tønnes Bekker-Nielsen (Hg.), Space, Place and Identity in Northern Anatolia, Stuttgart (Geographica Historica 29).

Bellinger 1939: Alfred R. Bellinger, The eighth and ninth Dura Hoards, New York (Numismatic notes and monographs 85).

Bellinger 1943: Alfred R. Bellinger, The numismatic evidence from Dura, in: Berytus 8.1: 61-71.

Bellinger 1949: Alfred R. Bellinger, The Excavations at Dura-Europos conducted by Yale University and the French Academy of Inscriptions and Letters. Final Report VI (edited by M. I. Rostovtzeff, A. R. Bellinger, F. E. Brown, N. P. Toll and C. B. Welles). The coins, New Haven/London/Oxford.

Bergmann 1977: Marianne Bergmann, Studien zum römischen Portrait des 3. Jahrhunderts n.Chr., Bonn.

Bricault, Delrieux 2014: Laurent Bricault, Fabrice Delrieux, Gangra-Germanicopolis de Paphlagonie. „Foyer des dieux“. Etude de numismatique et d'histoire, Bordeaux (Numismatica Anatolica 6).

Burrell 2004: Barbara Burrell, Neokoroi. Greek cities and Roman emperors, Leiden/Boston (Cincinnati classical studies, new series 9).

Butcher 1988: Kevin Butcher, Roman Provincial Coins. An Introduction to the ,Greek Imperials‘, London.
Cahn 1968: Herbert A. Cahn, Münzen aus fernen Gegenden in Augst, in: Stiftung pro Augusta Raurica (Hg.), Provincialia. Festschrift für Rudolf Laur-Belart, Basel/Stuttgart: 57-69.

Callataÿ 2006: François de Callataÿ, Quantifications et numismatique antique. Choix d'articles (1984-2004), Wetteren (Collection Moneta 52).

Callataÿ (Hg.) 2011: François de Callataÿ (Hg.), Quantifying monetary supplies in Greco-Roman times, Bari (Pragmateiai 19).

Callataÿ, Depeyrot, Villaronga 1993: François de Callataÿ, Georges Depeyrot, Leandre Villaronga, L'argent monnayé d'Alexandre le Grand à Auguste, Bruxelles (Cercle d'Etudes Numismatique. Travaux 12).

Carter 1983: Giles F. Carter, A simplyfied method for calculating the original number of dies from die link statistics, in: American Numismatic Society Museum Notes 28: 195-206.

Casey 2010: John Casey, Sinope. A Catalogue of the Greek, Roman and Byzantine Coins in Sinop Museum (Turkey) and Related Historical and Numismatic Studies. With contributions by Melih Arslan, Richard Brickstock and Julia Agnew, London (Royal Numismatic Society. Special Publications 44).

Çizmeli 2006: Zeynep Çizmeli, Le monnayage de Néocésarée et du koinon du Pont, Milano (Glaux 17).

Cox 1941: D. H. Cox, A Tarsus coin collection in the Adana Museum, New York (Numismatic notes and monographs 92).

Dalaison 2007: Julie Dalaison, L'atelier monétaire de Nicopolis en Arménie Mineure, in: Julie Dalaison (Hg.), Espaces et pouvoirs dans l'Antiquité de l'Anatolie à la Gaule. Hommages à Bernard Rémy, Grenoble (Cahiers du CRHIPA 11): 203-237.

Dalaison 2008: Julie Dalaison, L'atelier d'Amaseia du Pont. Recherches historiques et numismatiques, Bordeaux (Numismatica Anatolica 2).

Dalaison 2010: Julie Dalaison, L'atelier monétaire de Pompeiopolis en Paphlagonie, in: Fabrice Delrieux, François Kayser (Hg.), Des déserts d'Afrique au pays des Allobroges. Hommages offerts à François Bertrandy, Chambéry: 45-81.

Dalaison 2014: Julie Dalaison, Civic pride and local identities: the Pontic cities and their coinage in the Roman period, in: Bekker-Nielsen (Hg.) 2014: 125-155.

Dalaison, Delrieux 2014: Julie Dalaison, Fabrice Delrieux, La cité de Néapolis-Néoclaudiopolis: histoire et pratiques monétaires, in: Anatolia Antiqua 22: 159-198.

Dalaison, Rémy 2013: Julie Dalaison, Bernard Rémy, Les divinités d'origine indigène et iranienne sur le monnayage des cités du Pont sous les premiers Sévères, in: Revue Numismatique 170: 29-60.

Dalaison, Rémy, Amandry 2009: Julie Dalaison, Bernard Rémy, Michel Amandry, Zéla sous l'empire Romain. Etude historique et corpus monétaire, Bordeaux (Numismatica Anatolica 4). 


\section{ZUR MÜNZPRÄGUNG NORDANATOLISCHER STÄDTE IN DER RÖMISCHEN KAISERZEIT 207}

Dalaison, Delrieux, Ferriès 2015: Julie Dalaison, Fabrice Delrieux, Marie-Claire Ferriès, Abônoteichos-Ionopolis et son atelier monétaire, in: Clément Chillet, Cyril Courrier, Laure Passet (Hg.), Arcana imperii. Mélanges d'histoire économique, sociale et politique, offerts au Professeur Yves Roman, Volume premier, Paris (Mémoires de la Société des amis de Jacob Spon): 91-206.

Doğanbaş 2015: Muzaffer Doğanbaş, Preliminary results of rescue excavations in the Roman and Byzantine necropoleis of Amasya (1977-2014), in: Kristina Winther-Jacobsen, Lâtife Summerer (Hg.), Landscape dynamics and settlement patterns in Northern Anatolia during the Roman and Byzantine period, Stuttgart (Geographica Historica 32): 193-203.

Esch 2011: Tobias Esch, Zur kommunalen Neuordnung Kleinasiens durch Pompeius. Kilikia Pedias und Pontos - Ein Vergleich, in: Elmar Schwertheim (Hg.), Studien zum antiken Kleinasien VII, Bonn (Asia Minor Studien 66): 35-95, Taf. 12.

Estiot 2012: Sylviane Estiot, The later third Century, in: Metcalf (Hg.) 2012: 538-560.

Esty 1984: Warren W. Esty, Estimating the size of a coinage, in: The Numismatic Chronicle 144: 180-183.

Esty 1986: Warren W. Esty, Estimation of the size of a coinage: a survey and comparison of methods, in: The Numismatic Chronicle 146: 185-215.

Esty 2011: Warren W. Esty, The geometric model for estimating the number of dies, in: Callataÿ (Hg.) 2011: 43-58.

Fittschen 1982: Klaus Fittschen, Die Bildnistypen der Faustina Minor und die Fecunditas Augustae, Göttingen (Abhandlungen der Akademie der Wissenschaften in Göttingen., Phil.-Hist. Klasse, 3. Folge, 126).

Fleischer 1973: Robert Fleischer, Artemis von Ephesos und verwandte Kultstatuen aus Anatolien und Syrien, Leiden (Etudes préliminaires aux religions orientales dans l'empire romain 35).

Gilevitsch 1968: A. M. Gilevitsch, Antike Münzen anderer Städte aus den Ausgrabungen von Chersonesos (russisch), in: Numizmatika i sfragistika (Kiev) 3: 3-61.

Halfmann 1986: Helmut Halfmann, Itinera principum. Geschichte und Typologie der Kaiserreisen im Römischen Reich, Stuttgart (Heidelberger althistorische Beiträge und epigraphische Studien 2).

Harl 1987: Kenneth W. Harl, Civic Coins and Civic Politics in the Roman East A.D. 180-275, Berkeley/Los Angeles/London.

Howgego 1985: Christopher J. Howgego, Greek Imperial Countermarks. Studies in the Provincial Coinage of the Roman Empire, London (RNS Special Publication 17).

Howgego, Heuchert, Burnett (Hg.) 2005: Christopher Howgego, Volker Heuchert, Andrew Burnett (Hg.), Coinage and identity in the Roman provinces, Oxford.

Hnila 2015: Pavol Hnila, Rural necropoleis and settlement dynamics. Thoughts on Roman and Byzantine graves at Oymaağaç Höyük, Samsun Province, in: Kristina Winther-Jacobsen, Lâtife Summerer (Hg.), Land- scape dynamics and settlement patterns in Northern Anatolia during the Roman and Byzantine period, Stuttgart (Geographica Historica 32): 147-164.

Imhoof-Blumer 1917: Friedrich Imhoof-Blumer, Numismatische Miszellen, in: Revue Suisse de numismatique 21: 18-58, Taf. 2-3.

Ireland 1996: Stanley Ireland in association with Soner Ateşoğulları, The Ancient Coins in Amasra Museum, in: Richard Ashton (ed.), Studies in Ancient Coinage from Turkey, London (Royal Numismatic Society. Special publication 29 / British Institute at Ankara. Monograph 17): 115-137, plates 51-65.

Ireland 2000: Stanley Ireland, Greek, Roman, and Byzantine coins in the Museum at Amasya (Ancient Amaseia), Turkey. In collaboration with Helen Ireland and with the assistance of Ahmet Yüce and Celal Özdemir, London (British Institute of Archaeology at Ankara, Monograph 27).

Ireland 2005: Stanley Ireland, Coinage in Roman Pontus and Paphlagonia. Problems of evidence and interpretation, in: Stephen Mitchell, Constantina Katsari (Hg.), Patterns in the Economy of Roman Asia Minor, Swansea: 251-260.

Jahn 1984: Joachim Jahn, Zur Entwicklung römischer Soldzahlungen von Augustus bis auf Diokletian, in: Maria R.-Alföldi (Hg.), Studien zu Fundmünzen der Antike, Berlin: 53-74.

Johnson 2015: Peri Johnson, How did the landscape of Pompeiopolis become Roman?, in: Kristina WintherJacobsen, Lâtife Summerer (Hg.), Landscape dynamics and settlement patterns in Northern Anatolia during the Roman and Byzantine period, Stuttgart (Geographica Historica 32): 61-82

Johnston 1985: Ann Johnston, The so-called ,pseudoautonomous' Greek Imperials, in: American Numismatic Society Museum Notes 30: 89-112, pl. 32-38.

Johnston 2007: Ann Johnston, Greek Imperial Denominations, ca 200-275. A Study of the Roman Provincial Bronze Coinages of Asia Minor. London (RNS Special Publication 43).

Johnston 2012: Ann Johnston, The provinces after Commodus, in: Metcalf (Hg.) 2012: 453-467.

Kettenhofen 1982a: Erich Kettenhofen, Vorderer Orient. Römer und Sasaniden in der Zeit der Reichskrise (224-284 n.Chr.) (TAVO B V.11).

Kettenhofen 1982b: Erich Kettenhofen, Die römischpersischen Kriege des 3. Jahrhunderts n.Chr. nach der Inschrift Šāpurs I. an der Ka'be-ye Zartošt (ŠKZ), Wiesbaden (TAVO Beihefte Reihe B, 55).

Kettenhofen 1992: Erich Kettenhofen, Die Einfälle der Heruler ins Römische Reich im 3. Jh. n.Chr, in: Klio 74: 291-313.

Kienast 1996: Dietmar Kienast, Römische Kaisertabelle, 2. Aufl., Darmstadt.

Klose 1986: Dietrich O. A. Klose, As und Assarion. $\mathrm{Zu}$ den Nominalysystemen der lokalen Bronzemünzen im Osten des römischen Reiches, in: Jahrbuch für Numismatik und Geldgeschichte 36: 101-105. 
Kraft 1972: Konrad Kraft, Das System der kaiserzeitlichen Münzprägung in Kleinasien. Materialien und Entwürfe, Berlin (Istanbuler Forschungen 29).

Laflı, Christof 2012: Ergün Laflı, Eva Christof, Hadrianopolis I. Inschriften aus Paphlagonia. Mit einem Beitrag von Michael Metcalfe, Oxford (BAR International series 2366).

Le Guen, Rémy 2010: Brigitte Le Guen, Bernard Rémy, La cité de Sebastopolis du Pont, in: Anatolia Antiqua 18: 97-107.

Leschhorn 1992: Wolfgang Leschhorn, Die Anfänge der Provinz Galatia, in: Chiron 22: 315-336.

Leschhorn 1993: Wolfgang Leschhorn, Antike Ären. Zeitrechnung, Politik und Geschichte im Schwarzmeerraum und in Kleinasien nördlich des Tauros, Stuttgart (Historia Einzelschriften 81).

Marek 1993: Christian Marek, Stadt, Ära und Territorium in Pontus-Bithynia und Nord-Galatia, Tübingen (Istanbuler Forschungen 39).

Marek 2011: Christian Marek, Zur Epigraphik von Pompeiopolis. Eine Zwischenbilanz, in: Summerer (Hg.) 2011: 189-193.

Marek 2015: Christian Marek, Epigraphy and the provincial organisation of Paphlagonian cities in the Roman Empire, in: Kristina Winther-Jacobsen, Lâtife Summerer (Hg.), Landscape dynamics and settlement patterns in Northern Anatolia during the Roman and Byzantine period, Stuttgart (Geographica Historica 32): 307-328

Metcalf (Hg.) 2012: William E. Metcalf (Hg.), The Oxford handbook of Greek and Roman coinage, Oxford.

Mitford 1980: Timothy B. Mitford, Cappadocia and Armenia Minor: Historical Setting of the Limes, in: ANRW II 7.2: 1167-1228.

Nollé 1997: Johannes Nollé, Zur neueren Forschungsgeschichte der kaiserzeitlichen Stadtprägungen Kleinasiens. Der schwierige Umgang mit einer historischen Quelle, in: Johannes Nollé, Bernhard Overbeck, Peter Weiss (Hg.), Internationales Kolloquium zur Kaiserzeitlichen Münzprägung Kleinasiens. 27.-30. April 1994 in der Staatlichen Münzsammlung München, Milano (Nomismata 1): 11-26.

Nollé 2006: Johannes Nollé, Bronzene Reflexe einer Krise. Das städtische Münzwesen Kleinasiens als Indikator von Phänomenen der Reichskrise des 3. Jahrhunderts und von zeitgenössischem Krisenempfinden, in: KlausPeter Johne, Thomas Gerhardt, Udo Hartmann (Hg.), Deleto paene imperio Romano. Transformationsprozesse des Römischen Reiches im 3. Jahrhundert und ihre Rezeption in der Neuzeit, Stuttgart: 271-287.

Nordbø 1988: Jan H. Nordbø, The Imperial Silver Coinage of Amisus 131/2-137/8 A.D., in: AAVV, Studies in Ancient History and Numismatics presented to Rudi Thomsen, Aarhus: 166-178.

Olshausen 1980: Eckart Olshausen, Pontos und Rom (63 v.Chr. - 64 n.Chr.), in: ANRW II 7.2: 903-912.

Olshausen 1991: Eckart Olshausen, Feste Grenzen und wandernde Völker: Trapezus und die Boraner. Ein Beitrag zur Migrations- und Grenzraumproblematik, in:
Bernard Rémy (Hg.), Pontica I. Recherches sur l'histoire du Pont dans l'antiquité, Saint-Etienne, Istanbul (Varia Anatolica 5. Centre Jean Palerne - Mémoires 9. Céra Mémoires 1): 25-37.

Olshausen 2007: Eckart Olshausen, Römer und Sasaniden in der Zeit der Soldatenkaiser (3. Jh. n.Chr.), in: Anne-Maria Wittke, Eckart Olshausen, Richard Szydlak, unter Mitarbeit von Vera Sauer und weiteren Fachwissenschaftlern, Historischer Atlas der antiken Welt, Stuttgart/Weimar (DNP Suppl. 3): 218f., 262f.

Olshausen 2014: Eckart Olshausen, Pontos: profile of a landscape, in: Bekker-Nielsen (Hg.) 2014: 39-48.

Olshausen, Biller 1984: Eckart Olshausen, Joseph Biller, Historisch-Geographische Aspekte der Geschichte des Pontischen und Armenischen Reiches, 1: Untersuchungen zur Historischen Geographie von Pontos unter den Mithradatiden, Wiesbaden (TAVO Beiheft Reihe B, 29.1).

Özdemir 2015: Celal Özdemir, Preliminary results of rescue excavations at the Sanctuary of Zeus Stratios near Yassiçal, Amasya province, in: Kristina Winther-Jacobsen, Lâtife Summerer (Hg.), Landscape dynamics and settlement patterns in Northern Anatolia during the Roman and Byzantine period, Stuttgart (Geographica Historica 32): $135-145$.

Rémy 1986: Bernard Rémy, L'évolution administrative de l'Anatolie aux trois premiers siècles de notre ère, Lyon (Collection du Centre d'Etudes Romaines et GalloRomaines. Nouvelle série 5).

Rémy 1990: Bernard Rémy, Trouvailles de monnaies romaines et byzantines dans les cités de Neocaesarea et de Sebastopolis du Pont, in: Epigraphica Anatolica 16: 8190 .

Rémy, Özcan 1991: Birsel Özcan, Fouilles de la nécropole de Niksar (1982-1987) avec un appendix sur les trouvailles monnétaires par Bernard Rémy et Birsel Özcan, in: Bernard Rémy (Hg.), Pontica I. Recherches sur l'histoire du Pont dans l'antiquité, Saint-Etienne, Istanbul (Varia Anatolica 5. Centre Jean Palerne - Mémoires 9. Céra-Mémoires 1): 39-59.

Robert 1964: Louis Robert, Seconde Partie: La déesse de Hiérapolis Castabala à l'époque gréco-romaine, in: André Dupont-Sommer, Louis Robert, La Déesse de Hierapolis Castabala, Paris: 17-100.

Sauer 2014: Vera Sauer, Urban space: the evidence of coins, in: Bekker-Nielsen (Hg.) 2014: 109-124.

Sauer 2015a: Vera Sauer, The coinage of Neoklaudiopolis and Pompeiopolis against the background of minting practices of Pontic and Paphlagonian cities during the Roman Imperial period, in: Kristina Winther-Jacobsen, Lâtife Summerer (Hg.), Landscape dynamics and settlement patterns in Northern Anatolia during the Roman and Byzantine period, Stuttgart (Geographica Historica 32): 329-342.

Sauer 2015b: Vera Sauer, Two coins from Oymaağaç Höyük. Appendix to Rural necropoleis and settlement $d y$ namics by Pavol Hnila, in: Kristina Winther-Jacobsen, Lâtife Summerer (Hg.), Landscape dynamics and settlement patterns in Northern Anatolia during the Roman and 
Byzantine period, Stuttgart (Geographica Historica 32): 165-169.

Schönert-Geiss 1972: Edith Schönert-Geiss, Griechisches Münzwerk II. Die Münzprägung von Byzantion. Teil 2: Kaiserzeit, Berlin.

Schultz 1989: Hans-Dietrich Schultz, MegalopolisSebasteia, in: Georges Le Rider, Kenneth Jenkins, Nancy Waggoner, Ulla Westermark (Hg.), Kraay-Mørkholm Essays. Numismatic Studies in Memory of C. M. Kraay and O. Mørkholm, Louvain-la-Neuve (Numismatica Lovaniensia 10): 259-266, Taf. 57.

Schwarcz 1992: Andreas Schwarcz, Die gotischen Seezüge des 3. Jahrhunderts, in: Renate Pillinger, Andreas Pülz, Hermann Vetters (Hg.), Die Schwarzmeerküste in der Spätantike und im frühen Mittelalter. Referate des dritten, gemeinsam mit dem Bulgarischen Forschungsinstitut in Österreich veranstalteten Symposions, Wien: 4757.

Sear 1982: David R. Sear, Greek Imperial Coins and their Values, London.

Sørensen 2016: Søren Lund Sørensen, Between kingdom and koinon: Neapolis-Neoklaudiopolis and the Pontic cities, Stuttgart (Geographica Historica 33).

SNG Paris: Julie Dalaison, Sylloge Nummorum Graecorum France 7. Département des Monnaies, Médailles et Antiques. Paphlagonie, Pont et Arménie Mineure, Bordeaux (Numismatica Anatolica 5) 2015.

Speidel 1992: M. Alexander Speidel, Roman Army Pay Scales, in: Journal of Roman Studies 82: 87-106.

Summerer 2011: Lâtife Summerer, Pompeiopolis. Eine Zwischenbilanz aus der Metropole Paphlagoniens nach fünf Kampagnen (2006-2010), in: Summerer (Hg.) 2011: 3-15.

Summerer (Hg.) 2011: Lâtife Summerer (Hg.), Pompeiopolis I. Eine Zwischenbilanz aus der Metropole Paphlagoniens nach fünf Kampagnen (2006-2010), Langenweissbach (Schriften des Zentrums für Archäologie und Kulturgeschichte des Schwarzmeerraumes 21).

Summerer 2014: Lâtife Summerer, Topographies of worship in northern Anatolia, in: Bekker-Nielsen (Hg.) 2014: 189-213.

Vitale 2012: Marco Vitale, Eparchie und Koinon in Kleinasien von der ausgehenden Republik bis ins 3. Jh. n.Chr., Bonn (Asia Minor Studien 67).
Vitale 2014: Marco Vitale, 'Pontic' communities under Roman rule: polis self-representation, provincialisation and the koina 'of Pontus', in: Bekker-Nielsen (Hg.) 2014: 49-61.

Weiser 1988: Wolfram Weiser, SC als Revers einer Münze der ersten Emission aus Neokaisareia in Galatia unter Traianus, in: Schweizer Münzblätter 38: 9-12.

Weiser 1998: Wolfram Weiser, Namen römischer Statthalter auf den Münzen Kleinasiens. Corrigenda und Addenda zu Gerd Stumpfs Münzcorpus, in: ZPE 123: 275-290.

Weiß 2004: Peter Weiß, Städtische Münzprägung und Zweite Sophistik, in: Barbara E. Borg (Hg.), Paideia. The world of the Second Sophistic, Berlin/New York (Millennium-Studien 2): 179-200.

Weiß 2005: Peter Weiß, The Cities and their Money, in: Howgego, Heuchert, Burnett (Hg.) 2005: 57-68.

Williamson 2014: Christina G. Williamson, Power, politics and panoramas: viewing the sacred landscape of Zeus Stratios near Amaseia, in: Bekker-Nielsen (Hg.) 2014: 175-188.

Wojan 2003: Franck Wojan, Kérasonte du Pont sous 1'Empire romain. Etude historique et corpus monétaire, in: Revue Numismatique 159: 257-290.

Wojan 2006: Franck Wojan, Trapézonte du Pont sous l'Empire romain. Etude historique et corpus monétaire, in: Revue Numismatique 162: 181-229.

Ziegler 1992: Ruprecht Ziegler, Methodische Überlegungen zur Rekonstruktion von Nominalsystemen der städtischen Aes-Prägung im Osten des römischen Reiches, in: Litterae Numismaticae Vindobonenses 4: 189213.

Ziegler 1993: Ruprecht Ziegler, Kaiser, Heer und städtisches Geld. Untersuchungen zur Münzprägung von Anazarbos und anderer ostkilikischer Städte, Wien (Ergänzungsbände zu den Tituli Asiae Minoris 16).

Ziegler 1996: Ruprecht Ziegler, Civic coins and Imperial campaigns, in: David L. Kennedy (Hg.), The Roman army in the east, Ann Arbor (Journal of Roman archaeology Supplementary series 18): 119-134. 


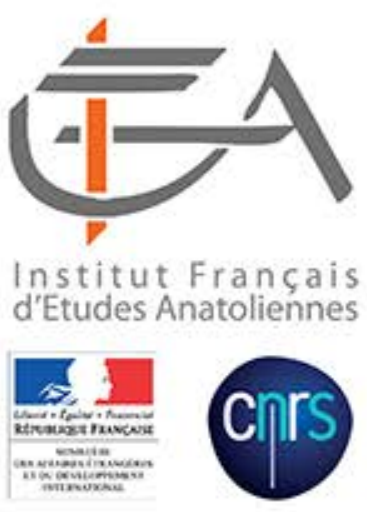

Eurômos : le temple de Zeus vu de l'Est (cliché Sönmez Alemdar).

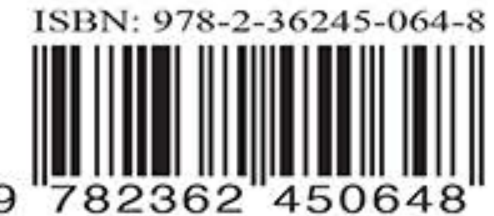

